ANN PHOENIX, JANET BODDY,

CATHERINE WALKER AND UMA VENNAM

\title{
ENVIRONMENT IN THE LIVES OF CHILDREN AND FAMILIES
}

Perspectives from India and the UK

$$
\text { POLICY PRESS SHORTS RESEARCH }
$$


ANN PHOENIX

JANET BODDY

CATHERINE WALKER

UMA VENNAM

\section{ENVIRONMENT IN THE \\ LIVES OF CHILDREN AND \\ FAMILIES}

Perspectives from India and the UK 
First published in Great Britain in 2017 by

Policy Press

University of Bristol

1-9 Old Park Hill

Bristol

BS2 8BB

UK

t: +44(0)1179545940

pp-info@bristol.ac.uk

www.policypress.co.uk
North America office:

Policy Press

c/o The University of Chicago Press

1427 East 60th Street

Chicago, IL 60637, USA

$\mathrm{t}:+17737027700$

f: +17737029756

sales@press.uchicago.edu

www.press.uchicago.edu

(C) Policy Press 2017

The digital PDF version of this title is available Open Access and distributed under the terms of the Creative Commons Attribution-NonCommercial 4.0 license (https://creativecommons.org/ licenses/by/4.0/) which permits adaptation, alteration, reproduction and distribution, without further permission provided the original work is attributed. The derivative works do not need to be licensed on the same terms.

British Library Cataloguing in Publication Data

A catalogue record for this book is available from the British Library.

Library of Congress Cataloging-in-Publication Data

A catalog record for this book has been requested.

$\begin{array}{ll}\text { ISBN 978-1-4473-3919-9 } & \text { (hardback) } \\ \text { ISBN 978-1-4473-3920-5 } & \text { (ePub) } \\ \text { ISBN 978-1-4473-3921-2 } & \text { (Mobi) } \\ \text { ISBN 978-1-4473-3923-6 } & \text { (ePDF) }\end{array}$

The right of Ann Phoenix, Janet Boddy, Catherine Walker and Uma Vennam to be identified as authors of this work has been asserted by them in accordance with the Copyright, Designs and Patents Act 1988 .

All rights reserved: no part of this publication may be reproduced, stored in a retrieval system, or transmitted in any form or by any means, electronic, mechanical, photocopying, recording, or otherwise without the prior permission of Policy Press.

The statements and opinions contained within this publication are solely those of the authors and not of the University of Bristol or Policy Press. The University of Bristol and Policy Press disclaim responsibility for any injury to persons or property resulting from any material published in this publication.

Policy Press works to counter discrimination on grounds of gender, race, disability, age and sexuality.

Cover design by Policy Press

Front cover: image kindly supplied by istock

Printed and bound in Great Britain by CPI Group (UK) Ltd, Croydon, CR0 4YY

Policy Press uses environmentally responsible print partners

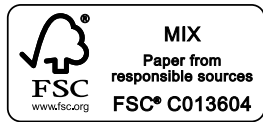


For Sisir, Gabriel, Oscar and Kimaya, who have advised and inspired us throughout our work. 



\section{Contents}

List of figures and tables

Notes on the authors vii

Acknowledgements $\quad$ ix

one Everyday engagement with climate change 1

two Ways of understanding family practices across contexts 21

three Environmental affordances and the work of everyday family lives 41

four Environmental concerns, identities and practices 69

five Children are the future? Power, generation and environmental practices 101

six Negotiating environments in children's and families' everyday lives 135

$\begin{array}{ll}\text { References } & 149\end{array}$

$\begin{array}{ll}\text { Index } & 165\end{array}$ 


\section{List of figures and tables}

Figures

1.1 Representation of children's role as the future 11

of environmental messages

3.1 "Like half our life is in the car" (Marnie) 50

3.2 Mamatha's mother repairing the family 'bathroom' 57

3.3 Chandrasekhar's parents working outside their home 63

4.1 "Me going down to the bus stop to get the bus to go to work" (Callum's mother, Katrina)

4.2 Chitra's family map $\quad 87$

5.1 An image of the child as an agent of change 102

$5.2 \quad$ The spaces where Solomon plays football 110

$\begin{array}{lll}5.3 & \text { Rahul's picture of rubbish dumped near his home } & 114\end{array}$

$\begin{array}{lll}5.4 & \text { Amrutha's family map } & 120\end{array}$

Table

2.1 Sample 34 


\section{Notes on the authors}

Ann Phoenix is Professor of Psychosocial Studies at Thomas Coram Research Unit, Department of Social Sciences, UCL Institute of Education and from 2016 to 2018 is the Erkko Professor at the Helsinki University Collegium for Advanced Studies.

Janet Boddy is Professor of Child, Youth and Family Studies in the School of Education and Social Work at the University of Sussex, where she directs the cross-disciplinary Centre for Innovation and Research in Childhood and Youth (CIRCY).

Catherine Walker is a Research Associate in Human Geography at the University of Leicester; in 2016, she completed her PhD at the UCL Institute of Education in London.

Uma Vennam is Professor of Social Work and Pro-Vice-Chancellor of SPMVV, the Women's University in Tirupati, where she leads qualitative research in India for the Young Lives study (www. younglives.org.uk). 



\section{Acknowledgements}

Above all, thanks are due to the families who took part in the research on which this book is based, and gave so generously of their time to help us learn.

The writing of this book was made possible by the award of the Jane and Aatos Erkko Professorship, Helsinki Collegium for Advanced Studies, to Ann Phoenix. The Family Lives and Environments research, on which the book is based, was funded by the Economic and Social Research Council's National Centre for Research Methods (NCRM) (R00793; RES-576-25-0053), as part of the NOVELLA node (Narratives of Varied Everyday Lives and Linked Approaches). Ann Phoenix was principal investigator of the NOVELLA node and Janet Boddy was principal investigator on the Family Lives and Environments project, for which Ann was co-investigator and on which Catherine Walker conducted a linked $\mathrm{PhD}$. Throughout the research, we also worked closely with the Young Lives study team, within which Uma Vennam, who collaborated in the Family Lives and Environments project, leads the qualitative research in India.

Within the NOVELLA node, the other four projects were: Parenting Identities and Practices, which returned to data collected in two previous studies conducted by Ann Phoenix and Julia Brannen and had a linked $\mathrm{PhD}$ project on online parenting; Families and Food, which applied narrative methods to publicly accessible archival data of different types; The Possibilities of Narrative Analysis for Paradata, which analysed micro-level marginalia on Peter Townsend's influential study Poverty in the United Kingdom: A survey of household resources and standards of living 


\section{ENVIRONMENT IN THE LIVES OF CHILDREN AND FAMILIES}

1967-69; and Food Blogs, which applied multi-modal methodologies to examine the construction of mothering and fathering in online visual and textual narratives about feeding families.

We have benefited enormously from collaboration with colleagues in NOVELLA, NCRM and Young Lives, and particularly thank Madhavi Latha, Helen Austerberry, Hanan Hauari and Natasha Shukla, who conducted interviews with us in India and/or the UK, and Virginia Morrow, Gina Crivello and Renu Singh for all their wisdom and support. The original idea for researching meanings of environment emerged from conversations with Claire Cameron, and we are especially grateful to her for inspiring the work contained in this book. Thanks are also due to Clare Shakya of the International Institute for Environment and Development, whose challenging questions have shaped our thinking throughout the project. 


\section{ONE}

\section{Everyday engagement with climate change}

"The number of plastic bottles not being recycled is staggering and will increase further if we don't take action," said Alice Harlock of Recycle Now. "Householders are often unsure if items are recyclable.... An easy way to tell is, if an item is plastic and bottle shaped it's recyclable." (Smithers, 15 October 2016: The Guardian)

Since the dangers posed by global warming aren't tangible, immediate or visible in the course of day-to-day life, however awesome they appear, many will sit on their hands and do nothing of a concrete nature about them. Yet, waiting until they become visible and acute before being stirred to serious action will, by definition, be too late. (Giddens, 2009: 2)

The institutionalisation of caring for and caring about others within 'family' systems is not only imbricated with practices of consumption consequential for the environment, but also frames support for biodiversity and room for manoeuvre towards the 


\section{ENVIRONMENT IN THE LIVES OF CHILDREN AND FAMILIES}

environmental and intergenerational justice advocated by those seeking a more radical response to climate change. (Jamieson, 2016: 339)

\section{Introduction}

The issue that underpins this book is climate change, but its contents may not be what you expect. Rather than focus on what people are doing to arrest climate change or what they should be doing, it addresses questions that we argue are more fundamental. In particular, it considers how families and the children within them think and feel about their local environments and how these 'small' environmental issues fit with 'big' environmental concerns about climate change in one country in the Majority world (India) and one in the Minority world (the UK). Why do we do this? There is a great deal of evidence that, while most scientists agree that anthropogenic climate change is a pressing issue and most people believe that climate change needs to be addressed, relatively few in countries that produce the most carbon emissions are prepared to make sacrifices to deal with it (Smith and Howe, 2015). Many researchers, governments and climate change organisations express bemusement about this, or take it as a sign of the inherent selfishness of populations. Some assume that it reflects the ignorance of the general population (as is implied in the epigraph from Smithers at the beginning of this chapter). Such assumptions are founded on an ontology that takes for granted that knowledge, attitudes and behaviour are causally linked. We argue both that the picture is more complex than this and that there is already evidence that motivations for addressing climate change are differentiated and understandable if viewed in the context of people's lives, much of which is spent within families. In addition, the trend to treat children as sites of intervention for climate change practices makes it imperative that we understand how families view their environments.

We question visions of climate change response that are rooted in the imaginary of the individual ethical consumer, where families and children are given particular responsibility for 'fixing' the problem 


\section{EVERYDAY ENGAGEMENT WITH CLIMATE CHANGE}

(for example by making changes to their household recycling and energy consumption practices). Instead, we argue for recognition that socioeconomic, geographical and national contexts differentiate and constrain possible actions - 'room for manoeuvre' in Jamieson's (2016) terms - for families as a whole and individual members within them. Overall, then, the book disrupts notions of individual responsibility for climate change response.

We critique the assumption that increasing knowledge leads to changes in attitudes and behaviour regardless of the context within which families live or the ways in which parents view children's knowledge and agency. We make a case for a focus on the everyday and for bringing together childhood and family studies (and hence generational understandings) with consideration of environmental practices. We also challenge the privileging of knowledge produced in the Minority world (so called because less than $20 \%$ of the world's population lives within the most affluent countries, with over $90 \%$ of the world's children living outside the Euro-Western Minority world). The vast majority of developmental and environmental change literature comes from the Minority world, particularly the United States (US) (Pence and Marfo, 2008). Agarwal (1998) suggests that women and children are disproportionately targeted in environmental policies, even though women and children living in poverty are the groups most likely to be affected by environmental changes and shocks. We consider how families in both Majority and Minority worlds think of, and experience, their environments.

The rest of the chapter is divided into six sections. The first section considers why individuals are often targeted in climate change policy, despite evidence that cognitive strategies, giving information designed to get individuals to change their behaviour, do not work. The second section looks at what we know about how understandings of climate change have shifted over time in order to get a sense of whether or not messages aimed at the general public have shifted awareness. The third section considers current discourses of the future, families and childhood in relation to environmental issues, while the fourth section examines what Taylor (2013) calls 'common world' approaches to 
climate change and actions to ameliorate it. The fifth section presents the notion of 'environmental affordances', a concept that allows us to engage with the ways in which climate change responses have to be viewed as linked with everyday practices, which are negotiated within families and situated in dynamic social, economic and geographic contexts. The final section concludes the chapter with an overview of the book.

\section{Why focus on individuals in climate change policy?}

Climate change is undoubtedly one of the major global issues of the 21st century. This was amply demonstrated in 2015 by the adoption of the United Nations' Sustainable Development Goals (SDGs) and subsequently the Paris Climate Accord. The SDGs - set out in Transforming our world: The 2030 agenda for sustainable development (United Nations, 2015) - consist of 17 aspirational 'global goals' brokered by the United Nations, through a deliberative process involving its 193 member states, as well as global civil society, and build on the principles agreed upon in a resolution popularly known as The future we want (United Nations, 2012). The Paris climate accord represented a consensus of the representatives of the 196 parties attending it, with 175 countries signing the agreement on 22 April 2016 (Earth Day). It came into force on 4 November 2016 when at least 55 countries accounting for $55 \%$ of carbon emissions ratified the agreement, raising hope that, globally, climate change can be seriously addressed (Espinosa and Mezouar, 2016). However, the Paris summit also highlighted global inequalities in climate change impact and response. Writing in the Financial Times, the Indian Prime Minister Narendra Modi argued that it would be 'morally wrong' for economically advanced countries that 'powered their way to prosperity on fossil fuel' to shift responsibilities for carbon reduction to the global south (Modi, 2015). His comments speak to concerns about 'carbon colonialism' and the dominance of moral narratives

of environmentalism that emanate from affluent, high consuming neoliberal cultures in the global north (Guha, 2006; Newell, 2012), 
and seem particularly pertinent in a political moment when (at the time of our writing in June 2017) the US President Donald Trump has withdrawn the US from the Paris climate accord.

While the Paris climate accord operates at the level of nations, a great deal of effort is expended by governments and non-governmental organisations to get individuals to change their behaviour in terms of water usage, energy usage and recycling. The question of how much the general population needs to address climate change as an everyday issue has exercised many researchers. The first two epigraphs at the beginning of this chapter show how easy it is for environmental organisations, governments and the media to blame individual householders for not doing enough to ameliorate climate change and to patronise them for being ignorant about what they should do. Yet, while research on public understanding of climate change has burgeoned, much remains sketchy about everyday negotiations of environmental issues. There is a dearth of research on families, children and environmental practices, even though environmental messages are frequently targeted at families, and at children with the expectation that they will influence their parents. This book is centrally concerned with both of these issues. It seeks to illuminate understandings of everyday engagement with climate change, by reporting the findings of a study that takes a common world approach to research with families and children in India and the UK. The study examines the gaps between environmental policy rhetoric and everyday practices for families living in different contexts by interrogating the utility of constructing parenthood and childhood as sites for intervention in climate change debates.

The targeting of climate change messages at individuals illuminates their strategic importance to environmental policy as governments pursue national and global aims and attempt to persuade the population to take up policies they have devised. Government campaigns to facilitate policy take-up and change practices generally give information on which the population is expected to act. For example, the 1980s UK AIDS information campaign had the slogan, 'AIDS: Don't die of ignorance!'. Such campaigns are premised on what Fishbein and Ajzen 
(1975) called 'reasoned action' in their psychological theory that has come to be known as the ABC model, where A stands for Attitude, $\mathrm{B}$ for Behaviour and $\mathrm{C}$ for Cognition. While the model continues to be widely used, including in governments' 'sustainable development' agenda, inconsistencies between attitude and behaviour led Ajzen (1985) to expand the model to one of planned action, including intention and the strength of belief. Social researchers, including those working on climate change issues, have drawn attention to the rationalist assumptions of individual agency that are embedded in many environmental policies in ways 'so pervasive as to seem natural' (Shove et al, 2012: 2). These assumptions pay limited attention to the complexity of the social world, and in particular to the social structures that limit choice and intention (Shove, 2010a).

Environmental psychologists such as Uzzell (2000) have theorised the disjunction between individuals' environmental knowledge and everyday practices as a 'knowledge-behaviour gap'. The factors found to account for this 'gap' include a sense of powerlessness caused because people feel that 'global' environmental concerns are too big for them to do much about, particularly in comparison with larger-scale emitters (Lorenzoni et al, 2007, in a UK study). From a Swiss study, Stoll-Kleemann and colleagues (2001) argue that people deny and displace individual responsibility for ameliorating climate change in order to avoid conflicts between their environmental attitudes and behaviours. These two studies suggest that political messages encouraging individual action on the basis of climate change knowledge may be undermined by individuals' awareness of the scale of environmental problems and the 'weakness of a political strategy that relies on individuals taking responsibility for solving environmental problems' (Middlemiss, 2014: 938).

A number of scholars have used social practice theory to argue that simply raising awareness of environmental concerns among the public is unlikely to lead to widespread changes in everyday practices, and can place unfair pressure on individuals. These scholars are mostly located in high-consuming societies where policy makers call for 'lowcarbon transitions' in everyday practices. They point out the difficulty 


\section{EVERYDAY ENGAGEMENT WITH CLIMATE CHANGE}

of changing practices that are embedded in everyday life through the 'nexuses of practices and material arrangements' that support human existence in situated contexts (Schatzki, 2010: 129; see also Warde, 2005; Pink, 2015). Many scholars argue that the policy focus on individuals serves to 'obscure the extent to which governments sustain unsustainable economic institutions and ways of life, and the extent to which they have a hand in structuring options and possibilities' (Shove, 2010b: 1274). Shove and colleagues (2012) explore the social and material elements that constitute everyday practices to argue for an alternative practice-based approach to environmental governance that attends to the interactions between the social and the material. Others have likewise identified a disjunction between the calls for reduced consumption and the principles of democratic consumer capitalism that encourage high rates of consumption (for example, Miller, 2012; Newell, 2012).

\section{Changes in understandings of climate change practices}

There is little research on how understandings of climate change practices have shifted over time and so whether pro-environmental messages delivered by climate change organisations, governments and the United Nations produce the desired impact. Capstick and colleagues (2015) attempted to provide insights into this issue by bringing together the findings of five published studies and one new study. They found that, from 1990 to 2010, there were three patterns. First, discourses about the relevance of climate change to everyday life had shifted so that more people are likely to see its relevance. Everyday climate change practices are now considered "appropriate or "normal" conduct within a culture' (Capstick et al, 2015: 737). Second, ethical principles about stewardship of nature, social justice and fairness remained relatively stable, with some participants attributing 'lack of pro-environmental behaviour' to 'personal deficiencies' (Capstick et al, 2015: 748). Finally, there were shifts in the belief that it is important to take personal action to help allay climate change, which many have come to consider reasonable and possible. These were, however, subtle 
shifts, tempered by what participants considered external, structural constraints on their lives (see also Shove et al, 2012; Agarwal, 2016). Their findings are supported by a US study that found that the global financial crisis led to a weakening in belief about climate change (Scruggs and Benegal, 2012). Commitment to action over climate change does not take a simple, upward trajectory, but is contingent on perceptions of social circumstances.

One of the reasons why it may be difficult to persuade those in the Minority world to reduce consumption, perhaps shifting their ethical principles in order to do so, was identified by US scholars Schultz and Zelezny (2003). They argued that environmental behaviours have been marketed in ways that run counter to US values of selfenhancement in terms of materialism, pursuit of personal wealth and self-interest, because the environmental movement in the US has framed environmental actions as rooted in self-transcendent values. In particular:

protecting the environment is framed as requiring sacrifice - conservation requires using less, simpler living, giving up some of the comforts that are available, and incurring greater inconvenience - for the sake of a broader goal. Such messages would appeal to people who endorsed the new environmental paradigm - people who rejected the life goals of materialism, personal wealth, and success. However, for people who did not endorse this emerging perspective, such messages would not be persuasive. (Schultz and Zelezny, 2003: 131)

Notions of 'saving', 'helping' or 'protecting' the environment require altruism, often at personal cost. Schultz and Zelezny suggest that environmental messages need to be reframed to persuade US people that they are in their self-interest.

Findings such as these indicate that dealing with climate change is not simply an individual matter related to knowledge, but is embedded in everyday life. As a result, social and material structures have an impact on responses to climate change knowledge. In addition, if environmental 


\section{EVERYDAY ENGAGEMENT WITH CLIMATE CHANGE}

issues seem too weighty or distant, people find it overwhelming to change their practices in line with climate change messages. They may agree that human action needs to be taken to avoid climate change but feel constrained from acting by their own circumstances, self-interest or complex ethical positioning. Capstick and colleagues' (2015) review showed that some people deal with the ethical issues of climate change by viewing their actions in individualistic ways as Minority world selfishness, without changing their behaviour. Given these differences and the importance of recognising intersections of material circumstances, structural constraints, ethical principles and national discourses, it is important to learn more about how people negotiate their understandings of climate change practices. This book aims to make a contribution to such understandings by focusing on everyday family lives and investigating how 'small' and 'big' environmental messages intersect to facilitate or limit agency in relation to climate change action.

\section{Futurity, families and children}

In a review of environmental policy, Walker (2017) proposes that both 'climate change' as a globalising narrative and 'sustainable development' as a policy agenda are premised around the necessity to act on futureoriented speculative scientific knowledge in the present in order to mitigate as yet unknown environmental degradation in the future. She suggests that the recourse to futurity is often expressed through references to 'future generations', as seen in the preamble to the SDGs, which states that sustainable development will 'benefit all, in particular the children, youth and future generations of the world' (UNDESA, no date). In these abstract formulations, children are made visible as embodied future generations who are particularly vulnerable to the effects of climate change, and who are responsibilised for making 'pro-environmental' changes in their everyday lives, including with their families.

Climate change does have a disproportionate impact on children and women globally (Agarwal, 1998; Haines et al, 2006). Children are 
overrepresented in the global population suffering from diseases linked to 'climate change' (Haines et al, 2006; UNICEF UK, 2013). They are particularly represented, along with women, in fatality rates in 'natural' disasters, and natural disasters are predicted to become more frequent as the effects of climate change intensify (for example, IPCC, 2014). The geospatial positioning of children in a world of uneven climatic conditions and exposures to the negative impact of the natural world means that children are differentially affected by events that are causally linked to climate change. Their biological vulnerability intersects with forms of structural disadvantage, including their generational positioning, gender and socioeconomic status, further to disadvantage some children in the face of environmental events.

Recognition of children's vulnerability, together with their positioning as those expected to live longest with environmental degradation, means that children are often treated, particularly in policy reports, as signifiers of the need to take a moral stance for action on climate change. For example, UNICEF UK (2013) describes climate change as a 'children's challenge', making the ethical argument that children are likely to outlive current generations of adults. The report suggests that they have the most to gain from activities and policies aiming to sustain environments that are particularly theirs and, as a result, should be actively involved in these activities (see Evans and Honeyford, 2012; Horton et al, 2013).

Children who attend schools have become central to environmental governance in recent years. Children are expected to take knowledge about environmental concerns from their schools into other spaces of their everyday lives, influencing the practices of those around them, partly through their 'pester power' (Satchwell, 2013: 298). Environmental knowledge, gained through education, is expected to cultivate 'environmental subjectivities' (Agarwal, 2005). Environmental education has been presented as 'humanity's best hope and the most effective means in the quest to achieve sustainable development' (UNESCO, 1997: 16). Through the Decade of Education for Sustainable Development (2005-14), led by the UNESCO, governments have been called to 'integrate the principles, values and 


\section{EVERYDAY ENGAGEMENT WITH CLIMATE CHANGE}

practices of sustainable development into all aspects of education and learning' so that students around the world may 'learn the values, behaviour and lifestyles required for a sustainable future and for positive societal transformation' (UNESCO, undated). As a result, recent years have seen the introduction of initiatives including Sustainable Schools and Eco-schools in the UK (Evans and Honeyford, 2012; Satchwell, 2013) and the National Green Corps in India (Ravindranath, 2007). These policy framings indicate that children, as the 'next generation', are expected to play a central role in climate change practices. As knowing subjects with agency to enact and influence moral actions, children are presented as 'agents of change' in their households, communities and the wider sociostructural spaces in which their lives are situated. Figure 1.1 (a stock image, designed for publicity and purchase) represents this idea of children as the future of the planet, with environmental issues apparently held in a child's fingers: they are responsible for the sprouting of green leaves in the future, for the continued health of birds and for policies such as energy from wind, which is represented as sheltering the family who are away from their detached home and car, balanced precariously on a twig.

\section{Figure 1.1: Representation of children's role as the future of environmental messages}

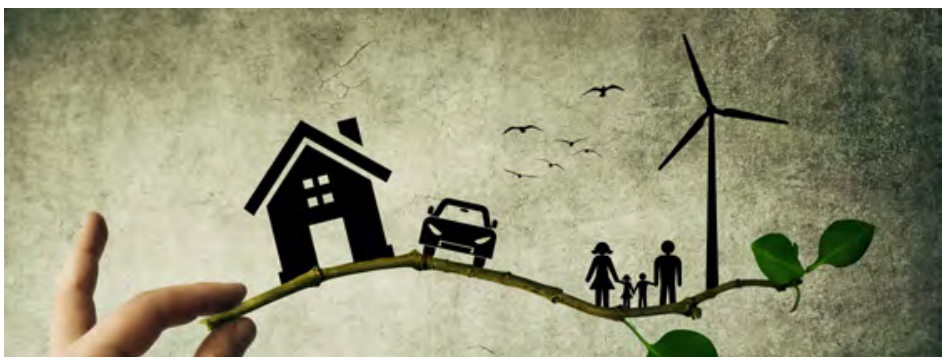

Source: www.alamy.com

Policy framings that foreground children are valuable in taking seriously children's moral and social capacities. Such approaches fit with developments in the sociology of childhood. However, they give little 


\section{ENVIRONMENT IN THE LIVES OF CHILDREN AND FAMILIES}

consideration to how children as a generational group are frequently disadvantaged in their attempts to negotiate and enact agency in societies that are 'generationally ordered' in favour of adults (for example, Alanen, 2009) and where parents frequently do not appreciate children's attempts to teach them new environmental practices (Uzzell, 2016). This is one example of the 'un-interrogated assumptions, rationales and technologies' found in environmental discourses, which erode possibilities for action led by the 'environmental citizen' (Oswell, 2013: 69).

There are, of course, strong ethical arguments for educating children about environmental concerns, particularly in contexts of existing structural vulnerability (for example, Horton et al, 2013). However, as with adults, it cannot be supposed that education will automatically produce changes in children's behaviour, or in the practices of the wider households in which they live. Such expectations are unlikely to be met if they fail to recognise the powerful challenges to sustainability present in consumer-oriented societies, and children's structural positioning in generationally ordered and socioeconomically structured societies.

Environmental practices designed to stave off climate change are frequently also family practices. Families are implicitly at the heart of many environmental policies and are frequently made responsible, in policy and media discourse, for arresting climate change, and yet there has been a surprising lack of attention to the complex relational dynamics of family lives. Writing about the concept of 'family', Edwards and colleagues (2012: 731) observe: 'Maintaining attention to "families" is crucial in understanding people's senses of connection and belonging in ways that stand over and above the sense of being an "individual".

To argue this is not to reify a particular concept of family with all its 'normative baggage' (Morgan, 2013: 4). Rather, we need to attend to the complexity and diversity of 'family' precisely to avoid the ideological stereotypes of the environmentally engaged Minority world, the white middle-class family and the good, 'green' parent (Edwards et al, 2012; AbiGhannam and Atkinson, 2016). The ways in

which families negotiate their environments and issues of sustainability 


\section{EVERYDAY ENGAGEMENT WITH CLIMATE CHANGE}

from different socioeconomic positions and in different countries are a central concern of this book.

\section{A common world approach}

The representation in Figure 1.1 (above) is an apt condensation of approaches that assume that arresting climate change is in children's hands. It also, however, condenses other categories that intersect with age and generation in that it is racialised (depicting a white child's fingers), depicts a presumably heterosexual, nuclear family and, from the type of house and car, is apparently situated in the Minority world. Environmental policy has been criticised for imposing a perspective devised in, and for the interests of, the Minority world, with solutions rooted in middle-class moral imperatives that have been questioned for their relevance (including the relevance of their ethics) to lowincome populations, especially in the Majority world (Guha, 2006; Boddy et al, 2016).

A different approach is proposed by Taylor (2013) and others, who advocate a common world perspective for understanding what 'environment' means for children and families. The notion of 'common worlds' comes originally from Latour (2004) and avoids making a distinction between human societies and natural environments, arguing instead for taking a perspective that views agency as distributed and collective. The common world approach aims to respond to ethical questions raised by notions that we are now in an Anthropocene age, a new geological epoch characterised by human overconsumption and fossil-fuel dependence that has permanently damaged our planet (Stromberg, 2013). It situates human lives as always entangled with those of other beings, human and non-human, as well as with non-living entities such as technologies, discourses and landforms (Common Worlds Research Collective, 2014). In doing so, it enables a holistic focus on aspects of children's lives and their interconnection with other people and species. Taylor and Pacini-Ketchabaw (2015: 507) explain: 


\section{ENVIRONMENT IN THE LIVES OF CHILDREN AND FAMILIES}

For a while now, we have been contemplating the pedagogical implications and affordances of repositioning children within the common worlds we co-inhabit and co-shape with a whole host of other species, entities and forces.... In an attempt to move beyond education's traditional focus on child development and learning within an exclusively socio/cultural (in other words, exclusively human) context ..., we deliberately reposition children within the full, heterogeneous and interdependent multispecies common worlds in which we all live. In line with this shift beyond the social, or beyond the exclusively human, we also move away from the individual child-centred pedagogies that predominate in early childhood education. We focus, instead, on the collective manners and means through which children learn from engaging with other species, entities and forces in their immediate common worlds. We call these collectively engaged modes of learning 'common world pedagogies'.

The study that informs this book was conducted in one Majority world country (India) and one Minority world country (the UK) and takes an approach that views these as part of a common world, resisting homogenised accounts of family lives in Minority or Majority world contexts. Analysis of social change and the reproduction of inequality can only be understood through attention to relationships within local-in-the-global worlds (Jamieson and Milne, 2012). As we discuss further in Chapter Two, inequalities, albeit very different in scale, disproportionately affect children and families within both India and the UK (for example, Agarwal, 1998; Ridge, 2013; UNDP, 2014; Eurostat, 2015). Environmental justice therefore depends on recognition of inequalities within, as well as between, nation states (Bulkely et al, 2014). Rising inequality - at global, national and local scales - is a problem for everyone, not just for the poorest in society (Wilkinson and Pickett, 2009; Koo, 2016). 


\section{EVERYDAY ENGAGEMENT WITH CLIMATE CHANGE}

\section{Environmental affordances}

One of the ways in which we have taken up the common world approach discussed above is by considering the cross-cutting commonalities and differences produced in different environments (urban-rural) in intersection with different socioeconomic statuses and nations (India and the UK) for families with a child of around 12 years of age and so of different generations. The notion of "environmental affordances' gives some purchase on these commonalities and differences in a common world perspective.

The psychologist James Gibson coined the term 'affordance' in what he called an ecological perceptual theory. It seeks to analyse the ways in which our interactions with our environments bring together the possibilities we are able to perceive as well as what the environment is like:

The affordances of the environment are what it offers the animal, what it provides or furnishes, either for good or ill. The verb to afford is found in the dictionary, but the noun affordance is not. I have made it up. I mean by it something that refers to both the environment and the animal in a way that no existing term does. It implies the complementarity of the animal and the environment. (Gibson, 1979/2015: 119)

According to Gibson's theory, we can only do things with the environment if we perceive possibilities for doing them; it is thus about the ways in which people are able to perceive what actions, objects and the environment itself enables or 'affords' them. As the quotation above makes clear, for Gibson affordances can be positive or negative. For example, snow can be a source of leisure or danger, depending on where it is, how much there is and whether it is stationary or moving as an avalanche. The enjoyment or dislike of snow will also differ between families and for different family members, depending on whether they have sufficient warm clothes, their previous experience of snow, and whether they can ski or have snowmobiles to allow them 
to obtain food and other supplies. People of different age groups and health statuses will also differ, and the affordance of snow for those who have chosen to encounter snow for reasons of leisure is very different from the affordance of snow for those who would prefer to avoid it. Rautio and Jokinen (2015), for example, take a common world approach to considering how snow-piles are a site of 'ongoing mattering' to Finnish children.

Environments are, therefore, not neutral in that the same environmental features produce different affordances for different people and there are multiple and potentially contradictory affordances from the same place or objects (Kyttä, 2003; Lewinson, 2011). Many studies find that socioeconomic status has an impact on environmental affordances in complex ways. For example, a Brazilian study by Freitas and colleagues (2013) found that, perhaps not surprisingly, parents from different social classes provided different play materials for their toddlers within the home. However, socioeconomic status made no difference to daily activities that were dependent on what parents could do with children without having to draw on economic resources. It is well established that parents from different socioeconomic groups generally provide different environments for their children in terms of housing, toys, books, leisure activities and the practices they facilitate in relation to leisure and education (for example, Lareau, 2011). These findings fit with Gibson's recognition that environmental affordances are social processes so that objects or places are experienced in relation to the communities in which they have meaning and affordances are partly provided by, and can be learned from, other people. To this we would add that they are psychosocial, bringing together psychological resources and processes with the social.

Gibson's theory has been widely used since the 1970s to analyse the transactional relationships between people and environments and to study the ways in which the material environment is inextricably linked with environmental psychology and social relations (Clark and Uzzell, 2002; Uzzell, 2016). Much research has been done on the psychosocial affordances of particular environments (for example, Ghanbari-Azarneir et al, 2015). Children and young people can 
shape environments to support their goals by realising, or actualising, affordances (Clark and Uzzell, 2002). However, their gendered and generational positioning in their environments affects how they use and come to know their environments through embodied interactions (Holloway and Valentine, 2000), which - along with exposure to environmental 'bads' such as pollution - differ by socioeconomic status and by global and rural-urban inequalities (for example, Wilson and Snell, 2010).

More recently, there has been recognition from the fields of environmental studies and family practices that environmentally consequential family practices are emotionally invested and enmeshed in everyday family routines of 'doing family' and being a good parent (Jamieson, 2016). Hence, these practices are tied to understandings of comfort and the consumption that is necessary for everyday care of family members (Chappells and Shove, 2005). As Henwood and colleagues (2016: 395) put it, 'everyday life is embedded in social practices that are themselves components of wider high intensity resource-using systems'.

\section{Overview of the book}

This book offers a fresh perspective on debates about climate change response, to build a common world understanding of meanings of environment in everyday lives and practices for families living in contrasting geographic and socioeconomic contexts in India and the UK. It questions the dominant moral narratives of environmentalism that come from high-consuming societies in the Minority world. By recognising the complex commonalities and differences between families in India and the UK, the book aims to shift debates on climate change and environments and understandings of children, families, everyday practices, childhood and parenthood. It is informed by a study that uses mixed qualitative methodologies linked through narrative analysis.

Through innovative qualitative research, paying careful attention to the narratives of different family members, the book examines 


\section{ENVIRONMENT IN THE LIVES OF CHILDREN AND FAMILIES}

how urban and rural living, and relative poverty and affluence, shape environmental practices. We see how the precarious conditions in which some families live make abstract environmental messages seem irrelevant, even as they view and deal with their environments in a variety of ways. Equally, affluent families in both countries may be well aware of moral environmental responsibilities, but feel bound to practices of consumption that promote family wellbeing. In differing ways across countries and contexts, the labour involved in everyday family practices highlights the value of feminist perspectives that foreground gendered intersectionality. The book also addresses children's positioning in debates about climate change response - both as the future generation living with the consequences of current and historic practices, and as a target for environmental education, made responsible for influencing family practices.

The research that informs this book is original in its approach, in that it focuses on family practices examined using narrative analysis of a range of innovative qualitative methods from a study that brings together research on Andhra Pradesh and Telangana in India, with research in Southern England in the UK. It takes a critically engaged approach to analysing children's and parents' viewpoints as well as family negotiations of their environments and the ways in which they make these meaningful.

The book will develop four sets of conceptual themes:

- the importance of bringing together perspectives from the Majority and Minority worlds fully to understand narratives relevant to climate change and to contextualising environments by making national, urban-rural and socioeconomic contexts visible;

- the inextricable linking of contexts and everyday environmental practices;

- the inherent relationality (and generationality) of practices, including relations between parents and children and local and national environmental policies;

- a critical interrogation of the ways in which parents and children are made responsible for climate change (causes and solutions). 
In order to do this, we focus on gaining insights into families' understandings and practices rather than on the science of climate change or on policy analysis. Our main objective is to disrupt simplistic, moralising constructions of environmentalism, and the false binary between 'big' and 'small', or global and local environmental concerns. We ask what environmental concern and environmental practice look like in everyday family lives across the contexts of our study. To this end, Chapters Three to Five consider the relationship between environments and families' situated and everyday meaningmaking practices and how these matter to children and parents and are negotiated within families. Chapter Two outlines the study that informs these analytic chapters and Chapter Six draws together the findings. 



\section{TWO}

\section{Ways of understanding family practices across contexts}

\section{A common world approach to the study of family lives}

The research presented in this volume forms part of a growing body of work that is concerned to challenge the dominance of understandings derived from the affluent Minority world, and develop new ways of understanding childhood and family practices across contexts. As discussed in Chapter One, we have drawn on the conceptual framework of 'common worlds' (Taylor and Giugni, 2012; Taylor, 2013) - a framework that seeks to avoid the idealisation of childhood or of a pristine nature, and thus 'seriously engages with children's relations with human and more-than-human others, [in order to] take up the ethical and political challenge of learning how to live well together and to flourish with difference' (Taylor and Giugni, 2012: 109).

Punch and Tisdall (2012) have similarly argued for a 'cross-world' approach to childhood research, criticising the 'false universalism' of Minority world perspectives and highlighting the lack of research dialogue across global contexts. To engage with the challenges raised 
by these perspectives requires a 'methodological shift' (Taylor, 2013), questioning the ways in which knowledge is (or should be) constructed.

\section{Contrasting contexts: learning from difference?}

The choice of India (specifically Andhra Pradesh/Telangana) and the UK (Southern England) as the study countries for this project was designed to challenge ideas of 'translatability' in cross-national research, as well as neocolonial assumptions about north-to-south (or Minority-to-Majority) directions of learning, predicated on 'a utopian and internationalist tradition, where the aspiration remains for the rest to catch up with the West' (Novelli, 2016: 851). We set out to disrupt such assumptions, and examine the potential for shared learning between two such different countries.

Lorenzoni and Hulme (2009) argued for in-depth cross-cultural research in the context of climate change, but most research to date has focused on high- or low-income countries and there is little work that attempts to bring the two together. This is perhaps understandable; contrasting social and demographic contexts are inevitably challenging for comparability and translatability across very different countries. However, a drive for comparability of contexts in cross-national research can itself be problematic if it fails to attend to difference and commonality at one and the same time. Regardless of the apparent comparability (or not) of two countries, 'concepts cannot be separated from contexts' (Hantrais, 2009: 72). What, then, is the nature of knowledge derived from cross-national comparison - is it overarching, or is it always locally situated? Perhaps the real danger in cross-national research arises when we make assumptions of conceptual equivalence (or difference) and neglect the particularity of concepts, contexts and terminology. Moreover, a drive towards 'comparability' or 'translatability' can neglect the potential for shared learning across contrasting national contexts. Such truly cross-national learning seems particularly relevant to the global challenges of climate change.

Conducting research in India and the UK created the possibility for a different sort of comparison, holding cases in conversation with 
each other to see what can be learned by considering similarities and differences within and across countries. We sought to learn from the diversity of family lives in relation to the environment, and to involve families with very different economic, social, cultural and demographic profiles. This approach to case-based research enables 'the application of explanations that are particularistic to a set of conditions for a particular person in a particular context and location that may not be ideal typical for a country pattern' (Brannen, 2005: 2). The aim was not to produce a representative sample, but rather to generate cases that would be emblematic of diverse social and structural contexts (Thomson, 2009).

Poverty has long been part of everyday life for many in India, but the middle and upper classes have increasing consumer power. This has been widely discussed in terms of the environmental impact of these 'new consumers' (for example, Anantharaman, 2014). Guha (2006) has written of a rising class of 'omnivores' within India, whose lives are increasingly differentiated in terms of possibilities for consumption in comparison with those he terms 'ecological migrants' and 'ecosystem people' (broadly, urban and rural people living in poverty). The Young Lives study (on which our research built; see below) shows that - while absolute poverty in Andhra Pradesh/Telangana has declined over the past 15 years - there are enduring and in some cases widening disparities in household consumption levels between social groups (for example, Galab et al, 2011).

Studies exploring the lifestyles of India's middle and affluent classes (who are predominantly based in cities) note growing polarities between the everyday experiences of children occupying different socioeconomic positions in cities, and how socioeconomic privilege can afford some level of protection from urban environmental hazards (for example, Mawdsley, 2004). Anantharaman's study of sustainable waste management in Bangalore highlights disparities between the lifestyles of the 'new' middle classes and urban people living in poverty, arguing that attention given to 'pro-environmental' middle class-led initiatives may 'laud the[se] often marginal voluntary actions ... without bestowing the same 'status' to those who already live within 
ecological bounds' (2014: 182) because they do not have the resources to consume more. Mawdsley (2004: 92) notes a 'middle class tendency to put the blame for environmental degradation such as deforestation or air pollution squarely on the poor, and especially on population growth'. Greenpeace India has also highlighted the 'growing schism of carbon emissions between the two Indias [with] the poor bearing the biggest climate impact burden and camouflaging the other India's lifestyle choices' (Ananthapadmanabhan et al, 2007: 2).

In the UK, relative poverty mostly results from income inequalities. At the time of our fieldwork, $15 \%$ of the national population $(21 \%$ after housing costs) were living in relative poverty ${ }^{1}$ (DWP, 2014), and the global economic 'downturn' has widened income inequalities in the UK, particularly for children and families (for example, Belfield et al, 2014). Ridge's (2009) research shows how, in a relatively wealthy society riven by inequalities, materially poor children may be particularly disadvantaged as they grow up in social and institutional cultures organised to suit the lifestyle and needs of those who are not poor. She argues that children living in poverty in the UK are 'key contributors to family life, playing an important role in mediating and managing the experience of poverty' (Ridge, 2009: 34).

As in India, there are direct links between socioeconomic positioning, consumption levels and carbon emissions in UK households. Research commissioned by the Joseph Rowntree Foundation found that energy emissions for the richest income decile in the UK were up to three times those of households in the poorest decile (Preston et al, 2013). This research, like that carried out by Greenpeace India (Ananthapadmanabhan et al, 2007), draws attention to the need for 'common but differentiated' policy approaches, taking into account local disparities in consumption levels and in meeting national targets for climate change.

In both India and the UK, policies emerging from the national 'sustainable development' agenda often have an individualistic focus

1 In the UK, a household is calculated as being in relative poverty if their household income is $60 \%$ below the median household income. 
that pays little attention to structural factors that may complicate such changes. In the UK, government policies promoting 'proenvironmental behaviours' usually centre on minimising household resource use, as seen in the identification of 'behavioural goals', such as better energy management, minimising water use or using public transport (Defra, 2008). In India, in addition to similar messages about lowered resource consumption, encouraging individual engagement in 'clean-up' activities has been a major area of focus in government environmental policies in recent years, including in the Swachh Bharat ('Clean India') initiative, which encourages citizens to pledge two hours per week to promote public cleanliness. This initiative has been targeted at all citizens, but particularly those living in poor and unsanitary living conditions (Roy, 2014), whose everyday activities are often vilified by other sectors of Indian society (for example, Ghertner, 2012). Roy (2014: unpaginated) notes that the Swachh Bharat 'pledge ... [includes] no mention of environmental pollution-whether of water or air, caused, not so much by the average citizen but by heavy industries, often transnational, and the land degradation that very often accompanies schemes of "development".

Socioeconomic disadvantage can exacerbate environmental vulnerabilities (Jamieson, 2016) and, as discussed in Chapter One, studies in both countries have drawn attention to the ways in which the most socioeconomically disadvantaged households may be disproportionately exposed to environmental 'bads' such as pollution, and risk of food insecurity and natural disasters (for example, Deshingkar, 2012). Between 2005 and 2012, 1,049 and 11,130 per million people in the UK and India respectively were recognised to have been adversely affected by a 'natural' disaster (UNDP, 2014: 211-214). Notwithstanding the impact of such events on households in both countries, this underscores the different degrees of environmental vulnerability in the two countries. 


\section{The relationality and materiality of everyday family lives}

To understand the relationship between family lives and understandings and experiences of the environment, it is necessary to attend to the materiality of everyday lives and practices (for example, Miller, 2012; Shove et al, 2012). But we do not only function as individuals; practices, and decisions about practices, are relational, dynamic, negotiated and maintained within wider social structures and within everyday family lives. Analysis and interventions concerned with climate change behaviour, nationally and internationally, have predominantly been focused on institutional/systems-level change, or on individual understandings and behaviours (see Shove, 2010b). Between community and individual levels of analysis sits the family. To understand the meanings of environment within families' everyday lives, we must attend to family relationships, and family practices (Morgan, 2013).

In our focus on the practice of everyday life, and its relationship with the quotidian spaces in which families live, the study forms part of a growing body of work concerned with understanding the everyday. Scott (2009) notes that the study of everyday life can sometimes be assumed to be trivial or mundane. Indeed, the very nature of the everyday - trivial or mundane, and easily forgotten - makes it difficult to research. Is everyday life, then, hidden from (the researcher's) view? Hitchings (2011) commented that researchers studying everyday life appear increasingly hesitant about using interview methods to study routine practices, given the disconnections between what people do and what they say they do. Ethnographic and particularly observational approaches are often seen as better suited to studying the everyday, precisely because everyday life is not readily disclosable. Miller (2012) argues convincingly for the importance of long-term ethnographic fieldwork as an essential method for understanding consumption in everyday life, and Pink's (2015 [2009]: 19) 'sensory ethnography' is designed to capture 'the multisensoriality of how people experience their homes, material cultures and domestic products and practices'. However, Hitchings (2011) argues that interviews are also worthwhile 
in studying everyday lives and practices, because of what we do when we tell of our everyday lives. The Energy Biographies research project in the UK has also shown that people's environmental practices are woven through their biographies (for example, Shirani et al, 2015).

\section{A narrative approach}

Narrative analysis, with its focus on meaning making, provides insights into the meanings of practices and their social, spatial and temporal nature (for example, Squire, 2013). Family narratives are always situated within time and place, and in social, cultural and economic contexts that contribute to the shaping of expectations, desires and responsibilities across generations (Bertaux and Thompson, 1993). A narrative approach is thus especially relevant to thinking about cross-national research, because, as a case-based method, analysis is contextualised for the individual or group that forms the case (Brannen and Nilsen, 2005; Riessman, 2008).

While traditionally associated with 'talk-based' methodologies, narrative researchers work with an increasingly varied range of data, including visual material, everyday conversation and the artefacts of everyday life (for example, Ochs and Capps, 2001; Luttrell, 2010; Bell, 2013). In the context of the performative nature of the interview interaction, narrative analysis also allows insight into the meanings that are made of everyday lives and the ways in which individual and family identities may be constructed. Analysis of 'small stories' of everyday lives 'enables attention on how people build their narratives and the performative work done by the narratives' (Phoenix, 2013: 73), providing insights into how personal and 'canonical narratives' of socially and culturally accepted norms fit together (Bruner, 1991). This conceptualisation looks beyond that which is neatly storied, to attend to that which is absent, hesitant or incoherent, or which does not 'fit' neatly with the dominant narrative in the interview (Phoenix, 2013). As Riessman (2003: 337) observes, 'informants negotiate how they want to be known by the stories they develop collaboratively with their audiences'. 


\section{The methodological process}

The study's methodological approach was also informed by its positioning within a methodological research programme, NOVELLA (Narratives of Varied Everyday Lives and Linked Approaches), ${ }^{2}$ funded by the UK's Economic and Social Research Council (ESRC) National Centre for Research Methods (NCRM) with linked $\mathrm{PhD}$ studentships on some projects. The five NOVELLA studies all combined methodological and substantive aims, re-using data in different ways in order to study aspects of family lives where policy has been concerned to exert influence. The projects all applied narrative and linked analytic approaches, and shared an interest in illuminating the (dis)connections between what people do and what they say they do, in order to think about how practices are negotiated within families, and how they relate to values, identities and society. The Family Lives and the Environment study, on which this book is based, incorporated a linked PhD studentship (Walker, 2016), which focused in particular on children's perspectives and experiences, and informs this book.

The Family Lives and the Environment study aimed to disrupt understandings of translatability and comparability (and directions of learning) between Majority and Minority worlds. While funded and led from the UK, the research sought to avoid treating the UK as the 'norm' to which the 'other' of India would be compared, and this concern informed the research design and later analytic work. The study was conducted in two phases:

- secondary analysis of eight family case studies drawn from a qualitative subsample of the Young Lives ${ }^{3}$ study in Andhra Pradesh/ Telangana;

- multi-method interviews involving 24 families with very different economic, social, cultural and demographic profiles in India (Andhra Pradesh/Telangana) and the UK (Southern England).

2 Full details of all the projects, and related publications, are available on the NOVELLA website (www.novella.ac.uk).

3

See www.younglives.org.uk 


\section{Learning from the Young Lives study}

A crucial first step was to build collaboration between researchers with expertise in childhood and family lives in India, and those with equivalent expertise in the UK, and we did this through collaboration with researchers involved in the Young Lives study. We were concerned that cross-national expertise should inform all aspects of the research, from designing methods to interpreting data from both countries, so as a team, we were looking from the inside and the outside, and questioning that which might otherwise be taken for granted. Collaboration was funded within the research process, building on existing research relationships, and linking the core UK research team (Janet Boddy, Ann Phoenix, Catherine Walker and, for the first part of the research, Natasha Shukla) with Young Lives researchers Uma Vennam, Madhavi Latha and Renu Singh in India, and Virginia Morrow, Gina Crivello, Jo Boyden and, for the first part of the research, Emma Wilson in the UK.

Young Lives is an international longitudinal cohort study of childhood poverty, involving a 'pro-poor' sample of approximately 12,000 families in four countries: Ethiopia, India, Peru and Vietnam. The Indian sample is based in Andhra Pradesh/Telangana, adjoining states in South-Eastern India, which together have a population of 85 million people. The research started in 2001-02 as a child-focused household survey; a qualitative longitudinal component was added in 2006 and is designed to complement and extend the quantitative cohort study, using a multi-method approach to examine how poverty interacts with other factors at individual, household, community and intergenerational levels to shape children's life trajectories over time. The Young Lives qualitative longitudinal research aims:

to capture both what we as researchers assume to be relevant and important (e.g. the move from one school to a different school, or death of a parent) and what our research participants view as important (e.g. a child describing as a 'turning point' the day when he was given his own small plot of land to cultivate on the family farm). (Crivello et al, 2013: 2) 
The qualitative longitudinal research has involved 200 children (and their caregivers) across the four study countries - including 48 in Andhra Pradesh/Telangana - and includes an older cohort (aged 12-13 years at the time of the first interview) and a younger cohort (aged 6-7 years at the time of the first interview).

Our joint work began with the core UK team learning from the Young Lives qualitative methodology, before conducting a case-based narrative secondary analysis of interviews from eight family case studies (four boys and four girls, living in rural and urban contexts) from the Young Lives qualitative subsample in India. These eight cases were not intended to be representative of Young Lives families, either in India or more generally. Cases with the potential to inform our understanding of family practices and everyday lives as they relate to the environment were drawn from the older cohort sample. 'Environment' was broadly defined to range from everyday local environments to major events and concerns, including environmental shocks such as drought and floods. In-depth case-based analysis, of interviews with caregivers and children over three rounds of data collection, was supplemented with contextual reading of group interviews with children, and interviews with community leaders. This secondary analysis was methodologically important in sensitising the UK research team to the Andhra Pradesh/ Telangana context and in drawing attention to the ways in which experiences and understandings of 'environment' (and environmental concerns) were woven into narratives within family members' accounts of their lives (Boddy, 2014a; Morrow et al, 2014; Shukla et al, 2014). This early work formed the basis of methodological development for subsequent fieldwork with a new sample of families in India and the UK.

\section{New data collection}

\section{Piloting and methodological development}

The new data collection - the material that forms the focus of this volume - built on the Young Lives methodology in developing a multi-method approach to learn about family lives. A challenge in 
researching the everyday and habitual is that many things people do regularly are taken for granted, given little thought and not readily remembered. From the outset, we planned to supplement interviews with visual and other ethnographic methods, including photography, building a 'mosaic' of information (after Clark, 2004) in order to capture information about families' everyday lives in time. In this approach, we were informed by methods used by Young Lives, such as community mapping and story completion (for example, Vennam et al, 2010; Crivello et al, 2013), as well as by work within visual methodology (for example, Luttrell, 2010) and sensory ethnography (Pink, 2009).

Following initial methodological development and exploratory piloting in England, the core UK team (Boddy, Phoenix, Walker and Shukla) visited Andhra Pradesh/Telangana, and worked intensively with the Indian team (Vennam and Latha) to develop and pilot methods over a period of about 10 days; we carried out role play together, observed each other's pilot interviews and discussed each other's fieldnotes as methods were developed and trialled. By the end of this intensive period of joint work, we had agreed a sampling strategy and set of methods and the UK team had learned something of the contexts in which the Indian fieldwork would be done. The UK researchers then took the methods trialled in India and spent a short period conducting further piloting in England, before returning to India for fieldwork; the final phase of data collection took place in the UK. ${ }^{4}$ This collaborative process was crucial to the success of the project. It ensured that expertise in the Andhra Pradesh/Telangana context was integral to the research design and implementation, and that (following from the secondary analysis of Young Lives data) the Andhra Pradesh/Telangana context (rather than, as is usually the case,

4 Interviews in India were conducted in Telugu, Hindi or English, by Madhavi Latha, Catherine Walker and Natasha Shukla. Interviews in England were conducted by Janet Boddy, Helen Austerberry, Catherine Walker and Hanan Hauari. 
the UK) was our starting point for understanding family lives in relation to their environments.

\section{The sample}

The sampling strategy was designed to incorporate intersecting structural diversities that would ensure contextual variety in children's and families' experiences and understandings of 'environment'. We worked in four different locations - London and rural Southern England in the UK, and Hyderabad and rural Andhra Pradesh/ Telangana in India - to incorporate geographical variation (urban and rural).

London and Hyderabad are cities of similar sizes, each with a growing population of around eight million residents at the last Census counts (Government of India, 2011a; ONS, 2012). Along with overcrowding, air pollution is a concern in both cities (Defra, 2014; Guttikunda and Kopakka, 2014). Growing inequalities in household income have been noted in both cities, along with disparities in residents' access to safe and affordable housing. Fourteen of the 20 local authorities with the highest rates of child poverty across the UK are in London (End Child Poverty, 2014). Around 35\% of the urban population of Andhra Pradesh (a third of whom live in or around Hyderabad) were reported to live in 'slums' at the most recent Census, often without access to basic services (Government of India, 2011b). Meanwhile, international investment has led to Hyderabad's rebranding as a 'global knowledge centre' and the development of formerly peripheral areas for those working in the city's expanding software campuses, research institutions and financial service centres (Rao, 2007).

The relatively low rural population density in England, along with more open spaces, higher air quality and the perceived safety of rural life, are often considered to make rural areas in England favourable to childhood (for example, Tyrrell and Harmer, 2015). UK-wide Census data from 2011 show that just $3.4 \%$ of the economically active rural population worked in the agriculture, forestry and fishing sectors (ONS, 2013). In contrast, agriculture is the main livelihood for the 
majority of rural households in Andhra Pradesh/Telangana, and many children engage in agricultural work (Morrow and Vennam, 2012; Galab et al, 2011). Recent years have seen persistent crop failures across many parts of Andhra Pradesh/Telangana, including in the region in which research for this study was carried out (for example, Galab et al, 2011).

We recruited a volunteer sample through schools, targeting children in school Years 7 and 8. In each country we approached schools with different characteristics (including fee structures, the proportion of children in receipt of free school meals in England, and location) as a way of incorporating socioeconomic variation into the sample. While relative poverty and affluence are of course very different in the two countries, the approach was designed to diversify the sample, and avoid a simplistic binarising of the global north and global south.

We interviewed 12 families in India (Andhra Pradesh/Telangana) and 12 in England (see Table 2.1). Most 'index' children (those who were the main focus and from whom we started to recruit the rest of the family) in the sample were 11 or 12 years old at the time of the research, although one child in the Andhra Pradesh/Telangana sample was 14. In focusing on this age group, the research built on understanding generated from our work with the Young Lives data, when children in the first round of qualitative interviews were of a similar age. It also allowed us to engage with the negotiation of family practices during a life stage when children in the two countries are facing changing expectations, for example in relation to autonomy and responsibility, and so is particularly relevant when thinking about children's responsibilisation in relation to climate change adaptation and mitigation (Uzzell, 2016). 
ENVIRONMENT IN THE LIVES OF CHILDREN AND FAMILIES

Table 2.1: Sample (all names are pseudonyms)

\begin{tabular}{|c|c|c|}
\hline India & State capital (Hyderabad) & Rural area \\
\hline \multirow[t]{2}{*}{$\begin{array}{l}\text { Government } \\
\text { schools }\end{array}$} & $\begin{array}{l}\text { Mamatha (girl, age } 11 \text { ) } \\
\text { Mother, father, two siblings }\end{array}$ & $\begin{array}{l}\text { Dharani (girl, age 12) } \\
\text { Mother, father, sibling }\end{array}$ \\
\hline & $\begin{array}{l}\text { Anand (boy, age 14) } \\
\text { Mother, father, two siblings }\end{array}$ & $\begin{array}{l}\text { Chandhrasekhar (boy, age 12) } \\
\text { Mother, father, sibling }\end{array}$ \\
\hline \multirow[t]{2}{*}{ Private schools } & $\begin{array}{l}\text { Gomathi (girl, age 12) } \\
\text { Mother, father, one sibling, } \\
\text { cousin }\end{array}$ & $\begin{array}{l}\text { Chitra (girl, age 12) } \\
\text { Mother, father, sibling }\end{array}$ \\
\hline & $\begin{array}{l}\text { Rahul (boy, age 12) } \\
\text { Mother, father, one sibling }\end{array}$ & $\begin{array}{l}\text { Hemant (boy, age 12) } \\
\text { Mother, father, sibling, two } \\
\text { grandparents }\end{array}$ \\
\hline \multirow[t]{2}{*}{$\begin{array}{l}\text { International } \\
\text { schools }\end{array}$} & $\begin{array}{l}\text { Amrutha (girl, age 12) } \\
\text { Mother, father, one sibling }\end{array}$ & $\begin{array}{l}\text { Reethika (girl, age 12) } \\
\text { Mother, father, sibling }\end{array}$ \\
\hline & $\begin{array}{l}\text { Aamir (boy, age 12) } \\
\text { Mother, father, two siblings, } \\
\text { grandmother }\end{array}$ & $\begin{array}{l}\text { Nageshwar (boy, age 12) } \\
\text { Father, stepmother, sibling, } \\
\text { two grandparents }\end{array}$ \\
\hline UK & Country capital (London) & Rural area \\
\hline \multirow[t]{4}{*}{ State schools } & $\begin{array}{l}\text { Phoebe (girl, age 12) } \\
\text { Mother, father, two siblings }\end{array}$ & $\begin{array}{l}\text { Amy (girl, age 11) } \\
\text { Mother, one sibling }\end{array}$ \\
\hline & $\begin{array}{l}\text { Nathan (boy, age 12) } \\
\text { Mother, stepfather, three } \\
\text { siblings }\end{array}$ & $\begin{array}{l}\text { Callum (boy, age 11) } \\
\text { Mother, one sibling }\end{array}$ \\
\hline & $\begin{array}{l}\text { Antonia (girl, age 12) } \\
\text { Father, mother, two siblings }\end{array}$ & $\begin{array}{l}\text { Helena (girl, age 12) } \\
\text { Father }\end{array}$ \\
\hline & $\begin{array}{l}\text { Solomon (boy, age 11) } \\
\text { Mother, two siblings }\end{array}$ & $\begin{array}{l}\text { Jack (boy, age 12) } \\
\text { Mother, father, one sibling }\end{array}$ \\
\hline \multirow[t]{2}{*}{ Private schools } & $\begin{array}{l}\text { Marnie (girl, age 12) } \\
\text { Mother, father, two siblings }\end{array}$ & $\begin{array}{l}\text { Rosie (girl, age 12) } \\
\text { Mother, father, one sibling }\end{array}$ \\
\hline & $\begin{array}{l}\text { Humphrey (boy, age 12) } \\
\text { Mother, father, one sibling }\end{array}$ & $\begin{array}{l}\text { Oliver (boy, age 11) } \\
\text { Mother, stepfather, two } \\
\text { siblings }\end{array}$ \\
\hline
\end{tabular}

\section{Methods}

To build a holistic view of family experiences and generational understandings, the study used mixed methods that crossed home and school. These were multi-sited activities incorporating mobile methods (see below), allowing insight into embodied understandings of practice including how messages and practices travel across spaces. Working with family group, caregiver-child, individual caregiver and 
individual child interviews illuminated the ways in which narratives of environment and of family practices are co-constructed, negotiated and resisted within families. It enabled accounts to be analysed 'in the context of participants, the worldview of the interviewer, and the relationships between family members and between the interviewer and the family' (Beitin, 2012: 245).

\section{Interviews with families}

Three sets of interviews were conducted with each family over a period of approximately two weeks.

Visit 1 involved a family group interview, with the index child and everyone in the household who wished to be involved. This first interview gathered contextual information about the family's situation and daily practices, and families constructed a joint map of places that feature in their lives (encountered frequently or regularly, or considered important). Finally, they responded to a short vignette designed to illuminate the ways in which environmental choices and practices might be negotiated within the family. At the end of the interview, families were given disposable cameras (one each for the primary caregiver and the target child, and a third camera for the rest of the family to use as they wished). They were asked to take photographs over seven days to help us to understand what 'environment' means in their everyday lives, including pictures of places, people or objects, and encompassing 'likes' and 'dislikes'.

Visit 2 was carried out at least one week later, and had two components. The caregiver and child (and anyone else in the family who wanted to come) took part in a walking or driving interview in their local area. Families were forewarned of this request at the end of visit 1 , and so had time to plan where they wanted to go, drawing on the family map. This mobile interview was designed to generate embodied understandings of the meanings of places for family members that would not be available to researchers through talk alone. The visit also involved individual interviews with the caregiver and child, where environmental concerns and understandings could be discussed 


\section{ENVIRONMENT IN THE LIVES OF CHILDREN AND FAMILIES}

in more detail, and in ways that might not be possible in the group context (for example, where family hierarchies might make it difficult for children to speak, or where participants wanted to raise topics that were not felt suitable for discussion across generations). At this visit we also collected the cameras.

Visit 3 took place once the photos had been developed, and involved photograph elicitation interviews. Individual interviews were conducted with the caregiver and child, and included the selection of five pictures to discuss with the rest of the family; meanwhile other family members separately chose three photographs from the third camera. This was followed by a family group interview, which involved a discussion of the selected photos, and a final choice of the three that best conveyed what was important to the family in their everyday lives and environments.

\section{School visit}

In addition to the family interviews, group interviews were conducted in the schools of participating children. These comprised a group activity with the children who took part in the family research and up to four peers. The children created and discussed maps representing their journeys to school, and discussed a hypothetical vignette and school-based environmental education activities. Where possible, the researchers also carried out a walking interview around the school with the children, and conducted a contextualising interview about the school with a member of staff.

The researchers kept detailed fieldnotes about each research contact with family members and schools. 


\section{WAYS OF UNDERSTANDING FAMILY PRACTICES ACROSS CONTEXTS}

\section{Analytic approach}

Interviews were transcribed ${ }^{5}$ and where necessary translated into English. Research activities were analysed by the research team using a case-based approach; we analysed themes and narratives within family cases, before looking thematically across cases, and then at narratives within themes (see Riessman, 2008). School interviews were analysed in conjunction with children's data (from individual and group interviews). Analysis moved backwards and forwards between data from families in India and the UK, in different schools, and in urban and rural contexts. If we had simply compared across contexts or countries, we would - inevitably - have failed to compare like with like, or would have simplified dynamic and intersectional experiences, obscuring the situated complexity that we aimed to illuminate. Instead, the analytic approach was designed to help theorise the complexity of family lives and environments, without losing sight of specific socioeconomic, cultural and historical contexts (Jamieson and Milne, 2012).

Crossing countries and languages has particular implications for narrative analysis in several respects. There are questions about understanding the cultural and contextual nature of genre story forms, given the differences in cultural formation and contextual understanding of different members of the research team. In addition, narrative analysis usually focuses closely on the particular linguistic devices used in story-telling (for example, Riessman, 2003), but analysis of choice of words, and of emphasis or absence in accounts, is much more complex when interviews are read in translation and across contexts. The partnership between Indian and UK researchers in this regard was of critical importance, and 'translation' within interviews often involved crucial contextualising explanations. Where interviews in India were in Telugu (or rarely Hindi) there were two layers of

5 The key transcription conventions for the extracts presented in this book are as follows: (.) and (...) indicate shorter and longer pauses in speech; [...] indicates that text has been edited; $[=$ and $=]$ indicates areas of overlapping talk; and italics denote emphasis in the tone of speech. 
translation - in the interview itself and at the transcription stage. The partnership between Indian and UK researchers was not restricted to the interview itself. The team's discussion of fieldnotes helped to build understanding throughout the research process in India. Financial and practical constraints meant that it was not possible to involve the Indian researchers in the UK fieldwork, but, in line with our objective of looking from the inside and outside in both countries, Vennam and Latha participated in the analysis of the UK data.

In the chapters that follow, the material we present has been translated into English where necessary. In order to be able to present as many interview extracts as possible in a short book, we have generally omitted interviewer interjections that were facilitative fillers such as 'mmm', 'okay' or requests for clarification. We have also omitted some of what participants said to save space; these omissions are marked by square brackets $[\ldots]$.

\section{Ethics considerations}

The research was conducted subject to ethics approval from an Institute of Education Faculty Research Ethics Committee (FREC Approval FCL 420), an approval that addressed considerations including freely given and appropriately informed consent; confidentiality (including limits on confidentiality if there was concern about risk of harm); the right to withdraw data; and plans for anonymisation and archiving. ${ }^{6}$ The approach followed the guidelines of the ESRC Framework for Research Ethics, ${ }^{7}$ and was additionally informed by the Young Lives guidelines on ethics in research with children (Morrow, 2013) as well as Boddy's (for example, 2014b) work on this topic. In negotiating consent, we followed the principle that, if the 'index child' in the family did not want to take part, we could not work with the family.

6 Transcripts from the school and family interviews are deposited in the UK Data Archive, see https://discover.ukdataservice.ac.uk/catalogue/?sn= 852492\&type=Data\%20catalogue

7 See: www.esrc.ac.uk/funding/guidance-for-applicants/research-ethics/ 
Beyond that, we emphasised that individual family members should each make their own decision about whether or not to take part, and a separate consent process was carried out with each family member. A few other specific ethics considerations relating to the research focus and methodology are worth highlighting here.

Narratives are always relational, and in framing the study's focus on 'family lives and the environment' we inevitably invoked expectations about our positioning as researchers. The research interview is a very particular form of conversation, and can be seen as a site of managed 'family display' (Finch, 2007), with narratives co-constructed for (and by) the interviewer in the context of that interview (Riessman, 2008; Phoenix, 2013). As middle-class researchers conducting research for which we have used carbon-intensive practices (such as long-distance air travel between the UK and India), we are in no position to claim a moral high ground in relation to environmentalism and we emphasised this in our explanations of the research and throughout fieldwork interactions. But families may have felt such expectations nevertheless, and been motivated to align their accounts with morally framed 'canonical' narratives of environmental concern. Some did not; instead, they eschewed engagement with such narratives or explained their scepticism about environmental practices. Narrative analysis attends to contradictions and commonalities, within and between families' and family members' accounts, and thus it is possible to examine the work that is done by family narratives, as well as the implications of morally framed conceptualisations of environmentalism for the families.

The study's methodological focus on the negotiation of family narratives and practices also revealed particular ethical tensions that arose from the effectiveness of the methods. In both countries, there were occasional tensions in family discussions - relating to who got to speak, or whose photograph was (or was not) selected in the final family photograph discussion. These moments are ethically sensitive precisely because they revealed family power dynamics (Robson et al, 2007), but we also have to reflect on the extent to which they were produced by the research, or merely observed through our work. As Kofoed and Staunaes (2015: 36) observe, when dealing with the everyday realities 


\section{ENVIRONMENT IN THE LIVES OF CHILDREN AND FAMILIES}

of relationships there is a need for 'ethical hesitancy', 'a place where there is doubt and pain. ... This kind of ethical hesitancy moves along the same tightrope between knowledge and non-knowledge, between certainty and uncertainty. ... [it requires] an embodied thoughtfulness that includes discomfort and uncertainty'.

\section{In summary}

This book is concerned with family lives across contexts and with the negotiated and dynamic complexity of childhood and of family lives. It has been informed by a common- world approach that seeks to avoid the unhelpful binarisations of 'big' and 'small' or 'global' and 'local' environments, which act as a barrier to understanding (Massey, 2004; Urry, 2011). It aims to understand interconnected lives in 'a heterogeneous, thrown together and precarious world' (Taylor and Giugni, 2012: 109). The methods outlined in this chapter were therefore driven by three linked imperatives. First, we set out to disrupt assumptions of Minority-to-Majority world learning, and homogenising notions of cross-national in/comparability, through a methodological approach designed to create an analytic conversation across diverse contexts within and between India and the UK. Second, we focused on the relationality and materiality of everyday lives, devising a multi-method approach in order to capture the interconnectedness of family lives and practices. Finally, by attending to the ways in which individual and collective narratives are negotiated, resisted and developed, the methods were designed to build understanding of situated, dynamic and relational complexities, and of the ways in which space, place and time intersect with meanings of environment in the everyday lives of children and families. 


\section{THREE}

\section{Environmental affordances and the work of everyday family lives}

In air pollution patients and the public have no impact on that. You are breathing the air that is out there. You can stop eating, but you can't stop breathing. (Darzi, 30 January 2017: BBC Radio 4)

"We cannot keep our windows and doors open because the VMC [Vijayawada Municipal Corporation] illegally keeps burning plastic and other non-biodegradable waste," said K Sujatha, a resident. [...] The residents had been reeling under the stench emanating from the dump and the resultant air pollution over the years. The unscientific disposal of garbage coupled with the greedy tactics of rag pickers who set on fire the mounds of garbage to extract metal scrap is posing serious health hazards to the residents of the locality, lamented Taxpayers Association secretary M V Anjaneyulu. (The New India Express, 13 February 2017) 


\section{ENVIRONMENT IN THE LIVES OF CHILDREN AND FAMILIES}

\section{Introduction}

To understand how 'big' environmental concerns and everyday 'small' environments are inextricably linked, and so how climate change can be addressed, it is crucial to consider how everyday environments are experienced and lived. Agarwal $(1998,2016)$ challenges the idea that there is a clear divide between everyday environments and the more global environments that are the focus of dominant policy and media narratives of environmental concern, noting that environmental issues are rooted in the materiality of everyday family lives and are differentiated by social class, caste, affluence, gender and location.

Since families live in diverse material circumstances, environmental messages are likely to be received in different ways and to have varied impacts on different families and children. This chapter, and the one that follows, present analyses that show differences and commonalities in what everyday environments 'afford' to families living in varied socioeconomic contexts in India and the UK. We analyse the narratives of families for whom everyday life is deeply patterned by the environments in which they live, alongside those for whom having the socioeconomic resources to control their environments is mundane. In the former case, environment is a consistent character in everyday family stories because it directly affects their homes, jobs or food supplies. In the latter, control of the environment is narrated as routinely deployed in the service of care for wellbeing and consumption, and environment is a more occasional, and sometimes stylised, character in family stories. The families' everyday practices are inextricably linked to what is afforded as 'big' and 'small' environments connect. The pleasures, risks and drudgeries of everyday lives inform the meanings of environment for different family members. These environmental affordances are generational and link with parents' hopes and fears for children's future lives (see Chapter Five).

This chapter first considers the sort of environmental issues that families in India and the UK had to negotiate: sometimes routinely (for example, pollution and danger from road traffic) and sometimes unpredictably (for example, flooding and other extreme weather 
events). It then addresses the complexity of the intermeshing of environmental concerns and practices by focusing on families who were so preoccupied with caring for their families and the daily grind of family maintenance that this superseded concern with climate change.

\section{Environmental issues in everyday lives}

The children and adults in our sample were frequently nuanced about what constitutes environment in their everyday lives. In rural England, the multi-layered complexity, as well as the binarisation, of 'environment' as a concept was eloquently captured by Jack, with his younger brother Lucas, at the beginning of their family group interview:

Jack:

'[Y]our environment would be where you live and things you do and where you go. And I think the environment would probably [...] it could mean two things. Environment could mean um (...) like the (...) like na, the natural world. Or it could also mean just um ...'

Lucas: 'Birds and stuff like that.'

Jack:

'It could, it just could, could mean the world as a whole or it could, or it could mean um (...) just the human side of it. That (...) if you're speaking about someone's environment it probably is just (...) it's, it's, it's not the na, it wouldn't be like the natural world as a whole. It would just be (...) um (...) where, where you live and (.) what you do ... and um what affects you.'

Jack's mother, Mary, went on to expand this definition with an emphasis (common to many families across contexts in our study) on attachment to place: 
Mary:

'No, but plus the I suppose (...) your mental environment and whether you're (...) feeling ... Like we were talking about living in [name of town], and I felt suffocated there. And now, even though actually I probably don't do anything particularly differently, um (...) being here I just feel more (...) at ease in my surroundings. And (...) I feel more of a connection I suppose (...) to (...) where we live and (...) does that make sense?'

One of the difficulties families face as they negotiate environmental affordances is the multiplicity of everyday environmental issues that they might encounter. These can seem so disparate that it is difficult to see the relevance of climate change and hard to perceive anything that they might do about it. For example, some of the rural Indian families faced apparent contradictions between both increased flooding and increased drought. Daya Vathi (the mother of 12-year-old Hemant) encapsulated the experiences of many of the rural Indian families who took part in the study as she discussed the family's experiences of drought and heavy, untimely, rains, both of which have proved problematic for them as a farming family.

Interpreter/interviewer: 'One problem is typhoon. What other problem this area faces? Is there any drought problem here?'

Daya Vathi: 'Water tankers are coming to supply water. It doesn't seem like there is drought.'

Interpreter/interviewer: 'Water tankers start coming only when there is drought. Since when are the tankers coming?'

Daya Vathi: 'It is only this year water tanker came here. There is no water in the canals either. We had tough time watering the crops. [...].

Interpreter/interviewer: '.. how do you feel about it?'

Daya Vathi: 'To the people who depend on agriculture this is the biggest worry. The rains are not falling on 
time. And then, it rains around the harvesting period. Due to untimely rains, the crop which is ready for harvesting gets ruined.'

Rural Andhra Pradesh/Telangana is flood prone and there have been unexpected extreme weather events in the forms of cyclones, drought and floods that may be a consequence of climate change. Three years previously, Daya Vathi and Hemant's family had been temporarily evacuated from their family home because they had been flooded, despite the fact that their house was raised off the ground. Many of the Andhra Pradesh/Telangana rural families explained that they prepared for flooding by storing food and other valuable objects in secure places, by strengthening the structure of the home and raising objects off the ground.

Flooding has increasingly become an environmental issue in the UK. None of the UK families in the study had been flooded, and when flooding in UK and global contexts was mentioned, it was generally framed as a distant and transient concern. For example, in London, Phoebe's mother Joanna explained:

Joanna:

'You hear about it when it's sort of worldwide issues, you hear about it on the news and whatever. But (...) this sounds really awful - because it doesn't have an immediate impact on us you don't tend to do anything about it. You know, obviously you see like about people flooded, even in a small sense (...) well smaller sense at Christmas in this country [...] Then you see bigger, you know, huge floods in other countries. Then you see droughts and you see ... And you, you do think, oh, it must be awful. But (...) I think it's (...) where it doesn't have an immediate impact you don't really do an awful lot about it. Which sounds really terrible, but I think that's the way most people are.' 


\section{ENVIRONMENT IN THE LIVES OF CHILDREN AND FAMILIES}

Some of the UK rural families were aware that they lived close to flood plains, where family homes not far from them had been flooded in recent years:

Meg (Amy's mother): 'And the other great thing about [name of village] is it doesn't flood ... Where of course [name of town], you've got so much ... of the [town] area that is, is um ...'

Interviewer: 'They've had flood warnings frequently'

Meg: 'Oh yeah! Yeah. The river's really high there. And it, and it's just, it's so nice not to have to worry about that side of things really. Because it, it is a real problem in [town] for certain areas. [...] Yeah. I, I think that it's quite (...) we're very lucky here that (...) you know, we've got some lovely buffer zones around us and (...) you know, it's ... The, the awful things that happen out there don't really affect us here. I mean, even, even the global warming and the issues with flooding and stuff in [name of town] ... we're, we're never on flood watch here. So even ...'

Interviewer: 'So that picture you took - you're not standing on that bridge thinking ...'

Meg: 'Well, that, I mean, we're standing looking at it kind of going, goodness, isn't it high. But actually it's not, is our home going to flood? ... It's (...) oh, no, will I not be able to get to work through the flood water? (...) You know, it's, it's will it stop the buses?'

Meg attributed flooding to global warming, but given that their house was on higher ground than those flooded, she was sanguine about the floods, expressing pleasure that they were in no danger from the river.

Changing weather patterns in Andhra Pradesh/Telangana are related to another environmental issue, namely the prevalence of snakes in 
a region with a high rate of snakebite mortalities (Gupta and Peshin, 2014), where children are particularly at risk following flooding (Bertho et al, 2012). The example below, from Chandhrasekhar's parents, condenses the issues raised by various Andhra Pradesh/ Telangana rural families:

Ananda Rao (father): 'There are lots of snakes around this area. We worry about children and people getting bitten by them. That's biggest problem for us. [...].'

Interviewer/interpreter: 'You said that there are more snakes around this area. Why there are so many snakes here?'

Sumathi (mother): 'The lake dries up in the summer. When it gets dry, the soil on the lake bed starts cracking up and heat starts emitting from those cracks. Not able to bear the heat, the snakes come out of that area.'

Ananda Rao: 'It is not just because of the lake, there is lot of empty places around here where the weeds grow uncontrollably.'

Concern about the prevalence of snakes provides a good example of the interlinking of place, environmental events, human action and families' perceptions of what they can do about environmentally produced concerns for children's safety (that is, environmental affordances). As Sumathi pointed out, weather conditions - including cyclones, floods and drought - all played a part, as did human action, as Ananda Rao indicated in his reference to neglect of vegetation. His understanding was shared by others who discussed snakes in Andhra Pradesh/ Telangana, and is consistent with research (for example, Gupta and Peshin, 2014). Chandhrasekhar's mother, Sumathi, had herself been bitten by a snake, and treated by a traditional healer.

Flooding and fears of snake bites were not central to the lives of many of the families in the study. Other environmental issues were faced by many participants in both India and the UK; in particular, high traffic levels made roads hazardous for children and produced air pollution. For Gomathi's family in Hyderabad, the intensity and relentlessness 


\section{ENVIRONMENT IN THE LIVES OF CHILDREN AND FAMILIES}

of local traffic came up as a source of danger in each interview, and meant that Gomathi was not sent out to do things that required crossing the road. Traffic dangers also restricted where she could play, and so her friendships were primarily with other children in the same apartment block. She took photos of play equipment in the apartment block's basement carpark, an example of how institutions outside the family affect environmental affordances: in this case, the apartment management's intervention creates an environmental affordance for resident children's play when heavy traffic renders outside play too dangerous.

Pollution also featured in the narratives of several UK families. In London, Solomon's mother, Angela, highlighted the additional vulnerability to pollution associated with medical conditions, including Solomon's and her own asthma. While the housing estate where the family live has green spaces (highlighted in her photos), she described adapting her practices to minimise pollution coming into their home, avoiding opening the windows and doors in the 'rush-hour' period when traffic is heavy: "And sometimes when you open the windows or door (...) burning my lungs. [... You can smell (...) the fumes coming up."

Also in London, pollution appeared as a more unusual affordance for Marnie's father, Tony, in discussing his motorbike:

Tony:

'Well the other thing about environment as well is living in London ... Because (...) maybe not so much for these guys, but I was a biker up until about a year ago. And I know what the environment's like because I had to breathe it in when I was biking ...'

Interviewer: 'And what was it like?'

Tony:

'Pretty horrible at times. And according to my wife, apparently I used to smell a lot when I came in ... Well you do. You smell of bike and fumes 
Saskia (mother): ' '... it's like a combination of ... It's like, you know if you walk into a mechanic's workshop, that oily kind of ... thing ... He'd take his head gear off and he'd have actually black where he'd been driving around.'

The permeation of the car into rural as well as urban areas meant that traffic was not only an urban issue. Oliver's mother, Vicky, discussed the roads through the beautiful British countryside near her home:

Vicky:

'Yeah, it is quiet. The only problem is that people use this as a cut-through [...] And they tend not to respect the speed limit (...) You can tell the cars who lives here (.) and who doesn't ... because of the speed they're driving (...) But the commuters just sort of cut through and steam through. And um (...) that is a bit of a problem. So (...) I wouldn't let them out (.) er, once it started to get dark (...) So if they go they have to go in the daylight (...) It's got to be absolutely full-blown daylight otherwise they can't go (...) Because also it's pitch-black. When it's dark it's absolutely pitch-black around here; there's no streetlights or anything.'

Angela, Tony and Vicky (above) indicated that they have taken action in response to traffic dangers (pollution and road safety). Their small stories show how people respond to what the environment affords using the resources available to them. In both India and the UK, more affluent families were able to protect themselves from the environmental hazards of pollution and traffic by using cars as a necessary practice of care. Vicky's children do not have to walk the dog, or walk back from school in the dark, and Tony can afford to stop motorbiking to work. His daughter Marnie depicted her family's dependence on the car in the photographs she took and in her interview (see Figure 3.1). 
Figure 3.1: "Like half our life is in the car" (Marnie)

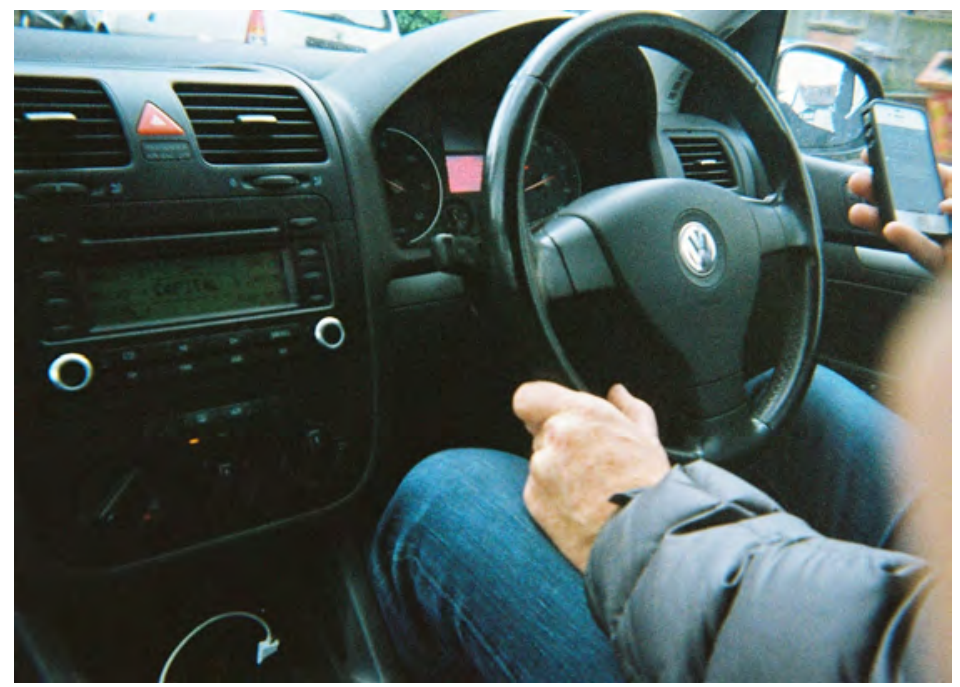

In Hyderabad, Amrutha's father, Vijay, discussed the necessity of driving because of problems he saw with the public transport infrastructure, and explained how he protected against pollution when driving in the city:

Vijay:

'So to be honest I don't like to switch on the AC [air conditioning] when I travel out but pollution inevitably makes me close the doors and switch on the AC. So again that's the other huge uh, burden on the resources.'

In contrast to these accounts of urban car use, the high carbon demands of country living were highlighted by Antonia's father, Hugh. Their family lived in inner-London, where both parents worked in professional occupations and the children attended their local state school. They emphasised their urban identity, and in highlighting the affordances of their city environment, Hugh told a 'small story', which imagined an alternative rural life: 
Hugh:

'But I would say that you know part, you know part of the reason that we live in this kind of environment is because we like urban environments and social diversity. Um (...) but also (...) part, part of the reason is that we like living a (...) a sort of (...) you know, in a way that's (...) sustainable. [...] In so far as our environment influences these sorts of decisions, um (...) you know, I think we take the view that your carbon footprint in the (...) countryside (...) is very much greater. Because probably we'd have two cars, probably we'd both drive to work. Probably would drive our kids to everything that they did. Probably would have to drop them off at school by day, every day by car. You know, probably would live in a big, detached house, which would have much higher fuel bills. All of that kind of stuff. So it's not prime reason that we live in the city but it's not (...) irrelevant. [...] The way that you can live in an urban environment is um (...) is in a way that has a relatively low environmental impact.'

Hugh's account of the necessity of rural car use was echoed by Rosie's mother, Sally, who told the story of their "forced" decision to buy a "ridiculous" four-by-four vehicle after being snowed into their rural village:

Sally:

'I mean we're not into having four-wheel drive necessarily, but someone said to me without one you won't be able to get to school ... [...] So we've been sort of (.) forced into one of these ridiculous four-by-fours, which (.) everyone at the school seems to have [laughs]. Which is a shame; we're in this little village and we shouldn't really need to run around in big cars. But, but it does mean 
that we can, I can do a lot of the drives without worrying about being stuck. So that's a bit of an impact (...) environmentally.'

Sally went on to detail the utility of her car in coping with the journey to school, before ending with a coda, justifying their choice of school (and so the need for the car):

Sally:

'But you know the, the, the, the school I think is, is wonderful for the children. One of the reasons we chose it was because it looks out. [...] And for argument's sake where Rosie's classroom is, the view she has is just stunning. And I mean, that's got to give you a sense of wellbeing when you work - you know, you work in an environment like that.'

In ending the narrative this way, Sally highlighted a different meaning of environment. Her discursive turn beginning "But you know ..." constructed the environment as a site of consumption and the fourby-four as necessary for her children's wellbeing and their access to the environmental affordances of their "stunning" surroundings.

In contrast to these accounts, the Andhra Pradesh/Telangana families who had directly experienced flooding, drought and snakes did not believe that they could eradicate these risks but worked to minimise their exposure to them by, for example, clearing rubbish from drains near their homes to avoid them overflowing, storing valuable items off the ground or in other family members' homes and passing on local knowledge about avoiding snakes. In Klocker's (2007: 92) terms, their agency was 'thin, rather than ... non-existent'. Together, these examples illustrate how environmental affordances are a mix of the possibilities that people perceive their environments to allow and having resources available to act on or ameliorate those environments.

Environmental affordances are not just what an environment affords, but are also the nexus of experiences, socioeconomic circumstances, 
beliefs and emotions that position people in relation to environmental issues and help them to position themselves. The implication is that engagement with climate change issues is not purely cognitive, the result of being convinced through accurate information, but more holistic. It is relational and simultaneously situated in what Bronfenbrenner (1977) calls ecological niches that operate at three levels: the micro level (for example, the home), the meso level (for example, institutions) and the macro level (for example, the nation and the state). As Agarwal (1998) observes, in India, environment is closely linked to the everyday lives and practices of rural families. This is not simply a matter of caste or social class; for example, air quality and floods can have widespread effects across social classes. However, the severity with which they are experienced and how they are negotiated are interlinked with the socioeconomic resources available to families.

\section{Relations of care and environmental affordances: "life is work"}

Family environmental practices were at play in everyday urban and rural lives in India and the UK in three ways. First, parents prioritised relations of care for their families within the possibilities of employment and environmental practices available to them through their own efforts and local and national government policies. Second, families had routines of work and travel to work that were, for many, repetitive, mundane and hard. These were part of the process of maintaining relations of care by providing food, fuel, shelter, clothes and physical care. For some families this left no time and energy for thinking about more abstract or temporally or spatially distant concerns woven into the global narrative of 'climate change'. Third, environmental changes affected both rural and urban contexts across the two countries (see Chapter Four). How family members reacted to those changes partly depended on their socioeconomic resources. There were differences across countries and between rural and urban areas and different socioeconomic circumstances, but the study's intergenerational, family approach also showed how processes were patterned in ways that cut across these groupings. 


\section{ENVIRONMENT IN THE LIVES OF CHILDREN AND FAMILIES}

The micro environments in which family members spend their days are inextricably linked with macro environmental issues so that, as Jamieson (2016: 336) suggests, 'the conduct of family life and personal relationships has profound consequences for environment and sustainability issues'. Families' practices are particular to the environments that constitute them and are produced by local environmental features, and in this way they overlap with consumption practices (Warde, 2005; Morgan, 2013). What, and how much, environmental resources are consumed by families depends on their environments. In both India and the UK, some families considered that the immediacy of their everyday family concerns left no space for environmental concerns, made them irrelevant or were beyond what the family could do as they strove to maintain or ameliorate their circumstances. For some - particularly urban and rural families who lived in poverty in India - hard work was inextricably linked with their environmental experiences and distinctive dependencies on their environments.

The examples that follow all come from the Indian sample. Only a small minority of people in the UK are directly subject to the vagaries of weather or other environmental conditions for their livelihood (ONS, 2013); dependence on environmental conditions and resources for work and everyday life is far from uncommon in India and our samples reflect this difference.

Mamatha's family (mother Syamala, father Venkatesh and two siblings) lived in Hyderabad and had moved from the countryside to find jobs. They lived in a temporary shelter made from wood, corrugated iron and plastic in an 'un-notified' community that is not eligible for a 'slum upgrading' scheme designed to improve sanitation and living conditions for people living in poverty in urban areas (for example, Ghertner, 2012). The year prior to the interview, the family had lived in a dwelling on the same site that was sturdier, with asbestos walls and roof, but it had been demolished by the government in a slum clearance scheme. Syamala told the story of this as a negative turning point in the family's economic fortunes. The family decided, with their neighbours, to rebuild their home, with the hope that, over 
time, the government would officially recognise their community, but did not invest their scarce resources in the new house, in case the government destroyed it. They had an ('illegal') electricity supply and relied on obtaining partially filled auto-rickshaw gas canisters in order to avoid having to burn wood. The unpredictability of this gas supply meant that Syamala continued to collect wood during her work as a labourer and they sometimes had no choice but to use it for cooking, although the smoke it produced affected their breathing and stained their walls. Everyday life was a constant struggle. The temporary roof leaked during the rainy season and Mamatha explained that the floor was too hot in the summer for her to walk in her bare feet. The water supply from the local tap was insecure and Syamala said she scolded the children for using too much water. Both Mamatha and Syamala were concerned about rubbish and human faeces that foul the local park (in the absence of adequate sanitation or rubbish disposal facilities in the community).

Alongside household commitments, the parents had a relentless work schedule, vividly articulated in the photo-elicitation interview during which Syamala discussed the gender-differentiated nature of her work in the family home before going to work as a cleaner or day construction labourer. The extract starts as Syamala showed a photograph of her daughters folding their bedsheets, something that has to be done every morning:

Interviewer/interpreter: 'While looking at it, that work, how do you feel?'

Syamala: $\quad$ 'Life is ever like this ... Life is work [laughs] ... Early in the morning have to cook and ... have to rush to work. Should wash the clothes before leaving, you know ... daily.'

This notion, that work is all-consuming, making place irrelevant, recurred in the family interviews as well as Syamala's individual interview: 
Interviewer/interpreter: 'What are ... the things that you're able to do by staying in this locality, you Mr Venkatesh?' Venkatesh: ' $\quad$... wherever we go have to work! There is nothing like doing a job or employment. Wherever we are there is nothing like doing a job, have to work! Even if we stay in the village have to work. Wherever we are this is the only work. [...].'

Syamala: 'As the problems doubled in village, felt better here. We shifted here and thought to do hard work and live.'

In her interview, Mamatha told a 'small story' about how the roof leaking during heavy rain made further work for her mother and herself.

Mamatha: 'On that day when they demolished the huts, we built [our house] again steadily, [but] the rain pours through the holes, isn't it, and complete house gets wet. When it pours in the home, complete home gets wet and I sweep [the] whole house when it pours, sweep all the water out and my mother washes completely.'

Figure 3.2 illustrates how extreme weather resulted in more work for Syamala. It shows her rehanging the plastic sheeting that separates the family 'bathroom' from the rest of their home, a task she described as a "regular event" following heavy wind or rain.

Asked about climate change, Mamatha's mother and father both focused on immediate family problems such as the children having problems travelling to school in the heat unless their father (an autorickshaw driver) can take them in the morning. During the rainy season, there were problems partly because the roof did not have a proper cover and partly because of inadequate sanitation in the locality, as Syamala explained: 
Figure 3.2: Mamatha's mother repairing the family 'bathroom'

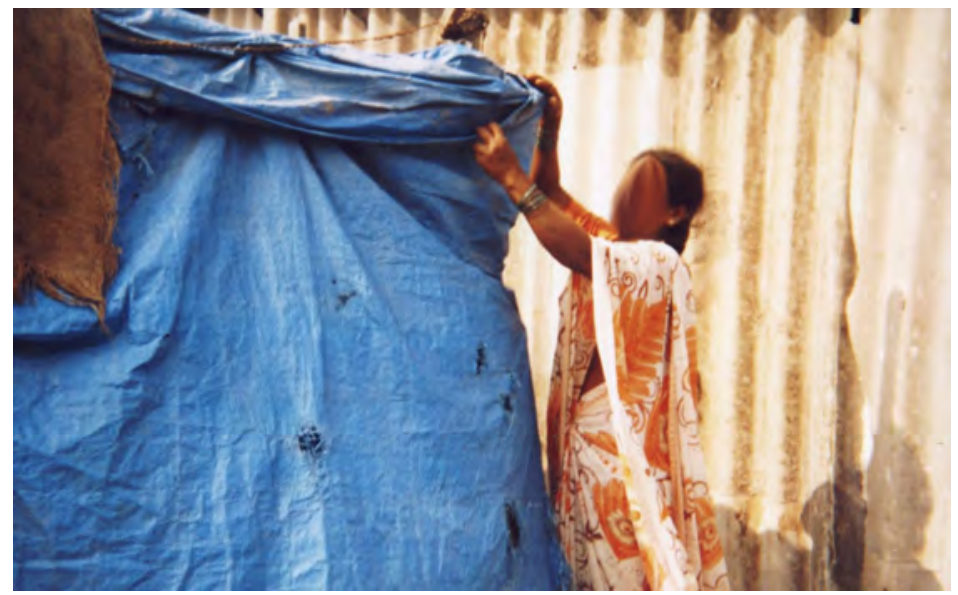

Syamala:

'It is all dirty! House flies, everywhere, and summer it is like this! And during rain ... [...].'

Interviewer/interpreter: 'Hot season, how will it be, here and the surroundings?'

Syamala: 'Will be neat.'

Interviewer/interpreter: 'Will be neat but how will be the heat during summer?'

Syamala: 'Too much heat.'

Interviewer/interpreter: 'Can we bear?'

Syamala: $\quad$ 'Have to, and we go to work, so ...'

The family's accounts emphasised the mundane yet precarious drudgery of wage labour (for both parents) and household work (for the mother) and appeared to pay little attention to climate change and macro environmental issues. But despite this all-encompassing labour, the parents had a future vision of a better life for their children, paid for their son (the youngest child) to go to a fee-paying school and ensured that both daughters went to a state school and did not have to do too much household work, as well as taking care to keep their daughters away from threats outside the home. 
While this family could be said to be at the mercy of their environment, they clearly exercised agency in struggling to make their lives as comfortable and secure as possible in very difficult circumstances and investing in the future for their children. The family had continually worked hard to improve their circumstances by moving to the city and persevering despite having had their home demolished. The much-repeated mantra about the parents' hard work - encapsulated in Syamala's 'life is work' - was instructive, in that working as hard as possible every day was the main way for them to maintain or improve the circumstances that were within their control. The parents also tried to spare their children the worst depredations to do with flooding.

Syamala: 'During heavy rains, we will send the three children to my mother's place; we both get drenched and stay, cover ourselves with blankets and sleep $[\ldots]$.'

Interviewer/interpreter: 'Then how are you managing?'

Syamala: 'What is there to manage? It's all tension, they will demolish this ... and [we are] afraid of when it happens! [...].'

Mamatha also told a story that positioned her as agentically proactive in the face of all the difficulties faced by the family. Having noticed that the number of mosquitoes had decreased after the local authorities cleared rubbish from the park across the road from their home, she had scolded local children for defecating in the park, on the grounds that this practice attracted mosquitoes. The Indian government's Swachh Bharat ('Clean India') campaign, launched in October 2014, has a focus on eliminating defecation in public places. Mamatha's account of her efforts took place in spring 2013, more than a year previously:

Mamatha: 'When children use it as toilet, I tell them to go away from there and do that at their home.'

Interviewer/interpreter: 'So you tell like that, when did you tell that?' 
Mamatha: 'When I was child, even now I tell. [...].' Interviewer/interpreter: 'And what do the other children say?' Interviewer/interpreter: 'What will they say, when you say like that, do they listen or tell you to go away?'

Mamatha: 'Some say that "is it your park, have you built it?" "We haven't built [it], but mosquitoes will reach our home, and it will be dirty, that's why I am telling you to leave this place." I say [it] in that way, then they leave.'

The family's narratives highlight that environmental affordances are about what family members perceive that the environment can afford them. Government decisions make a difference to families' environmental experiences and practices. Not surprisingly, both Mamatha and her parents discussed the intensification of their precarity and the pressures on the family produced by government intervention in demolishing their previous home. By the time we returned to Mamatha's school to discuss our findings with the children, her father - whose work as an auto-rickshaw driver in the city exposed him to extremely high intensities of air pollution- had died from a heart attack, making the family situation more precarious than ever.

Anand's family had also moved to Hyderabad from the countryside, in their case because of drought and crop failure, in order to find employment so that they could survive and raise their children. The family would have preferred to remain in the countryside. Instead, they were what Guha (2006) refers to as 'ecological refugees'. They lived in a small apartment on the top floor of a block next to a mobile telephone mast, which the family feared was subjecting them to harmful radiation, but they felt they had no other option. In parallel with Mamatha's family, both parents were waged workers but maintained traditional gendered practices and ideology at home. Anand's mother, Rajeswari, downplayed her role as a wage earner and constructed herself as a wife and mother, even though she worked as a domestic worker (housemaid) and a day labourer and was out at work from $9 \mathrm{am}$ to $6 \mathrm{pm}$. Anand's father, Ramanaiah, described himself as the 


\section{ENVIRONMENT IN THE LIVES OF CHILDREN AND FAMILIES}

provider, taking responsibility for the family. Yet, Rajeswari recognised that her schedule was punishing and, like Syamala, she described a life consumed by work:

Rajeswari: 'And all that I know is work and that's all ... I come back home only by six o'clock in the evening. You know I need to go and work in two houses. You know I work as a housemaid in two houses and also work outside apart from that. So I cannot remain at home. In case if I remained at home I would still be doing some household work.'

Given how busy she was and how few material resources the family had, it was not surprising that, in their individual interviews, both Rajeswari and Anand did not express concern about climate change, although Anand said that he had noticed that rain now, unusually, fell in the summer and that it could be cold in the summer as well. He also gave a narrative about seeing flood victims, whose houses had collapsed, in a local hospital. By contrast, Rajeswari refused to be drawn when asked about environmental issues.

Rajeswari: '[We usually keep away] from such issues and don't interact with anyone on those matters, we don't go there at all. [...] After moving over to this place, we don't feel anything, in fact everything is okay with us. We are fine. [...].'

Interviewer/interpreter: 'Here you don't have any problems and you are free from all those, but you are aware that it affects people in general. Tell me what you feel when it affects others.'

Rajeswari: 'Well, it affects and people face problems [but] it is difficult for me to tell about other people's problems and how it affects them. [Laughs] How can I relate myself and tell you about them? How can I tell you about other people?' 
Anand's parents' portrayed lives that were dominated by work, experienced as an all-encompassing ordeal, fatiguing, but necessary for the family's survival. They worked 'for the children's sake' but it prevented them from engaging in less immediate issues than daily survival. For example, they described themselves as too busy working to go to a parents' evening at school. Rajeswari had taken her eightyear-old son out of school to attend to his little sister during her working day, which she justified on account of his lack of interest in his studies. In previous times Anand had also stayed off school to do childcare. The children therefore contributed to the family economy of work and care. In these circumstances, it is perhaps not surprising that Rajeswari said that the family kept away from broader issues concerning the environment and could not relate to other people's problems. They portrayed themselves as uneducated and reliant on the protective knowledge of others, which they did not question. For example, Rajeswari explained that "[o]ur well-wishers, people known to us, the educated ones, tell us about environmental danger from [the mobile telephone] mast". She also described the family as devout and that religion provided comfort and hope; they went to church because the preachers told them that trust in God might transform their lives.

Chandrasekhar lived with his mother, father and brother in rural Telangana and attended the local (free) government school. The family belonged to the Padmasali weaver caste, and did padugu work, preparing threads to be woven into saris and other clothes. They also used to do weaving, but had given this up, as Chandrasekhar's parents explained:

Ananda Rao (father): 'We used to do this, weaving. As it wasn't profitable, we have started doing this [only threadmaking].'

Sumathi (mother): 'It wasn't enough.'

Ananda Rao:

'It wasn't enough when we did it.'

Sumathi:

'It wasn't enough when we did weaving.' 


\section{ENVIRONMENT IN THE LIVES OF CHILDREN AND FAMILIES}

Ananda Rao: 'As it wasn't profitable and four of us had to survive and our daughter had to be married.'

The increasingly precarious lives and livelihoods of handloom weaving castes, including Padmasali, are well documented (for example, Apparao, 2011), and the experience of Chandrasekhar's family has commonalities with that described in other research, not least that weaving involves the entire family, and is understood 'as a way of life rather than an occupation that merely provides livelihood' (Apparao, 2011: 146). In Chandrasekhar's family, the importance of their collective work and intergenerational identity as Padmasali was emphasised through detailed accounts of the practice of threadmaking, told and retold across interviews and in multiple family photographs, including all three photographs selected to represent the family in the final interview.

Figure 3.3 illustrates the process of drying threads for Chandrasekhar's family. Padugu work relies on the local environment; water is needed to starch and dye the threads, which are then spread in the road in front of the family home to dry in the sun.

Prakash and Singh (2012) have written about the relative scarcity of water for lower-caste groups, including Padmasali, in Andhra Pradesh, also noting that they live in less environmentally secure areas within their local communities. These factors were evident in Sumathi and Ananda Rao's account. The family lived in a low-lying area of their village, near a canal that floods regularly in the rainy season. Sumathi had to collect water every day from a tap provided by the local government, which was only available for a limited time each morning (30 to 45 minutes). The work was also seasonally determined. Ananda Rao explained that, in the summer, "many-a-times per week" the water would not go to the tap at all; then they had to travel to neighbouring areas and carry water long distances. Chandrasekhar said that in the rainy season "the whole area turns into slushy mud" and it is impossible to dry threads on the road. Sumathi described the impact of these seasonal changes: 


\section{Figure 3.3: Chandrasekhar's parents working outside their home}

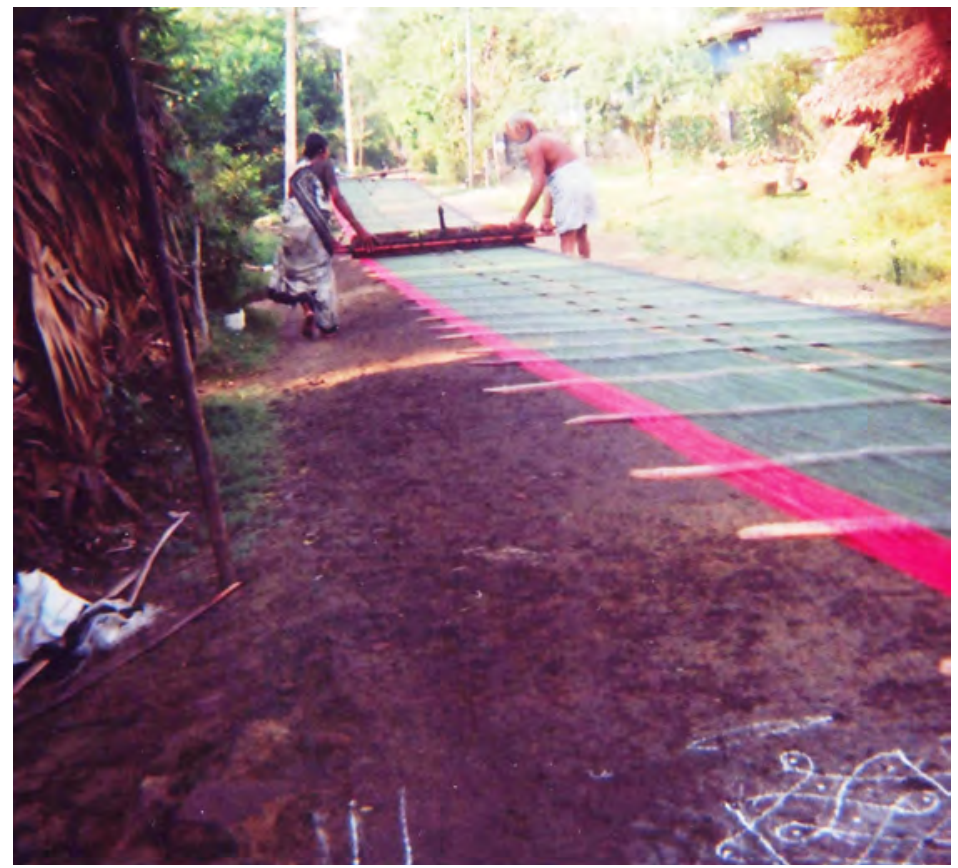

Sumathi:

'Last year we had water problem for at least for a month. It happened in the month of May and on some days, we could get not a drop of water from anywhere. It was very tough. We depend on this work for our livelihood. It is very difficult for us to make ends meet in rainy season. We never have enough food. We go through this kind of situation every year for two or three months. To survive in such situation, we take loan.'

Interviewer/interpreter: 'Did you face any other problem like drought or any problem related to the weather?'

Sumathi:

'Droughts occur due to the weather. In rainy season we cannot do our work at all. And we depend at the interest rate of 10 rupees per month. We end 
up paying the interest till the following year. Since we don't have the money to pay the principal amount, we keep paying the interest. We don't even know how much we pay towards the loan ultimately. As time goes by the interest keeps on increasing. For example, if we take 10,000 rupees loan, we have to pay 1,000 rupees interest every month. We are just paying the interest and we are not able to clear the actual loan amount. We face drought in this way. For us this is the drought. Since we are paying so much interest on loan, how can we take care of the children?'

Sumathi's environmental concerns were rooted in everyday interdependence with the natural world, managed through habitual family practices embedded in intergenerational relations. Mitigative practices entail hard work - for example, Sumathi described pain in her legs when carrying water over long distances - but this was taken for granted as inevitable in the family's narrative, described by both Sumathi and Anando Rao as "inconvenient" and by Sumathi as "unavoidable". In contrast to this relative pragmatism, both parents spoke quite differently about a cyclone with heavy flooding, six years previously. Sumathi explained:

Sumathi:

'Everything had drowned and was damaged, not a single [tool for weaving] was in a workable condition. We just had to leave everything including the eatables as it occurred at night. As it had gotten spoilt we had to buy everything from the beginning. We borrowed money from the money lender with an interest of 10 rupees [per 100]. Thus we bought the tools and started working and repaying the debt. Whenever we needed we borrowed money and thus the interest kept on accumulating. You can calculate how 
much it would come up to for an interest of 10 rupees. It feels like we are half dead because of the accumulated interest. The main reason for our deplorable situation is paying the large amounts as interest. Because of the interest to be paid we have reached this situation, our lives are ruined. [...]'

Interviewer/interpreter: 'Did you sell your old house because of that or was there any other reason?'

Sumathi: 'Yes. Because of these difficulties and loans and as we were unable to pay the interest, we had to sell the house.'

Sumathi's choice of language here was in stark contrast to the "inconvenient" everyday hardships that the family endured: they lost everything - she repeated the word 'everything' three times in the first three sentences of this short extract. And she spoke in the present tense: she summed up this short story of devastating loss with the statements that "we are half dead" and "our lives are ruined". This was an environmental concern that threatened their everyday lives, and continued to reverberate into their future lives.

The family's continuing financial precarity meant that they had no economic resources to protect them six years previously when the floods destroyed their tools; the accumulating cost of interest on the loans meant that they subsequently had to sell their house. Sumathi explained later that they had no option of seeking help from relatives because "[e]verybody has [the] same kind of problems". Her account highlighted the ways in which quotidian and seasonal environmental precarity intersected with major environmental shocks, and their concomitant reliance on the money lender, as in the following account of the precautions they took during the rainy season:

Sumathi:

'We bring all our tools inside and stay inside without stepping outside. We would make do with whatever we have to eat. If we don't have 
anything to prepare a curry, we eat rice with chilli powder. And in place of buttermilk, we just add water to the rice and eat it. We stop buying milk from outside. Or if we think that we cannot repay the loan we won't take any more loans. (.) Sometimes we would be already be owing money to the money lender. In such circumstances, we will make do with whatever we have instead of taking loan to eat. Till we clear the previous loan, we won't go for a new loan. I get really worried when we have loans to pay.'

The disproportionate economic impact of environmental shocks on people living in poverty in rural India is of course well established, and - as for Mamatha's and Anand's families - is known to be a trigger for rural-urban migration (for example, Deshingkar, 2012). Within our small sample, other families had changed family work in response to economic pressures, including pressures that were environmentally produced. Hemant's father, Vignesh, described diversifying from agriculture into fisheries, to mitigate the economic effects of climatic shocks on agricultural income. Dharani's family had moved to a larger village and given up agricultural work; her father worked in a petrol 'bunk' (station) and her mother as a seamstress. In explaining the family's decision to move away from agriculture, Dharani's mother, Rani, said that changing crop patterns resulting from changes in the climate had meant that the family could only rely on one annual paddy harvest rather than two as in the past and this was not enough to support them. Chandrasekhar's family tried to earn money in other ways. For example, his father, Ananda Rao, did catering work in the rainy season, but his parents saw few possibilities for change:

Ananda Rao: 'Now since our forefathers also were born and brought up in this we don't know how to do anything else. People who do this work cannot do that.' 
Sumathi:

'We don't go to do the field work as we cannot do it.'

Ananda Rao:

'Because of that we got used to this work.'

Sumathi:

'We have to be happy with whatever we get in this.'

\section{Conclusion}

The second part of this chapter has focused on families who might be described as environmentally dependent 'ecological refugees' or 'ecosystem people' within Guha's (2006) typology. For them, major environmental shocks intersect with poverty, caste and quotidian environmental hardships to generate environmental concerns rooted in existential threats to the family's survival. For those whose environmental concerns are inseparable from concern for family wellbeing, environmental concerns that entail care at a distance must compete with concerns for the family life that the family 'lives and breathes'. That tension is most evident in discussions of time-scarcity, which show how environmental concerns may be 'overpowered' by more pressing domestic and familial considerations. As we explore further in Chapter Four, simplistic moral judgements about environmental un/concern neglect the situated specificity of human interests, and the ways in which concern is produced (and managed) in the intersectional context of environmental affordances, where socioeconomic and geographic resources frame the gendered and generational relationality and materiality of everyday family practices. 



\section{FOUR}

\section{Environmental concerns, identities and practices}

The global does not represent the universal human interest, it represents a particular local and parochial interest which has been globalised through the scale of its reach. (Shiva, 1993: 151)

No matter what type of air pollutant it is, ... [it is] children who are most susceptible to its dangerous effects. In order to protect children from these air pollutants, follow these basic ways to reduce pollutant particles from your surroundings. Dr Krishan Chugh, director and HOD, Paeds and PICU and Dr Neetu Talwar, senior consultant, Paeds Pulmonoly, Fortis Memorial Research Institute share some effective tips to protect children from air pollution:

- Use of efficient stoves for safe cooking practices

- Avoid active and passive smoking both

- Use of efficient and low pollution vehicles

- Proper maintenance of your personal vehicles

- Using fan over air conditioners

- Walking or riding a bicycle, whenever possible [...] 


\section{ENVIRONMENT IN THE LIVES OF CHILDREN AND FAMILIES}

And last but not the least, going green. Plant trees and if possible place more and more indoor plants. Use of efficient stoves for safe cooking practices

- Avoid active and passive smoking both

- Use of efficient and low pollution vehicles

- Proper maintenance of your personal vehicles

- Using fan over air conditioners

- Walking or riding a bicycle, whenever possible

- Recycling paper, plastic, metals, and organic materials

- Washing laundry in cold water and line drying your laundry. (The Times of India, 2 December 2016)

'[G]lobal space' is no more than the sum of relations, connections, embodiments and practices. These things are utterly everyday and grounded at the same time as they may, when linked together, go around the world. (Massey, 2004: 8)

\section{Introduction}

As Shiva (1993) noted in the epigraph that opens this chapter, narratives of environmental concern that derive from particular Minority world contexts are not truly global. Popular images of an apparently depopulated pristine nature, such as the earth from space or the solitary polar bear, are quite literally distant from the lives of the majority. Yet, they are considered by many as foundational to galvanising environmentalism into a purportedly 'global' movement (Ingold, 2000). This kind of affluent Minority world imaginary is problematic in several respects. Images of depopulated pristine nature conceal the fallacy of nature-culture dualism (for example, Heise, 2008), rendering invisible the vast differences within and between countries in human-nature interdependence, and the ways in which children and families understand, value and are put at risk by their 'environments'. From a common world perspective, abstracted images of climate change are not merely emotive; they are also politically 
neutralising, concealing the ways in which powerful economic interests maintain and normalise high consumption (Newell, 2012). This has implications for our understanding of the 'other' in the face of climate change. When environmental concern is conceptualised in terms of an imaginary of depopulated pristine nature that is produced from the affluent Minority world, who (or what) is the object of concern?

During times of crisis, the vilification of the other becomes particularly acute (Joffé, 1999) and so the characterisation of contemporary times as constituting environmental crises has consequences for how the environmental other is viewed. This can be seen in the characterisation of 'uncivil others' in policy, media and academic narratives of environmental concern (Smith and Howe, 2015), contributing to the tendency for environmentalism or consumption to be reduced to 'matters of moral adjudication or political stance' (Miller, 2012: viii-ix). Hulme (2014: 308-309) argued that, to talk about climate change, we must start by asking what it means to be human: 'What is the good life and what therefore is an adequate response to climate change?' But simple moral characterisations neglect structural inequalities in the ways in which some lives - and not others - are framed as 'human', conforming to 'a culturally limited norm for what the human is supposed to be', and hence who is recognised as entitled to protection (Butler, 2004: 91). To consider how environmental concern is situated within family lives, we need also to attend to the object/s of that concern. With those arguments in mind, this chapter focuses on families who are emblematic of different ways in which environmental affordances intersect with environmental concerns.

The previous chapter showed how the necessity to engage in arduous, repetitive labour left no time for contemplating or attending to issues of climate change, even while environmental precarity and unpredictability exacerbated the hard work of family lives. We now examine the ways in which environmental concerns are situated in families' everyday lives across continents and contexts, aiming to disrupt binarising conceptualisations of 'global' versus 'local' concerns, or 'concerned' versus 'unconcerned' people, that construct an abstract, abject or immoral other, distanced from moral, environmentally aware, 
selves. We argue for a nuanced understanding, facilitated through a common world approach (Taylor, 2013), which attends to the quotidian and gendered interdependencies of domestic life (MacGregor, 2006), and takes account of the ways in which environmental concerns (plural) may be simultaneously distanced and made proximal as part of the relational dynamics of 'doing' family (Finch, 2007).

The chapter explores the ways in which environmental concerns and practices depend on the affordances of local environments. It discusses families who take a sceptical approach to ideas that climate change is anthropogenic, produced through human action and so amenable to human intervention, and those who accept that climate change is anthropogenic, but are sceptical about whether individual action can make a difference. Finally, the chapter focuses on families who have taken up environmental identities and are committed to practices designed to stave off climate change. By juxtaposing examples where environments exert a limiting effect on children's and families' lives with examples where families are able to exert more control over their environments, the chapter illustrates that families with different experiences of 'environment' can share similar attitudes to 'big' environmental practices, and shows why it is unhelpful to binarise the so-called local as grounded and everyday and the so-called global as abstract and superordinate.

\section{Family environmental affordances: beliefs in the irrelevance of human responses to climate change}

We begin by considering families where parents (and sometimes children too) questioned the relevance of human responses to climate change. Katrina was a lone parent who worked part time and lived in a rural hamlet in Southern England with her sons Callum (aged 11) and Marcus (aged eight). Their isolated location meant that they were not connected to mains drainage or to gas as a household fuel (as is usual in the UK); they could not afford electric heating and so relied on solid fuel, coal and wood. Of course, it could be said that, in choosing to live where she did, Katrina had simultaneously made 
macro-environmental choices. However, as with most family 'choices', it was a negotiated decision, made with the children's father when she was pregnant, so they could secure affordable housing and bring up their children in the countryside within reach of both their places of employment, relatively near family members and near potential schools. Their choices were thus contingent on imagined futures for the family, and the best compromises they could make to fit with and maintain their employment.

For Katrina, environmental affordances in everyday life involved hard work and financial management. As Jamieson (2016: 337) suggests, agency is 'anchored in the emotionally charged intimacy of embodied personal relationships'; Katrina's awareness of environmental affordances was fuelled by an understanding of how their ecological niche had an impact on herself and her children. Having no car in an area poorly served by public transport, she was acutely aware that, particularly in winter, when it was dark for much of the day and unsafe for Callum to cycle, the possibilities for her children and herself to move about their environment were extremely limited and dependent on lifts from other people more frequently than she would have liked.

Perhaps not surprisingly, Katrina now considered that it would be better if they lived somewhere else, but she was committed to staying put until her children were older and less dependent. Without a car, the family's carbon footprint was lower than it would otherwise have been, but this was an unchosen environmental affordance following an accident (and temporary, until they could afford to replace the car), so it was experienced as undesirable and outside familial control. Katrina's photograph taken on her walk to the bus stop on a dark winter's morning allows insights into how unpleasant she found this routine (see Figure 4.1). 
Figure 4.1: "Me going down to the bus stop to get the bus to go to work" (Callum's mother, Katrina)

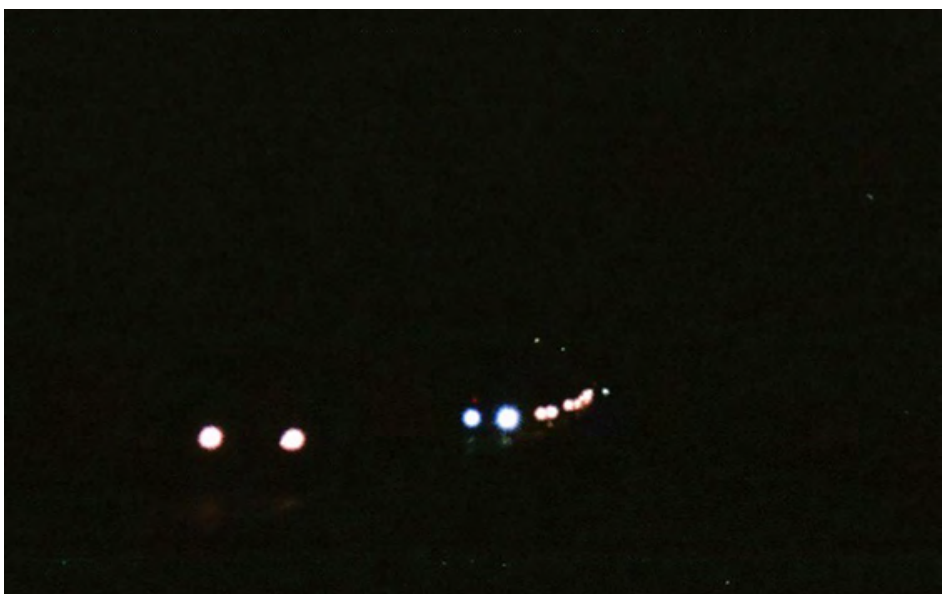

Katrina was also acutely aware of the cost of coal, and so did not keep the heating on continually. She also viewed coal dust as potentially damaging for their lungs, and clearly disliked the drudgery involved in lighting the fire each winter morning, sometimes after spending two or more hours travelling home from a 12-hour nightshift:

Katrina:

'We probably use about (.) 18 bags of coal over the winter ... They're 25 quid a bag so they're quite a bit.'

Interviewer:

'Hmm. And is it difficult to do?'

Katrina:

'Well it's just having to ... because it's not obviously it's not like, I'd love to have a switch and it all goes on and be lovely ... But (.) you have to start ... because when you're starting it off, you start the fire up and then put the coal on and it gets really, really hot. It gets extremely hot. And it does, it heats all the radiators and it also um, the excess heat goes on and heats some of the water as well ... then in the morning you have to come 
down, empty out the dustpan and then start it up again. And ... there's some residual heat in there, so you should be able to use a couple of sticks and it'll go up again and you just put some more coal in. But it is - it's not an easy thing.'

Interviewer: 'And then how long does it take for the house to get warmed?'

Katrina: $\quad$ 'Er ... about two hours ... Yeah. It's not too long ... But it's um (.) it's - it's not good for your lungs really. There's quite a lot of dust around in the winter in this house.'

For Katrina, macro environmental practices and local everyday concerns were interlinked and seasonal, with winter requiring the lighting of fires, cold waits at bus stops and both boys staying indoors a great deal because of the busy roads, lack of pavements and darkness outside. But the environmental affordances they perceived were not only negative. Callum and Marcus enjoyed climbing trees in the summer and keeping chickens while their mother enjoyed the garden and beautiful countryside. However, Katrina considered that environmental 'choices' were partly socioeconomically produced. The lack of choice encapsulated in Katrina's "Well it's just having to" (above) meant that these environmental affordances did not produce Katrina or her son, Callum, as environmental agents committed to preventing climate change. Instead, their narratives showed that they viewed themselves as having to negotiate what the environment afforded.

At the same time, Katrina said that she had been a committed recycler for 20 years and had taught her sons to recycle, not to waste water and to turn off the lights in empty rooms. But reducing water and electricity use served to reduce household bills, and Katrina explained that she recycled because she disliked seeing litter in her environment, not for environmental reasons. Indeed, she was sceptical (as was Callum) about climate change arguments on the grounds that climate change is cyclical and has been recursive over millions of years. She did not, therefore, believe that climate change is amenable to 
human intervention or her agency. This was also the case for Vicky, Oliver's mother, who also lived in rural England, albeit in more comfortable material circumstances than Katrina, and whose three sons went to a private school. Considering their narratives together reveals commonalities across socioeconomic groups, positioned in very different ways in their families and local environments. Asked what she thought about what people said about climate change, Vicky's reply paralleled Katrina's:

Interviewer: 'When you hear about people talking about climate change, or big environmental issues, what does that mean to you? ... How does it make you feel?'

Katrina: 'It worries me. It worries me about what the children are going to grow up ... and their children, you know finding with the world. But at the same time, I don't know whether it's often ... how ... things like these ... like the tsunamis and things have happened throughout time in the past anyway ... So it's just that the world ... how - how - how it is anyway. Um, like from the time of the dinosaurs there's been certain weather - certain things happening with the weather and everything. So it's like um, recycling. I've always recycled as much as I possibly can. The boys know, you know about recycling and they're very aware of looking after their environment.'

Interviewer: 'So why is that something that you've always done? Is it something that you've kind of always thought of as important? [...]'

Katrina: Um, I think just (.) I've always hated, since I was little, people littering. Um, and I think um, some friends that ... um ... recycled and had separate bins and I think that that was sort of, probably like 20-odd years ago, and I thought yeah, you know, that's a good thing to do.' 
Interviewer: 'What do you think ... when you hear people talking about (...) big things like flooding recently, or climate change, or things like that ....?'

Vicky: $\quad$ ' (...) Um (...) how much effort would I make? (...) In terms of, you know, the whole (...) thing like (.) global warming and stuff? Not much. Because I don't think it makes very much difference ... I'm afraid it's ... not a politically correct thing to say, but just that's the truth ... It's not about what impact can I have. It's about (...) is this actually anything to do with mankind? [...] We (...) we wouldn't think, let's not drive, let's walk, because that's going to save the environment ... We wouldn't think like that ... So, so (.) if I'm completely honest ... I don't think we make a lot of effort as a family ... To affect the ... I'd go mad if one of my kids threw a crisp packet out the window or something like that ... I'd have, in fact I'd stop the car and go back and make them get, pick it up. I would ... sort of thing. I really don't like ... And you know, my business (...) has got a policy about environment, and that recycles all sor- we do recycle stuff, but we have to otherwise we get fined, so that's probably why we do it. [...] But it's not actually about, you know, let's save our planet ... for the people who are going to live in 300 years or, you know, or whatever ... Let's stop our planet exploding and being burnt up ... Because we're not going to stop that.'

The notion of environmental affordances helps to explain commonalities across the material differences of these two mothers' families, showing the importance of understanding what family members considered that their local environments afforded and whether or not they considered that human action caused, or might alleviate, climate change. Neither 


\section{ENVIRONMENT IN THE LIVES OF CHILDREN AND FAMILIES}

mother could be said to be 'climate change deniers' since they agreed that the climate was changing, although both questioned whether this was anthropogenic. Yet, since both valued highly the beautiful countryside in which they lived, they were committed to behaviours that many would consider 'environmental' practices and to teaching their children such practices, although not for reasons of climate change.

Vicky's family lived in a detached house with a garden in a private estate surrounded by woods, 25 minutes' walk from the nearest shop, which was in a petrol station. They had lived in this home since Oliver's oldest brother (now aged 14 years) was a baby. Their home was not on any public transport routes, but unlike Katrina's family, the family had several cars and either drove where they wanted to go - including to the children's private school, in a village some 30 minutes' drive from their home - or used taxis. A key theme from all the three visits to the family was that they had little contact with their neighbours and were insulated from their surroundings. Vicky explained:

Vicky:

'I mean I think, we are a, we are sort of a convenience family, and ... finances do permit us to be like that. So we are (...) quite fortunate. Because there's things that we don't like to do ... like ... I mean you know for example, years ago, every Saturday morning I would walk around Tesco's and get the week's shop. I don't have to do that anymore because I can pay someone else to do it. So I do, because I don't actually like doing it ... and I don't want to spend my time doing things I don't like to do. [...] I think that's quite indicative of our life ... that we sort of do the things that we want to do and the rest of it we sort of get ... You pay someone to do it ... It sounds really awful but you know we do. [...] So ... that's the picture really.' 
Vicky's family's affluence insulated them from the everyday difficulties and privations that Katrina faced, and their interdependence on others (through paid help) was financially assured.

Vicky's family were aware of discourses about the global environment, although Vicky said that this was not something they had previously discussed at home, and they did not feel directly affected by, or concerned about, climate change. Nearby floods had not affected family life in any way. Oliver said in his individual interview that when people suggested that changing behaviour could avert climate change, he never felt that this applied to him. He considered that climate change was a distant problem, related to polar bears and shrinking ice caps. Vicky explained that she was affected when there were hosepipe bans because watering her garden was important to her, but she doubted the value of trying to conserve water when authorities did not mend leaking reservoirs, and considered that using less water would not benefit drought-affected people living in the global south. She also expressed doubts about the energy efficiency of recycling in comparison to landfill systems.

It is striking that both Katrina's and Vicky's families doubted that humans were responsible for climate change, raising the question of why governments and environmental organisations have not been able to convince families such as these. Their environmental affordances seemed to produce different reasons for their disbelief. Vicky's family considered that they were insulated against environmental problems to a large extent, as a "convenience" family (in Vicky's words), whereas Katrina's family were not insulated by socioeconomic resources in the same way, and perceived themselves to have little impact on ameliorating their broader environments. Both mothers, however, engaged in 'environmental' practices that accorded with their family values, including their appreciation of environmental beauty and their dislike of littering and waste.

The ways in which environmental affordances are part of the everyday were also illustrated by families living in India. For example, Gomathi's family (mother, father and two children) lived in a threebedroom apartment in central Hyderabad. Her father, Dilip, owned 
and managed a shop, while her mother, Sujatha, stayed at home and sometimes acted as an agent for a product sold through house parties and personal contacts. They were relatively middle income in our Indian sample, able to afford fee-paying schools and, like several families in both India and the UK, were badly affected by the volume of traffic near their homes. When asked about whether they had changed anything they do as a result of global warming, Sujatha mentioned that they used their vehicles less because of pollution:

Interpreter/interviewer: 'We are discussing about how can we protect the environment, but do you put these into practice, would you?'

Sujatha: 'Naturally. Now, if we have to travel a short distance, we don't take our vehicles but we go by walk. [...]'

Interviewer: 'Mmm, but when you go on your walk to the market, or to the movies, do you think about it because - do you go on the walk because you're thinking about the environment, or are there other things that you're thinking about?'

Sujatha: 'For both the reasons! Walking is good for health, keeps us fit, also, we don't actually need a vehicle for short distances, keeping the pollution in mind.'

This response is clearly co-constructed, stimulated by questions, towards the end of the final visit, about protecting the environment. It sounds somewhat theoretical, an impression reinforced by the fact that Sujatha had previously (in her individual interview) seemed to define climate change as akin to seasonal change:

Interviewer: 'So now I want to ask you about the big environmental issues. Like, have you heard about climate change? [...] And other problems like drought, flooding, all these things. So can you tell 
me uh, when you hear about these things, what does it mean to you?'

Sujatha:

'Whenever there is a flood or something, we feel like helping the needy. Previously, at our old residence we used to give away books, papers, old clothes and such material to a social worker (...) Old clothes, and toys also [...]'

Interviewer: 'So have you heard of climate change? Do you know - what do you think that means?'

Sujatha: 'Climate change means, it's'

Interpreter/interviewer: "We are able to find a change in the climate these days, right? What kind of changes do we notice these days in our climate?'

Sujatha: 'You mean changes in climate like rains in summer and heat in winters, right? ... It affects a lot ma'am. We get affected with colds and fevers.'

As the extract above shows, Sujatha saw herself as affected by climate only in terms of catching a cold and having fevers when the weather changed. Apart from that she perceived what the environment affords as requiring and enabling her benevolence to people living in poverty. In consequence, she did not see herself as subject to the environment or as causing climate change. The reason for this was partly because her environment consisted largely of the family apartment. The three photos the family chose to represent them showed them together on the sofa and Gomathi doing homework on her bed. None were of the world outside. Finch (2007) suggests that family photographs serve to display the family, including putting boundaries around it that define membership. The family's photograph choices delimited the family as a nuclear family and the family home as the site of Gomathi's play and school homework. They showed what Gillis (1997) calls 'the families we live by', our idealised families that are psychosocial, appealing to normative social ideals and the desires of family members and the family as a whole. For Gomathi's family, these images also idealised the boundaries of the apartment, signalling its centrality to 
their perceptions of environmental affordances. In that context, it is not surprising that the traffic was the major environmental issue that concerned the family since it partly marked the boundary to the apartment and so to the family.

\section{Home is where environmental affordances are: relations of care supersede concerns with climate change}

Relationality was also at the heart of the account produced by Jordan, a mother of four children, including Nathan (aged 11, who attended an urban state school). Ryan was stepfather to the oldest three children, and father to the youngest, aged 18 months. The family had a relatively low income in comparison with others in the UK sample because they were reliant on welfare benefits as neither Jordan nor Ryan were in employment. They lived in a rented housing association property in one of the most deprived local authorities in the country, with high rates of poverty (including child poverty) and relatively high rates of violent crime and fear of crime. Jordan's narrative succinctly highlighted the interlinking of environmental consumption, family practices, relationality and the socioeconomic circumstances in which families live. Like Sujatha, Jordan's focus was on her family home and children:

Interviewer: 'OK. And so I mentioned at the start that we're interested um (.) in what the (.) environment means and (...) in the context of family life. So I just wanted to ask sort of each of you that. When I say environment, what does that mean to you? What does it make you think of?'

Nathan: $\quad$ 'Just surroundings. [...].'

Jordan:

'Um (.) well (.) it's the (.) where (.) it's the area you live, the people you (.) associate with (...) the, the things you do. Your whole life really are, is like (.) around you is your environment ... Well my, my environment mainly is my house ... Because 
this is where I am most of the time ... So (...) that would be my environment. The kids, theirs will probably be the house, the park, school ...'

The family spoke very little about environmental concerns during their interviews, and Jordan repeatedly emphasised that problems in their local environment did not affect their family life. Early in the first family interview, the interviewer asked about the local area:

Interviewer: 'What is this area like? What's it like living here?' Jordan: 'Well to be honest we, I, we don't have any problems. A lot of people moan about the area and say it's a dump and this, that and the other. But it's (...) it's fine for us. [...] Well there's a lot of um (...) drugs and (...) gangs and (...) muggings and things like that. But nothing that's directly affected us. [...] I mean muggings and people stealing like bikes and stuff like that. That's rose, risen quite a lot over the past (...) couple of years.'

Nathan: 'Riots.'

Jordan: 'But it's not direct, that's not directed, directly affected us ...'

Ryan: 'Now there's the burglaries as well ... I'm saying now there's the burglaries. I mean there's a few of them.'

Jordan: $\quad$ 'Yeah. There's been a (...) the, the rise in burglaries and stuff and ... [...] But it's not affected us. Both of our neighbours have been burgled, but we haven't. $[\ldots]$... these two houses either side of us they're privately rented properties. Where this one's $[\ldots]$ like housing association property ...'

Jordan's response “we, I, we don't have any problems" reveals her expectation that the interviewers, like a "lot of people [who] moan", think that her environment is not good. She made clear that she was 
not concerned for her family - "it's fine for us" - but equally, her account did not idealise her environment. She gave a list of problems that were increasing, and when Nathan and Ryan escalated this list, talking about riots and burglaries, she provided the detail that both neighbours had been burgled. However, she distanced environmental concern from her family, even as she acknowledged this proximity, by positioning her household as different from her neighbours'. Like Gomathi's mother, Jordan set boundaries around her family, marking it out as separate from others around them, including in terms of their understanding of, and sympathy for, migrants. This contrasted with her neighbours who "don't see the bigger picture", which is that migrants were "grafting, working every single day", unlike those (non-migrants) who "are not working, that are sitting at home drinking and smoking and doing whatever they're doing (...) probably moaning about these people that are out there grafting”. Jordan's understanding of environmental concerns was situated in a relative sense of domestic security and a life that was predominantly home-based. Her security was partly biographical; she explained that - unlike the neighbours who were burgled - she had lived in the area her "whole life" and in her current house since before her children were born. Jordan's family had limited socioeconomic resources within a UK context, and careful financial management was a theme in their interviews. But UK welfare frameworks ensured the family's housing and basic income so that unlike many of the low-income families in the Indian sample - they were not dependent on the local environment for survival.

Jordan's holistic, relational and geographical approach fits both with theories of environmental affordances and family practices and relates to her equally strong feeling that environmental issues are less important to her than the everyday practices of care in a household of six people:

Jordan: 'What goes on in our lives every day (.) matters
to me more than (...) what goes on in the
environment. It's more important ... I'm not
saying that it's, it's (.) the environment's not 
important. But for me (...) what goes on in our everyday lives overpowers anything else.'

Nathan: 'Did you know, pollution can kill you?'

Jordan: 'Because that's what affects us the most.'

Interviewer:

'Are there any particular things in your immediate environment ... that affect you more than other things?'

Jordan:

'Well just every general daily life. Like making sure the kids get to school, the sh-the shopping's done ... You know, it's just (...) washing. Everything (...) general living ... that's what we have to deal with.'

Jordan's account eschewed a concern with climate change and made environmental issues subordinate to everyday family life. Her account was, however, more complex than this in that she took up an identity as a responsible mother who first and foremost fulfilled her care responsibilities, shown through the temporality of the everyday, mundane tasks of social reproduction. Environmental issues were low in her 'hierarchy of worries', in Backett-Milburn et al's (2006) terms. It would be easy to read Jordan's statement as indicating that she was only concerned with her family's everyday routines from her own perspective, particularly since she ignored Nathan's intervention "Did you know, pollution can kill you?". This was not, however, the case. Jordan's narrative shows that she perceived her environment as physical, institutional and bounded by national and local government decisions on schools and roads. She clearly paid attention to local politics and issues such as immigration and took a nuanced approach. Her overall point was that she was happy living in her area, where she had lived all her life, unlike those who moaned about it because "what you do in your everyday lives is, is important. What affects you (...) is important to you". For Jordan, environmental affordances were to do with family reproduction through everyday practices. But this was neither apathy nor ignorance; Jordan did understand climate change issues and did recycle: 
Jordan:

Interviewer: Jordan:

Interviewer:

Jordan:
'Yeah ... We do recycle, like our household waste and stuff. [...] I don't really pay attention to it. I just get on with my everyday life and (...) and that's it. I don't really (...) cha-do much to change things.' 'Could I ask you sort of why? [Laughs] [...].'

'I've got four kids to look after so I ain't got time ... to be [thinking about the environment; laughs] ... And that's the, that's the basic truth ... We just get on with our everyday life and ... let someone else deal with them kind of issues. [...].'

'And how (.) did you come about sort of (...) recycling?'

'The local authority ... have told us we have to ...

\section{Families protected from engaging in environmental practices by socioeconomic resources}

The previous chapter highlighted the intersecting environmental and socioeconomic precarity of Chandrasekhar's family who, in Guha's (2006) terms, were ecosystem dependent. Their experience sat in contrast to more affluent rural Indian families, even those whose livelihood depended on agriculture. Chitra's family, for example, owned eight acres of land, planted with paddy (rice) and black gram (lentils), and kept buffalo and oxen, from whom they got milk. As illustrated in their family map (see Figure 4.2), family roles were distinct: Chitra's father, Satyanarayana, gave an account of daily life centred on responsibilities for the farm and livestock; he also travelled daily to a nearby village for routine shopping and tea with friends. Other than Chitra's travel to school and occasional visits to the town to go to the temple or shop, both Chitra and her mother Prabhavathi described predominantly home-based lives. Prabhavathi described an everyday life centred on chores such as cooking, cleaning and laundry, and laughed when asked if she or Chitra ever visited the fields. Their domestic life was not wholly distant from agriculture: livestock were 
kept very close to the family home and crops were sold from the family compound. Their relative financial security, however, protected Prabhavathi and Chitra from hard toil and probably helped to keep them in farming since their rice planting was mechanised and they could afford to employ help when necessary.

\section{Figure 4.2: Chitra's family map}

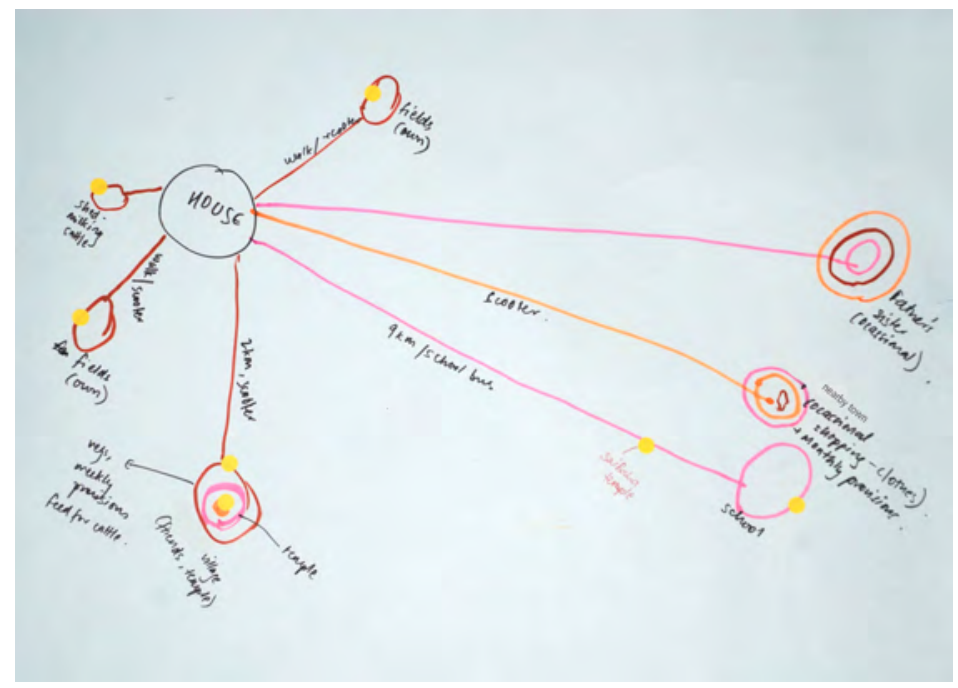

Prabhavathi said that when crops were destroyed during floods following a cyclone two years previously, the impact on family life was minimal. She said that "our regular lives did not get affected" and that although the family lost profits, "we did not lose everything" and "everything was normal here". Her distance from the impact, which was partly the result of gender-differentiated responsibilities, was made vivid when she was pressed for detail on the scale of the loss:

Interpreter/interviewer: 'Do you know how much was invested in those crops?'

Prabhavathi: 'My husband knows the details. I have no idea about it [laughs].' 
Interpreter/interviewer: 'Approximately?'

Prabhavathi: I I don't know.'

Interpreter/interviewer: 'If you lost two lakh rupees in one year, how much [would] the investment ... have been?'

Prabhavathi: 'I really don't know any of those details [laughs]. You must ask my husband.'

Satyanarayana (Chitra's father) spoke more about the effects of flooding, but depersonalised his account by situating it within a wider narrative about the government's lack of concern for farmers. He gave a detailed account of concerns about the changing local climate, concluding with the summative statement that "[c]limate is not stable". He attributed responsibility to government action at levels ranging from World Bank policy to local leaders and contractors, summing up: "This is the main reason why we are facing floods and cyclones." Satyanarayana's use of 'we', and the absence of a first-person account in his narrative, implies a level of generalisation - 'we' as a category of farmers, and 'we' as a family group discussing the issues - that was further developed as the interview went on. Through these accounts, both Prabhavathi and Satyanarayana situated environmental concern as distant from everyday family life. For Prabhavathi, it was a matter for Satyanarayana and agricultural work; Satyanarayana offered a narrative of the farmer's concern for the problems created by government, rather than as lived through hard, painful work. Instead, government policy was a matter for conversation with his friends: "It is just talking, exchanging ideas. It is not like doing manual work."

Both Chitra's parents' narratives reflected gendered positioning and the relative separation of agricultural work from domestic family life, but that is not to say that flooding was a remote concern for Chitra's family. As was true for several families in both India and the UK, they described watching reports of floods on television, and Chitra had taken part in fundraising efforts for flood relief through the school. In common with other Indian families living in flood-prone areas, they also made routine accommodations for flooding risk within their household practices; for example, Chitra said that the family "naturally 
take precautionary measures", such as turning off the mains electricity switch when there was a possibility of flooding.

Thinking about Chitra and Chandrasekhar's families together highlights the ways in which environmental 'concerns' are associated with differential impacts that are socioeconomically produced: an environmental 'shock' such as flooding can have a devastating effect on one family, leaving lives 'ruined', while for another, crops may be lost, but family life can continue 'as normal'. These families also experience quotidian or seasonal difficulties, which have to be accommodated in the habitual practices of family life. For Chandrasekhar's family, habitual environmental concerns intersected with environmental shocks to produce inescapable hardship; for Chitra's family, the effects were minimal and minimised in their narratives. These two families lived within 20 kilometres of each other but at different altitudes. Families living even closer to Chandrasekhar's but higher up were not as affected by the flooding that caused them to have to abandon their house; as noted in Chapter Three, caste intersects with socioeconomic resources and geographical positioning (Prakash and Singh, 2012) to create risk or protective factors for environmental insecurity.

\section{The importance of the state to environmental affordances}

Jordan's narrative (above) illuminates a key aspect of environmental affordances, which is that the impact of relationality is as much to do with state regulation as it is to do with relations of care and hopes and aspirations for children's future. Jordan recycled because " $[\mathrm{t}]$ he local authority ... have told us we have to" and had adapted the environment to make recycling seem 'like a natural process' rather than an imposed chore. Katrina and Vicky gave similar explanations that show how family practices and environmental concerns are interlinked because of the intervention of the state, consolidating compliance for some families and producing affordances that are consistent with climate change policies. It is important, however, to keep in view that affordances are both what the environment affords and what people themselves perceive the environment affords and what they 


\section{ENVIRONMENT IN THE LIVES OF CHILDREN AND FAMILIES}

can make of, and contribute to, it. Meg, Amy's mother, illuminated this complexity as she detailed her resistance to recycling despite the local authority's provision of recycling boxes:

Interviewer: 'I mean, we were talking about flooding earlier. And when you hear people talking about those kind of big environmental things, what does that mean to you?'

Meg: 'It [exhalation of breath] I (...) there's the, the (...) socially conscious side of me [laughs] that has one opinion. And the realistic side of me that has the other. And the socially conscious side of me thinks (...) you know (...) we have stripped and drained so much from this planet, and abused it so much ... that this is payback. This, this is planet's payback now. [...] Part of you looks at that and just thinks (...) what can I do? You know ... Is, is there any way of salvaging this? Does, is recycling really just a, a drop in the ocean? Is it actually going to make any difference now? (...) It's really, really hard (...) to think, right, I'm going to change my lifestyle and make things maybe a bit more difficult for me and do this, and put in a bit more effort and do that. When actually, you've got this bigger global picture where you've got these multinational companies ... that are actually (...) causing so many problems and issues anyway. So (...) hang on a minute; why does the responsibility sit with me? Then you have the other side ... that says, well if you don't start small, it will never get big will it? (...) So (...) you know (...) there's that. And also I have the little, my little voice of (...) conscience through there who ... pipes up with the, we should really be recycling this mum. Where's our 
recycling boxes? [Laughs] In the shed. Um (...) you know ... So it's kind of a catch-22 really.'

Interviewer: 'But do you think it ... ought to start from the top?'

Meg: 'I think, it has to start from the top because, you know ... that is when it's going to change. And that is the only way it is going to change. [...] These recycling boxes that they drop off with us, and the, the food recycling ... That is just lip service ... to some level. Because that's, that's saying to me it's my responsibility to do this and it sits with me. Actually it doesn't. [...] You know, what can I do about a company polluting water? ... What can I do about an oil spill ... from an oil tanker? ... You know, those sort of things, which are huge and have devastating ... effects. Um, or, or them not having enough (...) you know, flood defences and things ... Those are, those are big things, but actually (...) that's not me on a day-to-day ... situation. So it's quite hard because the things that need to change (...) aren't really things that I can touch really ... I can, I can maybe make my point by voting (...) or lobbying. But um (...) you know, how much of an impact does that have?'

For Meg, environmental affordance was complicated and conflictual. Her long narratives (edited here) about climate change detailed this complexity, as well as her doubts about possibilities for action. Her experience also shows how infrastructure intersects with 'environmental' decision making. Like Katrina, Meg was a single parent, living in a rural location while working part-time in a nearby town, and not using a car at the time of the interview. In Meg's case, local authority policies had made driving and parking expensive and slow, while facilitating good public transport, so she stopped driving to work and used buses. While she did not say so, this decision may 
also have been influenced by the family's socioeconomic positioning; Meg had stopped using her car altogether, keeping it off the road, so that she did not have to pay taxes on it. This highlights an issue raised by Guha (2006): that people living in poverty would consume more if they had the choice. If money was no object, Meg may well have kept her car taxed and available for occasional use. Her analysis of her own situation illuminates the importance of state intervention to the environmental affordances developed by individuals and families: "And admittedly when they started changing the roads I was thinking ... oh, for goodness sake! But actually it's been quite positive. If the structure's there ... If you don't have a good enough (...) um (...) you know (...) public transport system ... then it all falls down." In the case of using public transport, the local authority's system of rewards and punishments won her over. However, in the absence of sanctions on big business, the state requirement that households recycle waste did not successfully recruit her to the practice, even though she was encouraged by her children. Meg was much more convinced of the anthropogenic case for climate change than Katrina and Vicky, but she did not recycle while they did. The environmental affordances were different for each of their families, even if some practices were shared.

In India, policy initiatives including Swachh Bharat have focused on engaging individuals (particularly in low-income communities) in maintaining public cleanliness (Roy, 2014). Collection and disposal of household waste is provided by a range of actors, including municipal councils and private companies, and supported by informal labour (Anantharaman, 2014). The availability of services is closely aligned to the purchasing power of individual households and communities, and residents of low-income communities often have extremely limited provision for waste disposal (Joshi et al, 2011). The regular collection and disposal of household waste provided by local authorities across England means that there is relatively less exposed rubbish in public spaces, although provision of waste disposal services varies between local authorities. Nonetheless, the overall difference in structural provision between countries very likely accounts for why UK families 
generally spoke less about waste disposal as an environmental concern than those in India.

\section{Identities as committed environmentalists: distanced environmental concern?}

Environmental concerns were somewhat removed from everyday life for most of the more affluent families in the sample, and perhaps this is not surprising, given that socioeconomic resources buffer against the impacts of environmental shocks. But this relative distance has implications for the ways in which environmental concern is situated in family narratives. In this section, we focus on three families - Reethika's family in India and Humphrey's and Helena's families in the UK - to consider how pro-environmental concerns that might otherwise be 'distant' are woven into the families' narratives of their everyday lives through narrative imagination and values for upbringing.

Biographically rooted understandings were evident in the narrative framed by Reethika's mother, Parvathi. The family were landowners and had moved to a city for education (while maintaining their land and associated income). Parvathi and her husband spoke of making their children aware that "people are suffering without water, and how life will be without water in future", and in her individual interview, Parvathi told a story of the complex labour involved in securing drinking water in the village where she grew up, as in the following extract from a longer account:

Parvathi: 'Water facility is less there, have to consume salt water, otherwise have to fetch from streams, have to dig holes in the stream and catch those; we used to fetch in that way, had water problem and got salt water, have to fetch in that way and everyone in the village used to carry water by tying buckets to a wooden pole on the corners and carry those.' 


\section{ENVIRONMENT IN THE LIVES OF CHILDREN AND FAMILIES}

Parvathi ended her story with a dramatic closure: "now even that [approach to securing water] is unavailable". In this way, she showed her knowledge and personal experience, making clear that her current comfortable situation (where the family had access to a bore hole, and hence a secure water supply) did not diminish her personal understanding.

In discussing the subjects of her environmental concern, Parvathi offered a populated and sympathetic framing, not of an abstract other, but of the tenant farmers on her family's land. Rather than distancing, her narrative drew them closer through a biographically shared identity - "we were all born in agriculture families, did farming in the past, and father-in-law does even now" - an identity she reinforced through a detailed recounting of changing monsoon patterns. She noted, however, that the crop loss caused by this climatic change had had little direct impact on her family:

Parvathi:

$$
\begin{aligned}
& \text { 'Loss means, nothing much, but not having } \\
& \text { satisfaction. That is, we have leased our agriculture } \\
& \text { lands for lease to the tenant farmers. There is } \\
& \text { no proper yield for them. Even if they have } \\
& \text { experienced loss we too have our requirements, } \\
& \text { isn't it! You are aware of tenancy, they give tenancy } \\
& \text { amount, and we are taking from them even in loss } \\
& \text { period. And that too feels unsatisfactory. If there } \\
& \text { is good harvest, it's good, we feel that, and there } \\
& \text { is good harvest, which gives a different feel and } \\
& \text { satisfaction.' }
\end{aligned}
$$

Parvathi further emphasised her sense of connection when she said: "We do not have great respect for [the rent] collector, we have lots of respect towards a farmer, used to be like that!" Later, she asserted the value of this shared identity with a normative statement about Indian culture, repeating twice that the "farmer is the backbone of the nation". But the complexity of her moral position was also evident in her distancing of herself and her family from the rent collector 
that her family employed and her justification that "we too have our requirements". She both claimed an identity as environmentally aware and privileged family business over the difficulties of those affected by environmental shocks, which did not affect her family because they were socioeconomically buffered.

In inner-London, Humphrey's mother, Julia, set out an environmentally engaged family identity and "the issue of trying to live a sustainable life on the ground, which means that you are thinking about the wider environment as you go about your day-today business". Like Parvathi, Julia offered a detailed listing of practices - in this case relating to energy use - demonstrating the knowledge and thought underpinning her identity position as environmentally responsible. Her narrative built up to the story of doing a big "recofit", and ended with the feeling of responsibility it engendered, having "spent all this money":

Julia:

'You are thinking about the wider environment as you go about your day-to-day business. So that means you know (.) um (...) turning the lights off, not leaving equipment on standby, keeping the house somewhat cooler than some people like. Um (...) boiling our kettle with gas instead of electricity. Um (...) and we did do a big recofit, because the house was freezing um (...) so we ventilated all of our outside walls and we put a new roof on and we put in a photovoltaic and all that kind of stuff. So you think well we [laughs] we spent all this money and (...) used all of these (...) calories, if you like. You know (...) in the grand scheme of things in order to create this house, we should do our best (...) not to then just relax into normal usage.'

Humphrey's parents foregrounded their family environmental identity by contrasting it to the environmentally ignorant or (un)concerned 


\section{ENVIRONMENT IN THE LIVES OF CHILDREN AND FAMILIES}

'other', whom they problematised in contrast to their own knowledge and concern:

Roger:

'So yes. But I mean you could (...) we're not (...) hair shirt type things... you know, fanatics or something. ... We, we think that if (...) if everybody did (...) I suppose took the same responsible position that we were taking, then (.) the whole country's carbon footprint would be, you know, we'd meet our targets that we're supposed to be reducing by 2020 fairly easily I would have thought.'

Julia: 'I think it's partly because we read the newspaper. [Roger: mmm] I've (.) been quite (...) startled at (...) intelligent, I thought well-informed people (...) who just last year were not aware that fish stocks were running out. Now, if you read the paper ...'

Humphrey: 'Even I knew that.'

Julia:

'Well that's partly because we keep telling you. [Joint laughter] I think that indicates people who aren't reading the newspaper. Because it doesn't get covered a lot on television and radio news. [...] So it is partly simply that (.) people (.) just don't know.'

This family identity was thus one that allowed them to see themselves as more knowledgeable and aware even than people who were 'intelligent' and otherwise 'well informed'. A commitment to environmental practices enabled them to feel that they were helping the environment as well as building social capital for themselves. Julia's response to Humphrey's intervention, attempting to construct himself as like his parents by implicitly decrying other people's lack of knowledge, helped to illuminate some of the difficulties with expecting children to inform their parents about environmental issues. Since Humphrey's parents 
viewed themselves as highly knowledgeable, they viewed themselves as his teachers, not vice versa.

The extract above also illuminates aspects of environmental identities that families considered unattractive and unlikely to persuade others of the climate change case. Roger's phrase 'hair shirt' environmentalism was also used by Helena's father, James, who lived in a rural village where Helena attended the local state school:

James:
'And I don't want to (...) I could spend my whole time (...) um (...) in (...) um (...) threadbare woolly pullovers. Never shave. And people would say, "oh, James is great... [...] but (...) he's not really with us. He's not in the real world." Whereas (...) you know, because occasionally I put on a suit and tie, because I drive a car [...] I like to think they can see that my environmentalism doesn't (...) phrase, it's not hair shirt environmentalism. It's, it's, it's just ...' yeah.'

Helena: 'Just German.'

James: 'Yes. [laughter] Herr Shirt! [laughter] Herr Shirt,

As with Roger's family, James and Helena emphasised the importance of environmental concerns in their lives, detailing everyday practices to reduce energy use. By rejecting the 'hair-shirt' character of 'Herr Shirt', Roger and James defended their 'engaged' environmental identity from a disparaging archetype (Smith and Howe, 2015). James explained: "I'd like to seem terribly normal, but be doing everything I can ...' In this way, they also established a moderate positioning that avoided a charge of moral hypocrisy in relation to consumption practices such as car use and overseas trips. 


\section{ENVIRONMENT IN THE LIVES OF CHILDREN AND FAMILIES}

\section{Conclusion}

The examples presented in this chapter highlight the limitations of conceptualising environmental concerns through an affluent Minority world imaginary of the individual capitalist consumer protecting an abstract pristine nature from uncivil others. The families discussed in the chapter differ in many ways, including in terms of family structure, socioeconomic and geographical location and the extent and focus of their environmental concerns. By setting these diverse cases and concerns in conversation with each other, we have aimed to respond to Butler's (2004: 38) call 'to reimagine what it is to belong to a human community in which common epistemological and cultural grounds cannot always be assumed'. The analysis disrupts false and moralising binaries - 'nature' and 'culture', 'global' and 'local', 'concerned' and 'unconcerned' and 'selfish' or 'altruistic' - aiming for a more complex understanding of interdependence and environmental concern that is fundamentally situated in concern for the family and for upbringing.

The juxtaposing of different families' accounts helps to illuminate the complexity of environmental affordances, affected by the infrastructure around them and linked to the families' socioeconomic positioning and its intersection with the provision made by the state. Jamieson (2016: 340 ) suggests that ' $[1]$ evels of environmentally damaging consumption typically track levels of affluence; the environmental consequences might be called inadvertent'. In this study, more affluent families were able to use their resources to avoid or mitigate the most problematic effects of their environments on the family. The material interventions used to minimise families' exposure to localised environmental hazards often have ecological consequences that are felt by those for whom these interventions are financially unattainable (Shiva, 2006).

The ways in which family members were able to negotiate their environments, and their stated environmental practices, differed according to how they understood climate change and how they considered they could act on their environments. Yet, there were commonalities across socioeconomic groupings in both India and the UK that were produced by the intersection of the families' 
understanding of environmental issues and what they believed they could contribute to ameliorating climate change. A major issue here was whether the families constructed climate change as anthropogenic or simply as natural. It was noteworthy that families could deny that humans were responsible for climate change (see Norgaard, 2011), but continue to recycle because the state required it, or because they disliked littering. Equally, families who believed that climate change was anthropogenic sometimes did not recycle because they considered it contributed little to overall climate change or because they considered that their household commitments and relations of care took precedence over attending to climate change.

For Chitra's and Nathan's families, the security of everyday family life - while engendered in contextually specific ways - meant that geographically proximal environmental hazards such as crime (in London) and flooding (in Andhra Pradesh/Telangana) could be distanced, and family life continued 'as normal'. For Reethika's, Humphrey's and Helena's parents, environmental concerns were drawn into family talk and family display as the morally responsible choice of the good, 'green' parent. Overall, environmental affordances were developed from the intersections of constructions of environment with understandings of climate change, the material resources available to the families, state environmental policies and whether they considered they could act on their environments. 



\section{FIVE}

\section{Children are the future? Power, generation and environmental practices}

One day last October I found my five-year-old daughter, Rosa, leafing through my passport ... The ensuing conversation went something like this:

"How many times have you been on a plane to America?"

"About 40."

"And how many trees have you planted?"

"No trees."

... In the past year... Rosa has begun to recycle and energy-save and spout eco policy ... I suspect I am a pawn in a covert reeducation programme. I fear "pester power" is being organised to leverage pro-environmental awareness in parents - we are being bullied by a generation of pint-sized "eco-worriers". (Odell, 31 January 2009, The Observer)

By 2050, impacts of climate change on mortality are projected to be greatest in south Asia. These results indicate that climate change will have a significant impact on child health by the 2030s. (The Hindu, 19 February 2017) 


\section{Introduction}

Children are often responsibilised in environmental policy and media discourses in both India and the UK. This is illustrated in Figure 5.1, which marked a 2016 collaboration between Amar Chitra Katha, one of the largest comic book series in India, and the Ministry for Urban Development (Venkaiah Naidu). Abstract evocations of future generations materialise in many areas of climate change policy, based on the ethical argument that, as those imagined to outlive current generations of adults, children have the most to gain from activities and policies seeking to sustain the environments of which they are a part. Yet the centring of children in discourses of climate change impact and response is not without practical and ethical problems. Positioning children as 'undercover agents of change' for the environmental movement is as much 'an abrogation of responsibility for what are essentially the damaging environmental practices of adults, as is 'offshoring' environmental responsibility to the next

\section{Figure 5.1: An image of the child as an agent of change}

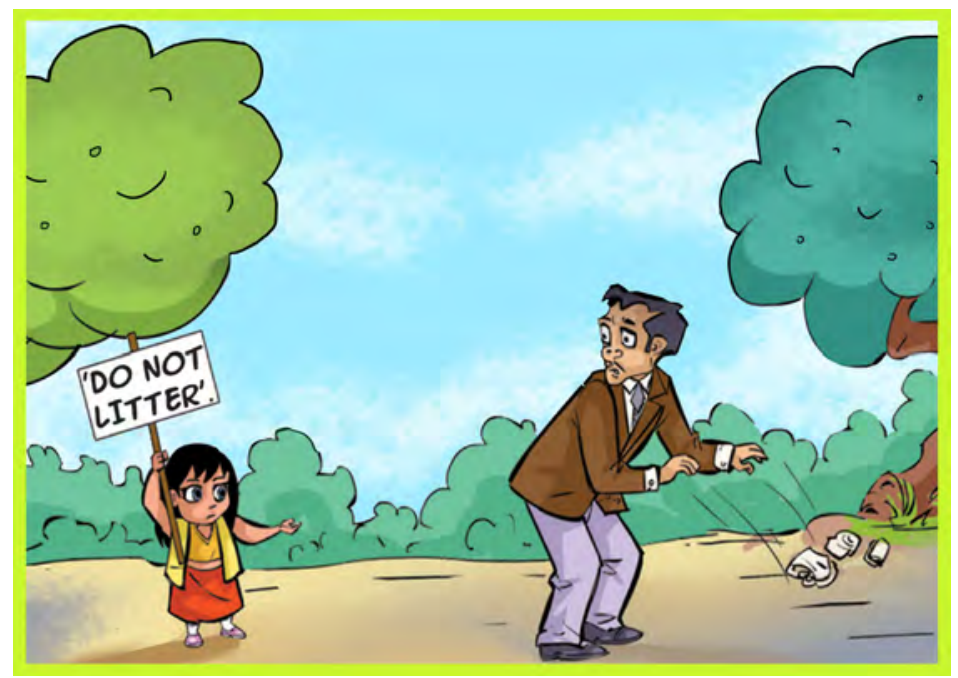

CAmar Chitra Katha Pvt Ltd, @ACKComics Twitter, 1 September 2016 
generation of 'stewards of the earth' Uzzell (2016: 483). This chapter illuminates reasons why this critique is so important, in contexts where children may be simultaneously characterised in adult narratives of environmentalism as a problematic and a vulnerable other.

The chapter addresses the generational positioning of children within adult, child and family narratives of environmental concern and environmental practice. In the multiple temporalities of family relationships, we see how imagined futures are lived in the everyday, helping us to understand environmental issues as negotiated in family lives. We consider the dynamics of intergenerational positioning of environmental concern: how adults position (and are positioned by) children, and how children position themselves. By examining how children and adults within families manage their environmental concerns - for themselves, their families, and abstract and quotidian others - the analysis shows that children are not merely passive recipients of adult education and concerns. The research reveals the constraints on children's agency within generational hierarchies across diverse contexts, but also illuminates the ways in which they do not fit with adult characterisations of the irresponsible, innocent or vulnerable child. To understand the positioning of children in narratives of environmental concern, and how we might more fruitfully engage with their own environmental concerns, we need to consider how these different characterisations compete and coalesce within family narratives.

The chapter has three main sections. First, it considers the ways in which some parents' narratives constructed children as threatened by imagined environmental futures, with the child as the object of parental environmental concern. Second, it discusses children's agency in relation to environmental affordances, including how their agency was constrained in various ways. Finally, it considers the ways in parents' and children's intergenerational positioning was interlinked with environmental concern, as some parents considered pro-environmental concern an important value to pass on to their children, while others also sought to protect their children from 'unbearable' climate change messages in order to retain children's innocence and optimism. 


\section{Imagined futures: children as parents' objects of environmental concern}

Chapter Three's discussion of Mamatha's, Chandrasekhar's and Anand's families highlighted the ways in which socioeconomic (in) security and the resulting precarity and hardship produces particular environmental affordances in families' everyday lives. In rural England, the experiences of Rosie and her family highlighted a very different kind of environmental concern, linked to children's present wellbeing and imagined futures. Rosie and her younger brother Peter were among the 7\% of UK children who attended a fee-paying school (Independent Schools Council, 2016). Rosie's family had previously lived overseas, and had moved back to the UK, and into their village home, just over a year before. The move abroad and return to the UK were partly prompted by employment opportunities for David, Rosie's father, but were also attributed to hopes for upbringing and the children's education, revealing a tension about the different affordances for the children of their everyday environment in the two countries:

Sally:

'I'm very torn, and this last year I've wondered whether I've (...) taken away their (.) childhood, and replaced it with just education.'

Interviewer: 'So was that what brought you back from [different country], or...?'

Sally:

'Work and (.) the fact that (.) we were offered help with education. And it seemed like a great opportunity. A family thing. So we (.) wanted them to ... Have the best. We thought, you know (...) but then I'd, within a very short time wondered whether this is actually the best, because now they've gone back to living quite (...) [restrictive] (.) lives [...] there's a real funny balance nowadays, isn't there? It's not the childhood we had, put it that way.' 
Sally's concerns here can be understood in light of a more fundamental environmental threat: a proposed industrial development nearby, which they learned about only after moving into the village. Their fears for this development were told and retold across the interviews, with reference to pollution risk and effects on local wildlife as well as present and possible future impacts on the family. This environmental threat is not equivalent to that experienced by the 'ecosystem families' (in Guha's, 2006, typology) discussed in Chapter Three. Rosie's family were not struggling to survive, but it was experienced by her parents as an overwhelming risk to their everyday wellbeing and imagined future lives, threatening the hopes that had brought them back to the UK. Rosie and Sally highlighted the effects on their family:

Rosie:

'And she um (.) she goes to lots of meetings about this [industrial development]. And she came home one night and she's still got it a bit, she had a big lump on her eye. And that [was' =

Sally: $=$ 'Convinced that it's my stress.' [laughs] =

Rosie:

$=$ 'pretty gross]. And she's saying it was more to do with like the stress of this and she'll come home all weary, angry and ... So that can affect her mood. A lot.' [laughs] [...]

Sally: 'Bearing in mind that we were hit with it sort of not long after coming back and I was still coping with coming back. So it wasn't great, wasn't great.'

This edited account highlights the immediacy and psychosocial nature of their concern about the industrial development: it took time, produced stress and was seen as giving rise to physical effects; Rosie commented that Sally's anger with the situation spilt over into life at home. Sally also made an important temporal link between the timing of being "hit with" the industrial development and returning to the UK, noting in another interview that "it has turned me a little bit sour" in her feelings about others in the village. 


\section{ENVIRONMENT IN THE LIVES OF CHILDREN AND FAMILIES}

When Sally spoke of moving back to the UK because they wanted "the best" for their children, and when she commented on the loss of a nostalgic vision of childhood, her remarks were inevitably coloured by the ways in which the industrial development threatened her imagined future family life. She spoke of the threat to local wildlife, including endangered species, and described walking in "stunning" countryside, "in the middle of nowhere, it's lovely". This is a familiar affluent imaginary of environmental concern, concern for environment as a place of consumption (Urry, 1995). While it has elements of a common world approach in its focus on wildlife and countryside, her narrative was partly framed as a threat to a pristine depopulated nature, experienced as an embodied threat to the parents' aspirations for a good childhood for their children.

Cushioned by socioeconomic security in the Minority world, the planned development was primarily a threat to the imaginary of a good childhood and a good family life. It had not yet begun at the time of the interviews, and more concrete impacts, such as any effect on the value of their house, were scarcely mentioned. Sally's concerns for her (relatively) affluent UK family might be dismissed as 'NIMBYism' (Not In My Back Yard), but as O'Hare and McClymont (2008) and others have observed, this is an unhelpful concept, resting on a moral framing of 'altruistic' versus 'selfish' environmental concerns. Compared with the families discussed in Chapter Three, Sally's family faced vastly different risks. Yet mothers in both India and the UK and in very different circumstances were worried about environmental threats to their families' present and future way of life.

Also in rural England, Helena's father, James, provided another example of a worried parent, offering a narrative of environmental concern that was focused on his imagined future for his daughter, in this case centred on the effects of climate change. A single parent, James lived with Helena in an English village where she attended the local state school. He was a freelance professional whose work involved overseas travel. Helena's mother lived nearby and Helena stayed with her regularly. They were typical of the rural sample in England in having moved from the city to the countryside to provide 
a better childhood. The future concerns that James described need to be understood in the context of the strongly environmentally engaged identity that both he and Helena set out in their interviews, depicting environment, in Helena's words, as "wherever you are [...] everywhere, and all, all round the world". James and Helena presented a joint narrative of anthropogenic environmental change, and of practices that connected them to the land, including attempts to grow their own vegetables, and walking in the countryside with the family dog. But, in his individual interview, James expressed his fears for the impact of climate change on Helena's future life:

James:

'You know, I (...) I (...) when I hear ... some extreme weather I, I think, yeah, and this is going to happen more and more. And I get worried (...) you know, will she get insurance? When she's 50 (...) maybe she's got a couple of kids. Hopefully she's got a partner (...) and (...) will she get insurance for that? Will insurance be viable? Will, you know (...) what happens when? You know, we've got fences here. Maybe you, maybe by then you won't have fences because the (...) there'll be too (...) it's one less thing to blow down if you don't have a fence. Um (...) what about trees? We need trees. But even healthy trees get blown down. Got an ash in the garden (...) might get the die-back disease. Um (...) I worry in that sense. Yeah.'

Interviewer: 'Mmmm. Do you think those are things that Helena worries about?'

James:

'I hope not in the sense that I hope she's still enjoying the innocence of her childhood. It's not something I want to (...) get her too aware of. I like to encourage the sort of (...) um (...) being economical with resources. Thrift.' 
This vivid imagining was local, personal and populated with Helena's future self as well as their contemporary family. As with Sally's environmental concerns, the future story that James told resonates with Weintrobe's (2012: 43) depiction of the 'unbearable anxiety' of environmental concern that 'undermines our belief in a reliable future $[\ldots]$ and our hope that we are generative, that our children will have children who will have children into the future'.

The merging of personal and societal interest was evident in James's detailed narrative linking of present and future, which positioned Helena as the object of future fears about the environment. He managed his fear by teaching Helena about "being economical with resources", and defused the tension in his account using humour, as he went on to joke about Helena saving yoghurt pots:

James:

'But we've (...) still got to (...) you know (...) It's good husbandry of resources. And I, I teach her that. I, you know (...) even to the point where she doesn't throw anything away, which can be a bloody nightmare. [...] often she won't throw away um (...) the container that she's had things in. She'll say, no, we can wash that; it might come in useful. As an idea that's great. Except you end up with a whole load of yoghurt pots that (...) you know you'll never use. Um (...) but they might come in useful [laughs]. One day. For something. That you can't imagine and probably never will happen. I like the spirit of it so I encourage it.'

There was a stark contrast between James's approval of Helena's smallscale agency in not wasting potential resources (for example, yoghurt pots) and her future orientation in doing so, and the potential horror of a future he feared (when Helena is 50 years old and struggling with the effects of climate change on her family). 


\section{Making the most of environmental affordances: constraints on children's situated agency}

To Shove and colleagues' (2012) conceptualisation of practices as dependent on meanings, skills and materials, a common world approach might add whether, and if so, how and why particular practices matter. Children who had access to high carbon resources (including technological objects such as iPads, mobile telephones, television sets and computers) recognised the ways in which these materials were embedded in taken-for-granted quotidian practices, necessary for school work and socially important for friendships and play. In a digital age, online and offline lives co-exist (Livingstone and Bulger, 2014), in school and leisure activities. Solomon - who lived with his mother and siblings in a block of flats in London - explained that he interspersed his digital play with other activities: "[I] go on it [the PlayStation] one hour, turn off, one hour, turn off, one hour, turn off." He took pictures to represent this mix: the PlayStation and television where he plays a football game, and the green space on his estate where he plays football outdoors (see Figure 5.2). His photographs highlighted the spatial expansions that the PlayStation affords (Oswell, 2013).

Other children in both India and the UK also illustrated the prominence of electronic resources in their daily lives. Nageshwar, who lived in a city in Andhra Pradesh/Telangana where he attended an international school, described his usual Sunday:

Nageshwar: 'Morning, waking up late. Playing computer, eating lunch and then going to friends' house. Evening uh, with my family going to uh, some other place.' 
Figure 5.2: The spaces where Solomon plays football

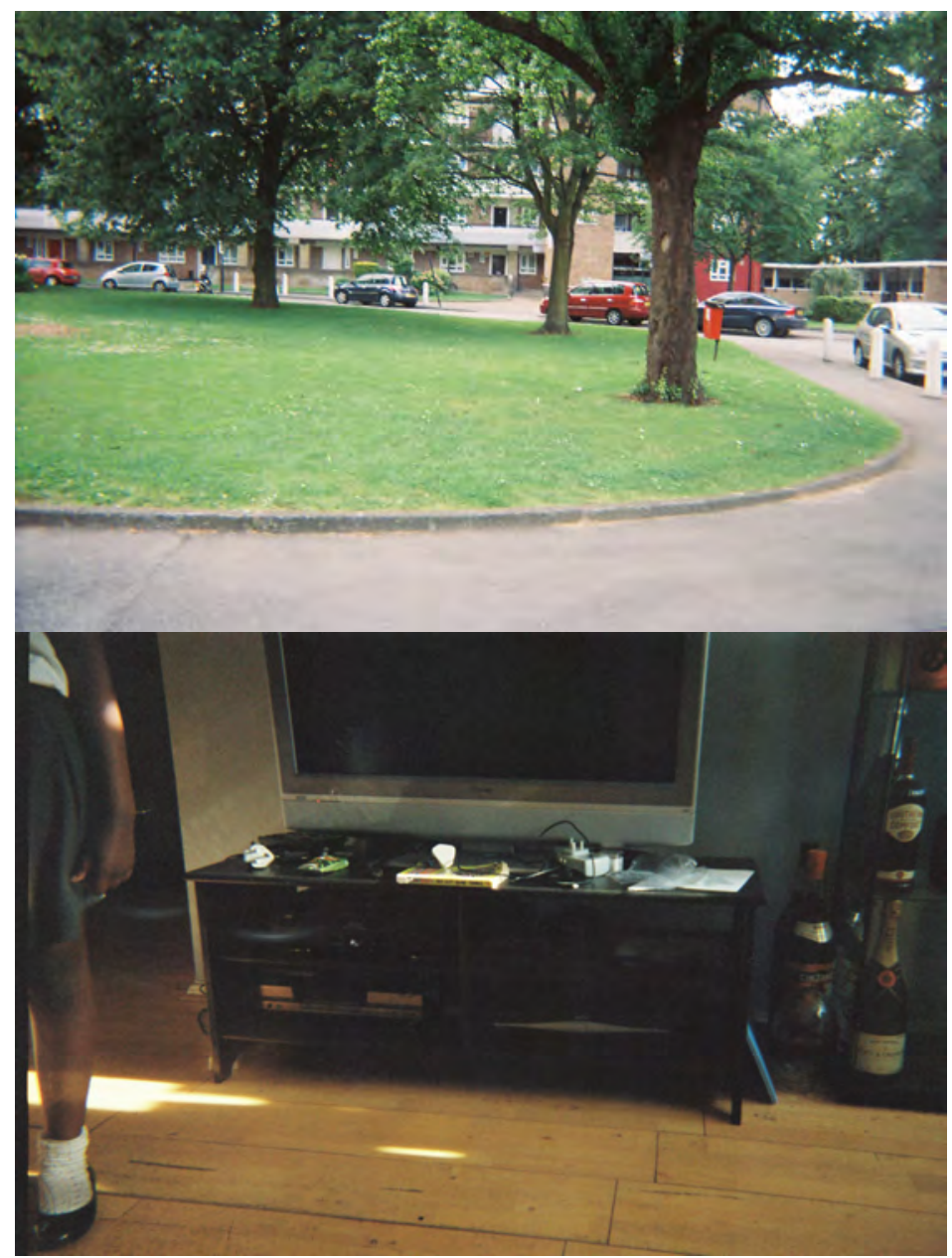

Rosie, in rural England, talked about her iPad, which her parents had purchased to help her keep in touch with far-off friends after the family had moved back to England from abroad. As well as overseas friendships, Rosie used the iPad to communicate with new school friends across a shorter, but still significant, distance: 
Rosie:

'We do Facetime together - that's how sad we are - we Facetime each other from our house, and it's the weekend. And we're going to see each other the next day.'

Among its multiple affordances, the iPad enabled the continuation of Rosie's school-based social life within the physical space of her home, compressing the affordances of the two spaces (Harvey, 1989). Her account underlined why the iPad mattered so much to her. Technological objects also had particular significance for children in rural Andhra Pradesh/Telangana; for example, Chitra said she enjoyed watching television at home because she had few friends and leisure possibilities nearby.

Such accounts are typical of the lives of children globally who are growing up in a digital age. They fit with a common world approach, where technological affordances are increasingly important for adults and children, but they do not imply that children in the study were apathetic or ignorant of environmental considerations. Many children expressed concerns about global and local environmental issues, even while recognising the constraints on their agency to act on those concerns. The following fast-paced discussion in a focus group in an international school in Hyderabad indicates how children have to negotiate environmental issues in relation to use of technology.

Interviewer: 'Is there anything that you've learnt about at school that made you want to do something differently at home?'

Aamir: 'Um, to be honest, I actually tried to change some things in my house but then I am lazy enough to just leave it and like, never mind anything [laughs] [...] I tried to cut short the usage of ACs [air conditioning] and all, but I kind of um, I'm addicted to those sort of things. Using the gadgets more often. [...]' 
Naren:

Amrutha:

Interviewer:

Amrutha:

Jahnavi:

Sandeep:

Jahnavi:
'Uh, I wanted to stop the use of the computers not actually stop but lessen the use because I read this - that every - every click of the mouse, we - we give off carbon fumes ... So till after some time, till after not even a month I have - I have not been able to stop the use of computers.'

'[I only stop it] like if we get some exams or something.'

'Ok, so for all of you would you say that using computers, and using AC, like Aamir said, is part of your life?'

'Yeah.'

'Like almost every day we get like a research task, like information ... But the thing is that if I sit in front of the computer, I open Skype, then I see something else, and [then' =

$=$ 'Facebook' $=$

$=$ 'so that's how] we - yeah, Facebook!'

These children expressed awareness that 'big' and 'small' environmental issues were linked and that their use of technology had environmental consequences. Their discussion highlighted the psychosocial nature of environmental affordances, invoking notions of inertia and addiction, even as they noted that their (affluent) school required the use of computers. Technological affordances are part of the common world in being relational, simultaneously non-human, and the means by which children and young people draw on global links (even if they are not themselves communicating with people in other countries). The technological environment is thus part of the common world in multiple ways.

While for Katrina (Callum's mother) and Vicky (Oliver's mother), in Chapter Four, concern about littering and waste was partly an aesthetic concern for a pristine unspoiled nature, young people's concerns about waste disposal sometimes had more direct implications for the safety and accessibility of outdoor space in both India and the 
UK. In inner-London, Tamsin, Nathan's sister, said she preferred to stay at home with her iPad than go to the local park because it lacked resources and was strewn with rubbish; in Hyderabad, Rahul expressed concerns about rubbish dumping near the family home.

Interviewer: 'Who throws garbage there [in an open space close to Rahul's home that he has just described in his interview] (.) do you know?'

Rahul: 'All the people who live in the area.'

Interviewer: 'In the area, OK (.) yeah. So what do you think could be different about that? What would you like to see changed there?'

Rahul: 'Uh, we should keep, uh, one big garbage over [tailing off in English then switching into Telugu]. We should put one big garbage bin there so that it does not pollute the air' [...]

Interviewer/Interpreter: 'Is there no dustbin?'

Rahul:

'They get the dustbin but take it away after a while and don't replace it.'

Rahul's assessment of the problem highlighted his knowledge of how the waste should be managed; he identified the problem (the bin is taken away for emptying and not replaced) and offered a solution (a larger bin). Through this co-constructed account we see how Rahul exercised a form of political agency - pointing out, and imagining alternatives to, the inadequate garbage collection in his community. He went on to take a photo of the garbage he was concerned about (see Figure 5.3). 
Figure 5.3: Rahul's picture of rubbish dumped near his home

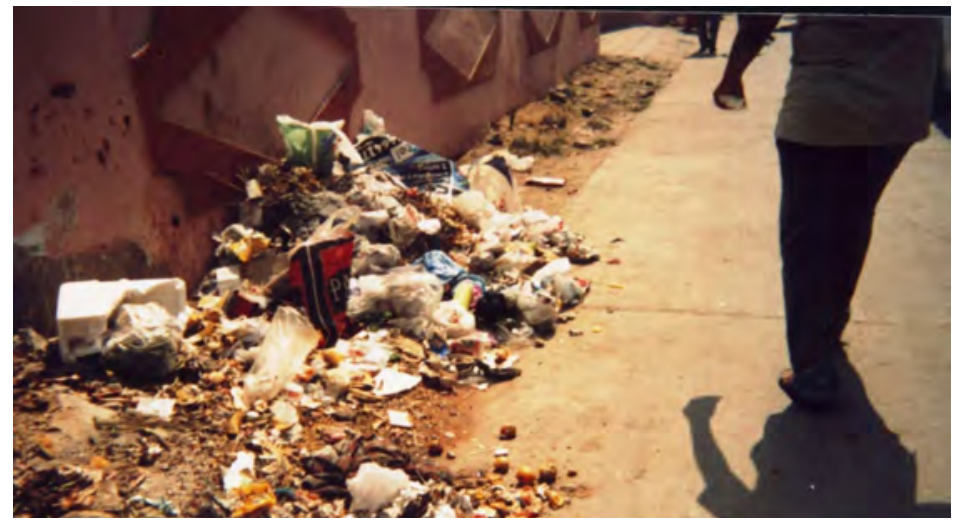

With the researchers' encouragement, Rahul pointed out his concerns to his father, Vinod, when they passed the site during the mobile interview, and Vinod encouraged Rahul to exercise a more direct form of political agency by emailing the local authority:

Vinod:

'We have to complain to GHMC [Greater Hyderabad Municipal Corporation]. There will be a portal for GHMC, no? [Rahul: 'Yes.'] We have to send an email in that portal. And they will take care of this.'

While Rahul's father's suggestion still relied on an individual doing something (in this case, emailing the local council), it reflected an assessment that necessary changes can only take place when local authorities act in responsible ways (as well as apparent faith that the local authority "will take care of this"). This view had commonalities with those of others in the study (see Chapter Three) who highlighted the limitations of individual action and the need for government interventions to improve the environment, but it was also an example of a parent taking seriously a child's environmental messages and encouraging his agency. 
Antonia attended state school in London, where she lived with her parents (both working professionals) and two siblings. She gave an account of constrained agency in relation to environmental issues, even while highlighting occasional guilt about her practices:

Antonia: 'Sometimes when I'm using electricity and stuff - I kind of know about global warming and all that stuff $\ldots$ and I kind of feel like I'm a part of this big thing that's causing global warming. [...] I kind of (...) I feel a bit bad, but then I also know that me, individually, I can't really do anything about global warming as much as I'd like to. [...] I can't do a lot against it.'

Interviewer: 'What do you think is the best way that people can do more?'

Antonia: 'I think if there was someone with quite a powerful position, like Barack Obama [then President of the US] or David Cameron [then Prime Minister of the $\mathrm{UK}]$... I think if they sent the message out and if, if they got (...) just (...) if they sent the message out and they got lots of people kind of aware of this kind of thing, then (...) quite a lot could be done.'

Like Rahul, Antonia identified political action as a way forward, but in this case (and apparently contradicting her argument that individual action had limited value) her account seemed to return responsibility to the individual, invoking the much-critiqued $\mathrm{ABC}$ model (Attitudes-Behaviour-Cognition) discussed in Chapter One. Her framing was partly co-constructed by the interviewer asking how "people can do more", but was clearly the main way in which she envisaged change, highlighting her constrained agency. In rural Andhra Pradesh/Telangana, Chandrasekhar also drew attention to the limits of possible action as he related family practices designed to improve the area immediately around their home, including working with his father 
to clear drains blocked by weeds and rubbish. He recognised that the best solution - provision of a paved road through the community - was beyond the family's agency "because we don't have money". Family practices such as clearing the drains are examples of environmental affordances and 'thin agency', 'decisions and everyday actions that are carried out within highly restrictive contexts, characterised by few viable alternatives' (Klocker, 2007: 85).

Jack's family lived in an English village where the children attended local state schools. Like Antonia, his parents, Mary and Julian, were working professionals. Jack's parents placed strong emphasis on environmentally sustainable values and Jack also set out a strong identity as knowledgeable and concerned about climate change and sustainable practices. In his individual interview he spoke about the need for macro political changes (such as investment in nuclear and tidal energy) and cited vegetarianism as an example of individual action, while emphasising the difficulties of completely changing one's way of life:

Jack:

'I'm try (...) I've got, I've got a book, one I got from the library. It's how to reduce your carbon footprint. And I've had it out a few times. Um (...) it's (...) and we've done some stuff. And um (...) just (...) you, it's, it's kind of that feeling that you try and try and try, but you're never going to get anywhere. [...] However hard we try we just (...) um (...) we can't do that much effectively if we want to completely, unless you want to completely change our way of life, which is quite ...'

Interviewer: 'So do you think there's anything that can be done?' Jack:

'Yes, there is. That, I, I'm trying to (...) stop, like um ... There is lots of things that can be done. [...] there's also like going vegetarian, which would help, but (...) I can't see me doing it. I really can't see me doing it.'

Interviewer: 'You're not that keen on vegetarian food?' Jack: 'No' 
Interviewer: Jack:

Interviewer: Jack:
'Is anyone in the family vegetarian?'

'Um (...) I know there was for, um, a few years. And then um (...) [laughs] when I was little I did it for a week [joint laughter]. I ate loads of eggs. [...] I ate loads of eggs and vegetables. Oh, um (...) but it all ended when (...) er [laughs] it all ended when we had some chicken.'

[Laughs] 'Hard to resist.'

'Hard to resist.'

These children's narratives show that even in constrained circumstances, they were not ignorant of environmental issues, but were keen to act as much as they could, given the affordances they saw, sometimes in concert with other family members. For those whose family socioeconomic resources gave them environmental choices, attempting to behave in ways they and their families considered pro-environmental sometimes entailed a struggle against habits, preferences and competing demands (such as school requirements).

\section{Generational positioning and environmental concern}

Contemporary discussions of climate change response frequently emphasise individual moral responsibility and - as indicated by Figure 5.1 and the newspaper extract that opened this chapter children are often assigned a particular role as 'agents of change'. Families, however, generally take a more nuanced approach. The telling of 'moral tales' is a family practice, providing ethical accounts that are in part shaped by public discourses of the morally responsible family, but also based in everyday practices (including gendered practices of care and upbringing) and rooted in complex and interdependent networks and sets of relationships (Morgan, 2013). Moral tales are part of 'doing family' and producing family 'myths' - intergenerational stories that guide action and construct family identities (Bertaux and Thomson, 1993). In relation to concern about the environment, parental or upbringing practices took two main forms: efforts to engender 
responsibility in relation to (environmentally) ethical principles; and making bearable the fears that might follow from environmental concern.

\section{Parents' framing of environmental concern as a value for upbringing and family life}

Relatively affluent families in both India and the UK often constructed moral tales of responsible privilege that were framed in relation to values for upbringing, and environmental concern. In London, for example, Antonia's parents talked of teaching the children about environmental issues and embedding environmental practices as a mundane part of their lives:

Hugh:

'Yeah. We do, you know, we do talk about environmental issues. Um (...) so we talk about you know (...) um (...) I mean global warming's quite big on the agenda at their schools, so you know, they, they come back and initiate conversations about climate change (...) and, and, and have views on that. And you know, we'll sit and discuss that round the (...) dinner table. [...] $\mathrm{Um}(. .$.$) and you know, we try and involve them in$ (...) thinking about using the recycling ... scheme properly. Um (...) you know, we try and involve them in, in, in sort of walking and cycling rather than nagging us to drop them off places.'

Interviewer: 'Yeah. And do they nag you to drop them off places?'

Hugh: 'Yeah. Yeah. They do. I mean particularly Adrian [Antonia's 14-year-old brother]. Yeah. And we generally say no. [...] Um [laughs] ... You know, we get them to think about energy use. I mean we've had a, had a little bit, a little bit of a drive recently to try and get Adrian to spend less time 
in the shower $[\ldots]$ because of you know sort of issues of hot water use.'

Hugh recognised the children's contribution to family discussions of climate change, and in her individual interview Antonia also observed that these dinner table conversations were part of their habitual family practices. But Hugh's narrative was exclusively centred on the parents' efforts to educate and adapt the children's practices. The oldest child, Adrian, was drawn as a stereotypical teenager, nagging to be given lifts and wasting hot water. Hugh characterised the children as both educated and in need of education, revealing the limits of their capacity to act as agents of change. Later in the same interview, Hugh commented: "I can't think of a specific example of anything that any of them have (...) come home from school talking about that's meant that we've changed our (...) family practices."

Children's use of technology was a recurrent topic of adult concern, often presented as an example of young people's taken-for-granted high carbon practices. For example, in Hyderabad, Amrutha's family also set out a strong identity position of environmental awareness and concern. They lived within a gated community where Vijay, Amrutha's father, said his wife and children spent "90\% of their lives", and Amrutha and her sister attended an international school. Like Rosie's family in England, they had previously lived overseas, and their narratives often incorporated comparison between the different places in which they had lived. Environmental concerns were narratively linked to their identity as a cosmopolitan and globalised family, integrating practices and perspectives from their time in the global north into their lives and identities in an Indian context. Narratives of responsible privilege were often framed through a repeatedly expressed parental concern that their children's lives were (too) separate from the 'real India', as Vijay explained.

Amrutha's family map (see Figure 5.4) made visible the complexity of the 'families they live by' (Gillis, 1997). Markers of globalised consumption (such as movies and the local mall), and universal practices of affluent childhoods (such as tennis and music lessons), 


\section{ENVIRONMENT IN THE LIVES OF CHILDREN AND FAMILIES}

were juxtaposed with practices that emphasised traditional Indian values and 'responsible privilege', such as shopping for vegetables at the local farmer's market and visiting temples or a local orphanage on the children's birthdays.

\section{Figure 5.4: Amrutha's family map}

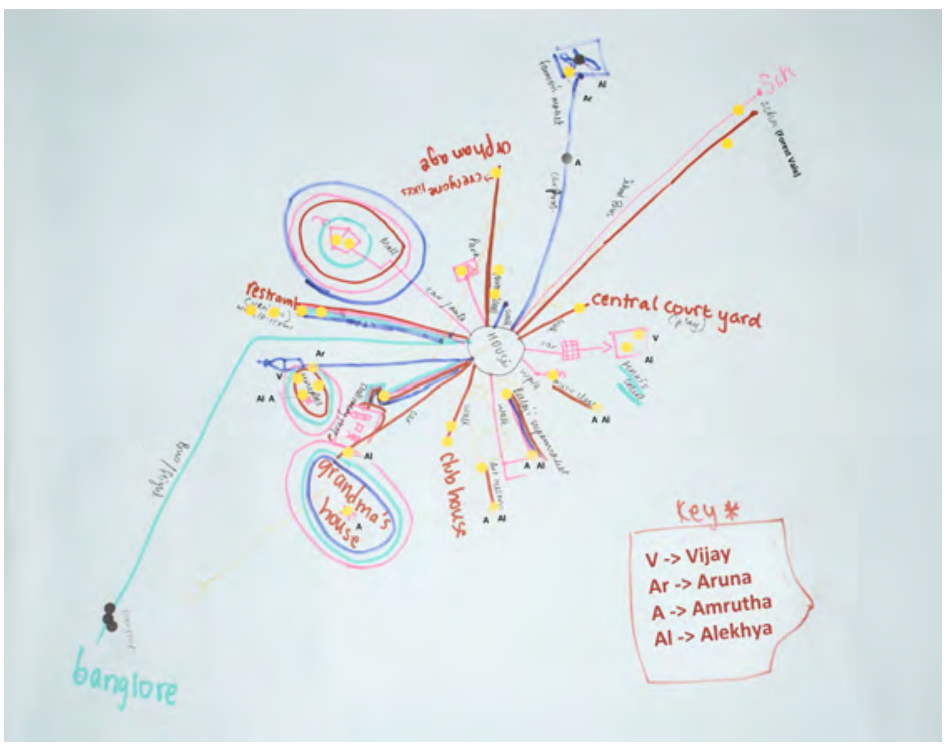

In both the children's and the parents' accounts, environmental concern was populated, but situated at a distance from the comforts of the gated community. In a family discussion of water scarcity, Amrutha and her younger sister Alekhya framed a distanced concern for the other, drawing on knowledge gained in school, as in Amrutha's distinction between urban dwellers who "waste water" and "like people, like tribes who live in forests, they don't have taps like we do or something". Their parents, by contrast, discussed water scarcity in relation to their own upbringing, referencing traditional Indian values as helpful in teaching the children about responsible privilege: 
Vijay:

'And that's the reality, that's what we were talking about where life is so shielded out here, pretty comfortable and this is not the true [India life' =

Aruna: $=$ 'maybe more than] books they have learnt it from there only because when we go there they'll be given only half bucket full of water and they have to take bath with that - that water only'.

Amrutha's parents' concern that she and her sister did not live in the 'true' India was echoed by a similar contrast that Amrutha drew, in her individual interview, between her own 'luxurious life' and the lives of people living in poverty in rural areas:

Interviewer: 'And ... when ... you see reports of other people whose lives are affected by things which are happening in the environment - how does that make you feel?'

Amrutha [speaking in English]: 'It makes me feel bad, I mean, we have such a luxurious life and people in the rural - rural areas - a tongue-twisting word! In those areas, they, like, are poor, they're not educated.'

In Chapter Three, we saw how socioeconomic resources could ameliorate potential environmental discomfort due to pollution. Retreat from heat, as a key source of discomfort for families in a region of India where temperatures often rise to $45^{\circ} \mathrm{C}$ in summer, was also resource dependent. In keeping with adult narratives of responsible privilege, air conditioning was highlighted as a necessary consumption practice, and moreover as a practice of care, by both Aamir's and Amrutha's mothers. Aamir's mother, Zoya, explained that air conditioning was 'not a luxury', but was purchased as a necessity for her father's health. Zoya also spoke of trying to reduce air conditioning use to "develop this habit in [the children], like how to avoid wastage", drawing a generational contrast: 
Zoya:

'In my childhood I did not know what AC is. Only when I go to some big hi-fi place I used to feel that when I was very small, like my children, like I have come to a very big place, where see it has AC, air-conditioning, AC. But now it is very common, for my children it is very common thing, like how we switch on the light, how we switch on the fan. AC is like the same for them.'

Zoya's positioning of herself as the expert within this narrative is consistent with other research that highlights generational hierarchies in families (for example, Robson et al, 2007). But air conditioning and water use were not only taken for granted as necessary practices for children, as we see in Zoya's account of her own routine when coming back to the house during the heat of summer:

Zoya:

'When I come back home it is terribly hot, I take bath, eat my lunch and then switch on AC and take a nap for some time.'

There was little discussion among families about the disjuncture between adult narratives of the need to educate children to be environmentally responsible, and parents' justification of their own carbon practices within environmentally responsible identity positions. This is perhaps not surprising. In the UK, while survey data suggest that the majority of adults express concern about climate change (for example, Randall, 2011), intergenerational exchanges within the home about the environment are limited - in some cases this is because children's knowledge disrupts the role of the parent as 'expert' (for example, Duvall and Zint, 2007).

Amrutha's family partly framed environmental practices as a contrast between tradition and modernity (as in their discussion of water use, above), but they also narrated environmental responsibility as a practice of modernity learned abroad, drawing on their experiences of living in the Minority world. Alekhya spoke of learning about 
the environmental threat to polar bears through a cousin overseas, Aruna talked of having 'learnt' recycling when living overseas, and Amrutha and Vijay both talked of learning about 'carpooling' when living abroad. For example:

Aruna:

'[Recycling] is a good thing I learnt it, I should apply it in India as well, I mean in my day-to-day basis as well. Even my maid knows about it "Amma where should I put this?" - "Drop it in that bag."” $[\ldots]$

Amrutha: 'Like in America we used to carpool. Like there were like three of us people in our complex used to go to the same school, so we used to carpool. But then other people they like - they pollute the air a lot like, they go by different cars to the same place, even though they live in the same place, like near or something. And that's like causing a lot of air pollution, so I'd recommend them to carpool or something like that, or go by school bus.'

Through their interviews, Amrutha's parents repeated a framing of environmental concern as characteristic of India's developing modernity, described by Vijay as "catching up today" (with the Minority world). In this context, it is striking that Aruna's account (above) of her (transnational) recycling knowledge was centred on teaching her (less knowledgeable) maid. Later, she and Vijay told a joint story that attributed the maid's purported lack of environmental concern in managing the family's rubbish to Indian cultural norms.

Interviewer: 'Umhmm and what do you - you think the reason is for the maid not putting (.) the rubbish [in the chute?' =

Aruna: $\quad=$ 'They're in a rush], they just want to fly away. [...] Many times I tell them, "throw it in the bin". They look at me as if they don't understand my 
language? Hindi mein bolo (tell them in Hindi) they won't understand, if you talk in English they won't understand, you tell them in Telugu, they won't understand. [They just stare at me like this and just go away' $=$

Vijay: $\quad=$ 'I think it's part of, part of =] Yeah, I think it's just part of the culture. Um if you compare India with, let's say US or UK, we keep our house clean but not our surroundings.'

In her individual interview, Amrutha reprised her parents' narrative of maids not knowing how adequately to dispose of rubbish. The family's sympathetic framing of the remote villager sat in contrast to their problematising account of the maid, and the vexed question of whose rubbish it was remained unspoken. Their accounts illuminated the ways in which uncomfortable socioeconomic inequalities may be obscured in narratives of responsible privilege. Even when their narrative imagination drew environmental concerns into the family's comfortable everyday life, the objects of concern remained distant and othered.

Through these accounts, Vijay, Aruna and Amrutha put boundaries around family membership, situating their environmental concern within a privileged moral position as part of an 'élite consensus' (Swyngedouw, 2013), ahead of uncivil others who were 'catching up'. Their attempts to engage their daughters in morally (and environmentally) responsible activities served to sustain their élite moral position into the next generation. Such narratives constituted family display, creating a shared identity as an environmentally aware family who, while they lived in India, had gained superior understanding by living in the Minority world.

The families discussed in this section filtered their environmental concerns through narratives of privileged responsibility and knowledge. Some lower-income families also prioritised environmental concern as a value for upbringing and framed their narratives of responsibility around scarcity rather than responsible affluence. In rural Andhra 
Pradesh/Telangana, Dharani's family showed how children could bring their awareness of environmental issues to their family's attention and gain support for their perspectives, as became evident in the family discussion of the research vignette on water use. Dharani's parents and grandparents recalled Dharani coming home from school with stories of what would happen if people did not reduce their water consumption. They encouraged her to tell one such story in the family interview.

Rani (mother): 'How was the story you told us, after coming back?'

Dharani: 'One son comes, "Grandpa, Grandpa, why are we taking a bath only once a week?” ... Then, people of previous generations used more, they created shortage for us. If they prevented each drop of water, had they used like this, this situation would not have come. Grandfather told this, his grandfather.'

This story, which Dharani recalled being told by a teacher, presents a clear causative chain between the resource use of one generation and the possibilities for resource use of subsequent generations. It highlights both the wisdom of older generations and the need for intergenerational cooperation. The knowledge on which the story is based may not be new to older family members, yet they appeared to have appreciated Dharani's telling of this story, which connected her school knowledge to their historical experience.

\section{Protecting innocence? Making environmental concerns bearable}

Intergenerational links and legacies were also of concern to James, Helena's father. His concern to protect Helena's innocence of the consequences of climate change (described above) highlights a specific problem with calls to (environmental) action that rely on invoking fear. Faced with unbearable anxiety, families strive to find protective 
strategies, particularly for their children. In Sally's account of her involvement in protesting the planned industrial development, she noted that the local landowner had threatened her with legal action, and joked: "If I'm shot with a pheasant shooting rifle, you'll know who it was. My head's on the wall." Sally's joke was perhaps possible because her family were in most ways secure, but her use of humour was also a protective strategy. Rosie also joked, twice talking about moving to the moon in response to her mother's talk about the threat of industrial development. For example, when Sally said: "And what are we leaving them? [...] You know, what's the legacy we're leaving behind?", Rosie replied: "We're going to the moon apparently." Rosie's joke disrupted Sally's expression of concern for her children's imagined future, making things safe for herself and her mother through a light-hearted, imagined alternative. Other families also brought humour or notions of 'fun' into family narratives of environmental concern. And - as with Rosie's reference to the moon - these accounts often drew on distant or abstract symbolism, distancing a potentially unbearable future.

The polar bear as a symbol of globalised environmental concern was woven into several families' narratives of environmental practice. For example, Amrutha's mother, Aruna, told a small story about air conditioning use:

Aruna:

'One quick [story] you can call it as a joke, if I switch on the AC in my car, my kids will shout, Amma you are increasing the global warming, switch it off, polar bears will die [laughs]. Every time this is the fight in the car. [...] We just laugh [laughs]. We keep telling them it is not just because we switch on the AC, it is one of the factors though.'

Interviewer: 'So then what happens, who wins?'

Aruna:

'Definitely them, you cannot argue with them, then after a couple of minutes they will forget and then I will switch it on. I am not supposed 
to lie though [laughs]. Especially this girl is very particular: "Let's open the windows and we drive, because we will be killing the polar bears." I say: "Where do you see polar bears here?" [laughs] She heard this one from her sister, and just that point went into her brains maybe and since then this is what, and whenever she turns on the AC when she wants to sleep, I tell her "polar bears are crying, why are you switching on the AC?" [laughs] Sooo.'

Amy's family also joked about helping polar bears. Her mother Meg (discussed in Chapter Four in relation to her scepticism that recycling made a difference) said she was prompted by "drilling in the ... Antarctic you know" to sponsor a polar bear to "bring aspects of it here":

Meg:

'So I mean, thinking about it we, you know (...) recently we have tried to sort of (...) bring aspects of it here. Sort of like the polar bear thing that we did ... [Amy: 'Oh yeah.'] ... recently, where we, we sort of (...) um ...'

Amy: 'Sponsored a polar bear.'

Meg:

'But then again, it's very removed, isn't it. I mean, you know, I did say to the children that you know, we've got a polar bear; they're going to deliver it soon. But they um ...'

Amy: 'Mum.'

Meg: 'Yes.'

Amy:

'You said no more animals.'

Meg:

'That's what I said. The Greenpeace man said I could have a polar bear.'

Amy: 'Mum. Imagine what a polar bear would do to [family pet]. [...] Mum! Imagine what it would do to you!' 
Meg:

[Laughs] 'You know, you can think about that and think about ... But actually it's so far removed. You know, we're talking about drilling in the Ar, Antarctic you know. It's (...) so ... yes, we discussed it and thought ... [...] it's awful and we'd like to help and support that. But ... Actually (...) you know, we signed up for it, we (...) got all the booklet and we, we read through that. [...] But um ... [Amy: 'Mum.') Yeah. It's not something that we sort of (...) live and breathe every day, is it ...??

Amy: 'And if we did have a polar bear what would happen if you (...) um (...) forgot to feed it?'

Meg: 'He would eat one of you. It would be absolutely fine. And it would be a friendly polar bear. The Greenpeace man said so.'

Both Meg and Aruna positioned polar bears outside their immediate environment. While Aruna joked "where do you see polar bears here?", in Meg's telling, the joke was that the family were waiting for the polar bear to be delivered and Amy joined in, reminding her mother that polar bears were too dangerous to live in their home. For both families, the use of humour was distancing, making clear that the polar bear was not part of the family, even as they were drawn into the family narrative. It enabled a family display of environmental concern that was fun rather than threatening, emphasised in Meg's summative comment that the polar bear was "not something that we sort of (...) live and breathe every day". While the invoking of polar bears at first seems to be part of a common world approach, the jokey distancing makes them extreme conceptually as well as physically remote and exotic, rather than part of a common world. In doing so, it paradoxically dilutes environmental responsibility for practices that might harm polar bears.

Phoebe, who lived in a socioeconomically disadvantaged area of London with her parents (who both worked) and two siblings, 
was sceptical about children's agency in changing family practices across generational hierarchies, as illustrated in a light-hearted family discussion in relation to the vignette about water use:

Phoebe:

'Like there will, like she'll tell her parents and they won't listen like [...] And then um (...) like so they'll just keep on using it and then there will be like a drought and then they'll like realise that they should have like saved the water.'

Interviewer: 'Why do you think the parents wouldn't listen?'

Phoebe: 'Because they care like, not, not more about their house than their child. But they don't like, because they just think it's not like (...)'

Nicholas (younger brother): 'They're too clean.'

Phoebe: 'No. They're like just thinking it's just a thing they've [the school] made up to make them like be interested in but it's not like ...'

Interviewer: $\quad[\ldots]$ 'Yeah. So any other opinions?'

Colin (father): 'Yeah. I think they would come home and they would have a sensible discussion ... [joint laughter] ... and work out ... [joint laughter] ... water saving devices. [...] Like putting a brick in the toilet. Only showering.'

Joanna: 'They'd love it wouldn't they?'

Colin: 'Sharing the bath water.'

Phoebe: 'Eugh.'

Colin: 'And that's what I think they would do.' [joint laughter]

Within narratives of responsible privilege, raising awareness of less fortunate others, two of the more affluent UK families - Oliver's and Marnie's - told stories of holidays in Africa involving visits to village communities. Saskia, Marnie's mother, explicitly attributed her children's understanding of water use to their village visit, saying: "They're conscious of water as well, because we took them to Africa 


\section{ENVIRONMENT IN THE LIVES OF CHILDREN AND FAMILIES}

for an experience $[\ldots]$ and we went into a village where they have to get water from a well." But Hudson, Marnie's younger brother, disrupted his mother's moral tale, interrupting eight times to repeat that the experience was "really fun". Towards the end of the narrative, Marnie joined in her mother's moral framing:

Marnie: 'It made me think that my life is like (...) extremely like (...) I'm privileged to have (...) this, this ... [...] And then when you think about, like somebody will say, oh I want a bigger house and I want (...) a nice car, it's like (...) like you [inaudible] like the people in Africa don't have anything. They don't say to them, I want a nice car, I want a nicer house, because they have to work really, really hard [...].'

Saskia: 'We tried to give these guys respect for the planet, because they are rather lucky I think just to have all the nice, the simple things that come into their life, like water, food, and nice schools. Um so we do like to give them a bit of the Wild West every now and then just to ... [laughter] ... just to ground them.'

At this point, Hudson interjected again, drawing Marnie back to a definition of these memories as a fun, rather than learning, experience:

Hudson: 'It was really fun when we were sitting down on the floor when (...) even if you was like (...) even if I hadn't eat with my hands before, like with like really got messy. And I, and I didn't know (...) I thought there was no wa (...) I thought there was water but I wasn't, you had to like wash your hands with a cloth. And it was much different to England.' 
Marnie:

'Ate everything of the chicken, didn't we; every bit of the chicken including its eggs inside it, its head, [I] was nibbling on the head.'

This narrative of giving the children "a bit of the Wild West" in order to ground them corresponds with Wetherell and Potter's (1992) cultureas-therapy discourse. Marnie and Saskia contrasted less fortunate others who "don't have anything" with the normative, "the nice, the simple" things of the modern Minority world, while for Hudson, cultural strangeness was fun to consume and hence not disadvantageous. A different framing was evident in Oliver and his brother's observations about their visit to an African village. They also drew a contrast with their own taken-for-granted modernity, but here, the other's lack of resources was naturalised and hence not constructed as a problem:

Oliver:

'I mean it would be really (...) annoying if we didn't have electricity from now. But if we'd never had electricity it wouldn't make much difference. $[\ldots]^{\prime}$

Max: 'If we started living with electricity but we didn't have it (...) it would just be (...) bad. But if we started without electricity (...) it would be fine because we wouldn't know (...) like (...) what it would be like to have it. And it would just be fine.'

Vicky: 'We've met children that haven't had electricity, haven't we?'

Oliver: 'Yeah. But ...'

Interviewer:

'When you were in Tanzania?'

Vicky:

'I think so yes. [...] They didn't know they didn't have it.'

Oliver:

'If you start with it and then you don't have it, you know what it feels like. But if you start without it (...) you just won't know and then you'll just (...) be happy.' 
For Hudson, Oliver and Max, their experiences apparently emphasised difference; they did not produce feelings of environmental responsibility, solicitude or mutual recognition. Their parents' aim of getting the children to recognise their privilege was only partially met, leaving a gap between the taken-for-grantedness of environmental resource use in the Minority world and the inability to link this psychosocially with people's lives in the Majority world. For both sets of children discussed above, such visits did not produce a common world perspective. There was no real discussion of what 'responsibility' meant or of what the children were meant to do as a consequence. Uzzell's (1999: 401) distinction between three planes of environmental education is relevant here: while the children may have been positioned by their parents as 'acquiring learning', it was less clear that they were 'developing concern' or 'solution finding'. Punch's (2015) admonition to use 'cross-world' analyses and Taylor's (2013) common world perspective do not appear to operate at the level of familial practices for these children from the Minority world who have some experience of the Majority world. However, the analysis does show, as Punch suggests, some of the ways in which lives lived in the Majority and Minority worlds are interlinked.

\section{Conclusions}

In contexts where socioeconomic resources protect against quotidian environmental hazards, environmental concerns can be made proximal within the family as a practice of upbringing and responsible privilege, but some parents are concerned to do this in ways that they hope will not threaten what they construct as childhood innocence. Humour and fun make environmental concern bearable, distanced into an apparently altruistic concern for a benign, unfortunate other, corresponding to a 'Northern-centric spatial imaginary' of the affluent ethical consumer practising care at a distance (Gregson and Ferdous, 2015: 253). The iconic image of the polar bear offers a way for the good, 'green' parent to make 'global' environmental concerns 'utterly everyday and grounded' (Massey, 2004: 8). But even as it does this, their difference 
and distance from the polar bear is underlined in the families' use of humour. In Rosie and Helena's family narratives, environmental concerns are largely personal, narrated as threats to the children's present and future lives. Humour functions protectively to help them manage the unbearable anxiety of environmental degradation for the family (Weintrobe, 2012). But when environmental concern is populated by more distant others, positioned as irresponsible, abstract or abject, the 'other' is used by parents and other adult carers as a foil to make children appreciate how lucky and comfortable their own lives. Children are brought into contact with other environments to produce positive affordances in their own. In these contexts, humour acts to moderate concern, paradoxically distancing rather than enabling a common world perspective. As with the discussion of air conditioning use, narratives of (environmentally) responsible privilege act as a form of family display (Finch, 2007) that helps to justify practices of comfort and 'necessary' consumption (Shove et al, 2008). What does this mean for the positioning of children as targets of environmental education, and as agents for environmental change? The analyses presented here show that children are neither apathetic nor ignorant about environmental concerns, but they also highlight the sticky problem of children's constrained agency within the micro and macro generational power structures of families and societies. 



\section{SIX}

\section{Negotiating environments in children's and families' everyday lives}

The answer ... put simply, is that everyday life is the wider picture. None of these larger scale events could occur without there being individual people doing little things in local places. (Scott, 2009: 1)

Just how one goes about moving from the dualism of Humanity and Nature to the dialectics of humanity-in-nature has been a vexing, and largely unresolved, problem for Green Thought and critical theory since the 1970s. (Moore, 2017: unpaginated)

Nudging, tweaking, or cajoling people into piecemeal behavioural changes like re-using plastic bags is not a proportionate response to climate change. Engaging the public through their personal carbon footprints is really only a means to an end - and that end is a political and economic system that has sustainability as its central organising principle. (Corner, 13 December 2013, The Guardian) 
In a period when, as Smith and Howe (2015) observe, 'the social drama of climate change has come into being', it is not uncommon for academics to point out that narratives of climate change are unequal to the task of arresting it. Smith and Howe (2015: 53) suggest that climate change is a 'somewhat disorganized drama, marked by incoherence, disengagement, and proliferation'. The way forward they argue is through a more coherent narrative of climate change to make it a 'universal social drama that would compel decisive public action and institutional reform'. From a different perspective, Moore (2017) suggests that the conceptual problem is treating nature and culture as binary opposites when they mutually constitute each other in the 'web of life' within specific historical and geographical contexts. Both these formulations are compelling. Yet, our engagement with research on family lives and environments in India and the UK gives fresh insights into why they do not meet the substantial societal challenges posed by climate change. The reason for this is highlighted by Räthzel et al (2014) in their study of transnational corporations from the viewpoint of workers; having struggled to fit their research findings into existing theoretical frames, they concluded that ' $\mathrm{f}$ ] $\mathrm{rom}$ the point of view of workers, all the dimensions that have segmented into different scholarly traditions and interests have a bearing on their lives simultaneously' (Räthzel et al, 2014: 277). Our book has shown why a holistic perspective is central to addressing climate change.

Working with a common world approach, we have built on a 'humanity-in-nature' conceptualisation as advocated by Moore (2017) in the epigraph above and set diverse experiences in conversation. Our aim has been to move beyond social drama to examine the complex ways in which environmental affordances, socioeconomic resources and opportunities shape understandings and practices. Through in-depth qualitative research with 24 families who live in differing contexts in India and the UK, we have shown that environmental practices are inextricably relational, and linked with dynamic family practices, childhood and parenthood. Holistic understandings of environmental practices, and of children and families, benefit from juxtaposing Minority and Majority world understandings and so challenging 
patronising (colonial) moral discourses of environmental concern that are rooted in Minority world understandings of the affluent ethical consumer practising care at a distance. This approach helps to build the new global perspective based on dialogue between childhoods in Majority and Minority worlds that Punch and Tisdall (2012) advocate, and so to understand 'other' lives, in context.

The research illuminates the dangers for policy makers and environmental organisations of imagining 'family' as a homogeneous entity. No one family in our study is in any way representative or typical of family lives in India or the UK. Rather, they are emblematic of a variety of experiences, living in diverse family formations, and socioeconomic and geographic contexts. As we have shown, family practices are negotiated in the context of environmental affordances, including risks, material opportunities, socioeconomic and temporal resources, and priorities of care. Family members may not share understandings of the importance or meanings of practices, and the generational power positioning of children means that even in families that foreground identities of environmental concern, children may be knowledgeable and agentic, but have limited scope to influence family practices. Families who are sceptical about, or seem to be unaware of, the anthropogenic causes of climate change, and those who are sceptical about the capacity of individual action to mitigate the effects of climate change, may both engage in what are generally considered environmentally protective practices such as recycling. One benefit of a focus on everyday family lives is its illumination of the differing reasons for similar practices. The reasons that families recycled included that it was: a 'way of life'; the product of the intersection of socioeconomic constraints and environmental affordances, facilitated by structural factors (such as, in the UK, local recycling systems and sometimes fines for not recycling); driven by values for the upbringing of children; or driven by aesthetic environmental concerns. Across both countries, use (or not) of private cars was for a similar mix of reasons. Notions of 'way of life', socioeconomic resources and interventions by municipal authorities all affected the environmental affordances of car driving and relations of care for family members. In India, air conditioning use 
was, of course, linked to the material resources available to families, but also with what Hall (2016: 1017) calls the 'moral geographies of family' where the 'caringscapes' constituted through the ethics of care and responsibility come together in the 'doing' of intergenerational family relations. Providing care and comfort for family members and the self is frequently bracketed off from environmental concerns (Jamieson, 2016).

In other contexts, families' precarious living conditions make abstract environmental messages seem irrelevant, even as they view and deal with environmental affordances, and with minimal carbon resources, in their daily lives. This may be partly, as Lertzman (2015) suggests, that it may not be possible to direct protest and anger to more powerful people (as for example when the local state cleared slum dwellings, leaving families more exposed to flooding in India). As a result, ambivalence, melancholia and denial are understandable responses (Norgaard, 2011; Adams, 2016).

\section{Every little helps? Beyond 'ABC' (Attitudes-Behaviour-Cognition)}

The attention to everyday lives implied by the epigraph from Scott (2009) above, could erroneously be interpreted as a call to climate change response through individual action - the idea that 'every little helps'. This is the moral case that dominates popular media and policy discourses in both India and the UK (and in many other countries, too). The neoliberal world has a strong preference 'for voluntary, private and market-based responses to environmental challenges', and individualising moral narratives of environmentalism can be seen as compatible with the requirements of capitalism and business-as-usual economics (Newell, 2012: 157). The 'affluence hypothesis', framed in relation to the economic model of the 'Kuznets Curve' - which postulates that environmental awareness is correlated with economic development - provides an example of this (Duroy, 2008). This hypothesis would imply that the carbon impact of economic growth should eventually be mitigated, presumably through the adoption of a Minority world narrative of environmental concern. 
The epigraph from the Guardian newspaper that opened this chapter reports on a two-day conference in 2013 at the Royal Society in London, which, it states, "made clear, "every little helps" is a dangerously misleading mantra when it comes to climate change'. The analysis presented in this book lends weight to that argument in several respects. First, detailed attention to the dynamic relationality of everyday lives shows why individualising 'ABC' approaches are unlikely to be effective. When we recognise the relationality of family practices, we see how potential environmental actions that demand sacrifices may not be taken up because they are understood to risk other aspects of child, parent or family life. For families whose resources permit, air conditioning is understood as necessary to protect the health of older grandparents, or to ensure children's ability to sleep in $45^{\circ} \mathrm{C}$ heat; technological devices such as computers are necessary for work, school and social relationships; and cars are seen as essential to access places of work and education, because they protect scarce family time, and shield children and parents from risks - such as pollution and traffic danger - that cars in turn create. To frame such decisions as self-interested or apathetic is to ignore the relational commitments that underpin everyday practices, as Morgan (2011: unpaginated) explains: 'In carrying out these everyday practicalities, social actors are reproducing the sets of relationships (structures, collectivities) within which these activities are carried out and from which they derive their meaning.'

Within Shove and colleagues' (2012) conceptualisation of practice as comprising meanings, materials and skills, we need to acknowledge that meanings are inherently relational and quotidian. Attention to 'family' reminds us that we are not individual practitioners, and so demands recognition of relationality, and the real and imagined 'others' who populate our everyday lives. The research shows how and why families who present environmentally engaged identities maintain high carbon practices that they see as necessary for family life and wellbeing. Taking the example of a family in India discussing air conditioning, is it surprising that the mother prioritises her temporally and geographically proximal concerns for her children's wellbeing and comfort over 
the more remote polar bear that has assumed mythic status? Her negotiation of the morality of this choice within an environmentally engaged family display is mitigated by jokingly distancing the polar bear - she reminds her children: "where do you see him?". Those she lives with, and loves, are prioritised over the more distant other(s) she and her children can only imagine.

\section{"It's like I was a witch": the unhelpfulness of moral binaries}

Families' accounts echoed dominant canonical narratives - in media and political discourse - of the heroes and villains of climate change. We saw how they navigate the 'social drama' of climate change in contexts where hegemonic narratives of environmental concern reflect on the moral character of those making claims and define performative actions as worthy or unworthy (Smith and Howe, 2015). Efforts to negotiate moral discourses of environmental concern were vivid across the two countries in our study, evident in the guilt-laden characterisations of self and other in parents' and children's narratives about practices that did not fit 'pro-environmental' norms, and in their scepticism that their individual actions could make a difference. Even when participants expressed personal feelings of guilt - for example, about using the 'wrong' bin - the practices they appeared to vilify persisted. At the same time, understandings of necessary consumption can be enabled through an identity position of moderate, responsible privilege that avoids the troubled subject position (Wetherell, 1998) of potentially being disparaged for being a humourless, 'hair shirt' environmentalist, even as it enables moral superiority in comparison to an other, constructed as unconcerned or ignorant.

A holistic perspective on environmental practices necessarily entails considering embodied and emotional as well as social issues (the psychosocial). Ahmed's (2008) concept of 'sticky affect' is relevant here. High carbon practices may be framed as morally problematic within an identity position of environmental responsibility, but they are also justifiable. Narrative characterisations of environmental concern may disparage environmentally ignorant or apathetic others, even while 
high carbon practices are judged to be essential for family life, comfort and convenience. This narrative practice helps people to negotiate an uncomfortable subject position, making themselves feel better by characterising 'uncivilised others' as the real cause of the problem. It shows how "ffeeling good" becomes attached to other kinds of social good', in ways that allow structural inequalities, including inequalities in resource use, and historical injustice to disappear (Ahmed, 2008: 124).

Narrative characterisations of responsible privilege and the irresponsible other fit with Guha's (2006) critique of a Minority world imaginary of environmental awareness as a 'full stomach' phenomenon. They highlight another problem with moralising conceptions of environmental practice and environmental concern: individualising approaches to climate change response that derive from affluent and Minority worlds are inherently depoliticising, relying on an 'overall model of elite consensus' (Swyngedouw, 2013: 6) that neglects structural and socioeconomic inequalities. Through a common world approach, we have juxtaposed the narratives of families for whom everyday life is deeply patterned by their quotidian environments with those for whom having the socioeconomic resources to control their immediate environments is mundane. For families that fit with Guha's (2006) conceptualisation of 'ecosystem people' and 'ecological refugees', environment is an inescapable character in stories of their everyday lives; environmental practices are not a matter of 'choice' but are rooted in the materiality of quotidian practices and differentiated by social class, caste, affluence, gender and location (Agarwal, 1998). For example, four of the families in the study (Chitra, Hemant, Dharani and Chandrasekhar's) lived within 20 kilometres of each other but - as is commonly the case for 'lower' caste groups such as Padmasali (Prakash and Singh, 2012) - Chandrasekhar's family lived in a less environmentally secure area at a lower altitude, and so were exposed to greater risk of flooding and less reliable water supplies than the other families. Socioeconomic positioning and the land itself - topography and climatic conditions - intersect to create risks for families. 
Even when (as in the UK) family lives benefit from infrastructural resources such as public transport and waste collection, not all families (and not all family members) are equally shielded from environmental hazards. Environmental affordances - both good and bad - depend on the ways in which socioeconomic resources intersect with the particularities of geographic location, and with gendered and generational responsibilities and practices of care. The juxtaposition of cases between India and the UK serves as a stark reminder that poverty and environmental risk are not equivalent in the two countries. At the same time we have shown commonalities in the ways in which relative poverty restricts control over environmental affordances, and so of the meanings of environmental concern in everyday family lives. Families' differential positioning in relation to the benefits and hazards of cars is a clear example of the localised inequities of environmental vulnerability, which link to wider socioeconomic processes shaping the demand and availability of vehicles and, for some, normative understandings of the necessities of everyday life (for example, Shove et al, 2012).

\section{Futurity, families and children}

Ahmed's (2008) concept of 'sticky affect' is also helpful in thinking through the affective complexity of children's positioning in debates about climate change response. The hopes and fears of adults' imagined futures for younger generations coincide with conceptualisations of children as vulnerable, innocent and in need of protection - but also as ignorant, irresponsible and in need of education. Children's own perspectives, and their agency within family and wider social and political structures, are situated in the context of this sticky affective mix. In our study, a few families displayed what Lertzman (2015) and Adams (2016) describe as 'unbearable anxiety' about climate change in the future. In that context, parents sometimes showed a desire to protect children. For families such as these, the research showed the ways in which parents and children manage the potential distress of bringing environmental concerns into everyday family life through strategies such as humour. Concern is simultaneously displayed, neutralised 
and disconnected from solution finding (Uzzell, 1999). This could be seen as parental overprotection, contributing to children's structural vulnerability and thinning their agency as environmental actors within the family (Klocker, 2007). We did not find that children were less knowledgeable or concerned than parents about environmental issues, although they were often positioned as such. But children's constrained agency within family hierarchies was certainly evident across diverse family contexts. Some parents were clear that they knew more about the environment than their children did. Others either did not find the school knowledge children brought home relevant, or felt themselves to be powerless to change their environments. In a similar way, Hall (2016) found that some parents resented teachers whose (non-shared) moral values intruded into their homes. In this context it is important to note that family members could disagree with each other on environmental practices. Parents sometimes disagreed about recycling and some children tried unsuccessfully to get their parents to take action against climate change. Those children with the socioeconomic means to have electronic gadgets frequently disagreed with their parents about how much to use them and considered them complementary to the 'natural' environment when their parents did not.

There were, however, cases where parents did take very seriously their children's environmental concerns or the knowledge they brought home. One case, where a father encouraged his son to send an email to the local authority, stands out as an example of developing political agency through dialogue. This is not environmental action as an ethical consumer; it is political action, driven by concern for the local environment and an awareness that the quality of this environment and the quality of one's own life within it are inextricably linked. His experience raises a critical question for policy and professional actors. When we educate children about climate change, and climate change response, what are we aiming to do? Are we hoping that 'every little helps', or do we seek a more fundamental systems change? Carlsson and Jensen (2006) distinguish between approaches to environmental education that are based on the individual or school as consumer, and approaches based on developing political agency. They highlight the 
need to work more explicitly with barriers and resistance to genuine dialogue between children and adults, which relies on better insight into power relations. They say: 'This means involving the students in a way that promotes their action competence - not only promoting predefined solutions to environmental problems' (Carlsson and Jensen, 2006: 255).

Adults (most notably parents and teachers) play a role in promoting what these authors term children's 'action competence'. Lansdown (2010: 13) observes that popular understandings of children's participation often eclipse the ways in which '[children's and young people's] opportunity to participate is usually dependent on the goodwill of adults involved in the child's life'. In contextualising children's participation, there is a need for greater attention to intergenerational dialogue and intergenerational learning (Mannion, 2007).

\section{Implications for policy and practice}

In documenting the dynamic, spatial and temporal complexity of a common world environment across diverse family lives, what does the research described here offer those who seek to develop environmental and educational policy initiatives to mitigate and raise awareness of climate change? Put simply, so what?

First, the study adds to a growing literature that builds a holistic understanding of why existing approaches to climate change response may be ineffective, and ethically problematic in exporting ideas from affluent Minority world contexts to less privileged lives in Majority and Minority worlds. Wilson and Chatterton (2011) argue that policy makers pick and mix from menus of conceptually contradictory approaches, tools and measures in attempts to see 'what works'. The research that informs this book shows why 'every little helps' narratives that rely on piecemeal individual behaviour change are unlikely to result in significant changes to carbon-intensive family practices. To paraphrase Scott (2009), in the epigraph that opened this chapter, the little things that people do in their local places may contribute 
to climate change, but they are experienced as necessary practices of care in everyday family lives.

Second, the research shows how abstract environmental messages may be unhelpful because they can serve to distance environmental threats, marginalising them and making them appear purely symbolic. Just as Ingold (2000: 211) writes that the image of 'spaceship earth' may in fact contribute to a sense of alienation from 'nature', when environmental concern is focused on geographically and temporally distant objects, it is possible for more affluent people to distance, and alienate, human others who are disproportionately affected by climatic shocks. In this way, environmentalism becomes an abstract moral, rather than everyday, issue in family lives. The study shows that families and their differently positioned members view environmental concerns as multi-layered and local as well as about 'big' environments.

Third, as argued in the epigraph from Corner's Guardian newspaper article (2013), some families and family members considered that environmental change was the responsibility of (transnational) corporations that were damaging their environments with the collusion of government in both India and the UK. This, together with the fact that some national and local state policies facilitated (while others hindered) environmental practices makes it important for policy makers not simply to individualise environmental messages. Shove (2012: 421) presents an example of how state policies can work positively in pro-environmental directions:

In 2005 the Japanese government took a step in this direction. The idea was simple: government buildings would not be heated or cooled between 20 and $28^{\circ} \mathrm{C}$, and male office workers would be encouraged to remove jackets and ties in the summer and wear more in the winter (called 'Warm Biz'). The effect was to change the meaning of normal clothing, along with the technologies (levels of air-conditioning) and competences (of dress and of facilities management) involved in the routine enactment and effective accomplishment of office life. ... This strategy appears to have transformed collective conventions rapidly and on a 


\section{ENVIRONMENT IN THE LIVES OF CHILDREN AND FAMILIES}

significant scale. The Cool Biz programme worked on a number of fronts at once. Established marketing techniques were used to transform the meaning of smart and appropriate wear. The then prime minister, Mr Junichiro Koizumi, and members of the Cabinet were shown wearing loose-fitting short-sleeved outfits in formal settings. Successful business leaders were involved, the clothing industry responded to the challenge and large department stores promoted especially designed garments under the Cool Biz name.

For some of the families in the study reported in this book, family practices and environmental concerns - such as (not) using public transport or recycling - were interlinked because of the intervention of the state. This relates to a fourth point: while children tend to suffer disproportionately deleterious effects from climate change (Agarwal, 1998; Jamieson, 2016), they are positioned as less powerful in generational structures. They, therefore, cannot generally make changes to household practices unless their parents want to make those changes.

In highlighting relationality and practices of care, the book evidences the need for approaches to environmental policy and education that take account of the intersectionality of socioeconomic resources, environmental affordances, and gendered and generational concerns. We see in particular how environmental concerns compete with other priorities for mothers' gendered work, especially (but not only) in time- and resource-poor families where caring concerns overwhelm a more abstract concern for 'the environment'.

Generational perspectives also show why environmental concerns might be distanced because the likely impact of climate change gives rise to unbearable anxiety in parents' imagined futures for their families (Weintrobe, 2012). Where resources and environmental affordances permit, parents do what they can to protect 'childhood innocence', often drawing on a Minority world imaginary of the 'good childhood' (Balagopalan, 2014). Without those affordances, environmental precarity poses a direct threat to families' present and 
future survival, and protecting 'childhood innocence' is scarcely an option as children are recruited into household survival practices. These generational intersections highlight the importance of recognising children's potential agency within family lives, as well as the ways in which agency may be 'thinned' or constrained. The Young Lives study highlights children's active responses to their family's constrained economic circumstances; as Boyden and Crivello (2012: 176) note, 'there is an expectation that children will share, rather than be shielded from, the burden of family difficulties'. Our research shows children's competency and engagement with environmental concerns, not least in supporting family practices in everyday life, in working for the family, and in protecting and defending their local environment, particularly when environmental change or precarity means that family wellbeing or survival cannot be taken for granted. The future consequences of climate change engender an ethical imperative to ensure political agency for children across socioeconomic groups in Majority and Minority world countries, as well as for their parents. This requires moving the policy agenda away from moralising notions that many people (and especially children) are apathetic or ignorant about environmental issues in their everyday lives. It also requires that children's viewpoints be sought and discussions facilitated between children, teachers, parents and local state officials.

A common world perspective on environmental affordances illuminates that policy makers and non-governmental organisations (NGOs) have to think about climate change policies in complex, multi-level ways. Families do not respond well to being responsibilised for ameliorating climate change while more intractable carbon producers are not made the targets of environmental strictures. Instead, effective policies have to be crafted from recognition that environmental practices are relational and about care. Thus, for example, policy initiatives getting families to use less air conditioning or reduce central heating would require creative policies that support familial maintenance of comfortable, but more pro-environmental temperatures, as in the Japanese case described above (Shove, 2012). Equally, some families are in such precarious situations that they cannot 
attend to messages asking them to change environmental practices that do not directly contribute to improving their lives. Ethically, such families require more consumption of the earth's resources and need global action to help them to do so in sustainable ways. Early findings from an ongoing UK study of families living with fuel poverty highlights the familial as well as the environmental benefits of installing solar panels (Fox, 2015). For families in relatively affluent and relatively constrained circumstances, rather than a policy focus on children as 'agents of change', a more helpful and ultimately more sustainable approach might be to focus on the ways that family members work together to enact changes in their everyday lives, amidst ongoing conflicts and negotiations.

Overall, the climate change narrative told by governments and NGOs needs to be modified to be inclusive of all families. Bulkely and colleagues (2014) argue for a conceptualisation of environmental justice that encompasses recognition of the 'other', because framing justice predominantly in terms of responsibilities focuses attention on the middle classes in ways that neglect structural inequalities, and the very limited contribution to greenhouse gas emissions from low-income households. In the face of an unbearably precarious environmental future, we need a holistic and relational approach to climate change policy, which does more than simply teach (parents or children) behavioural solutions in ways that continue to be unsuccessful because they maintain the current generational and economic status quo. 


\section{References}

AbiGhannam, N. and Atkinson, L. (2016) Good green mothers consuming their way through pregnancy: roles of environmental identities and information seeking in coping with the transition. Consumption Markets and Culture, 19(5), 451-474.

Adams, M. (2016) Knowing and not knowing about anthropogenic ecological crisis. In M. Adams, Ecological crisis, sustainability and the psychosocial subject. Basingstoke: Palgrave Macmillan.

Agarwal, B. (1998) Environmental management, equity and ecofeminism: debating India's experience. The Journal of Peasant Studies, 25, 55-95.

Agarwal, B. (2016) Gender challenges. Volumes 1, 2 and 3. Oxford: Oxford University Press.

Ahmed, S. (2008) Multiculturalism and the promise of happiness. New Formations: A Journal of Culture, Theory, Politics, 63, 121-137. Ajzen, I. (1985) From intentions to actions: a theory of planned behavior. In J. Kuhl and J. Beckman (eds) Action-control: From cognition to behavior. Heidelberg, Germany: Springer.

Alanen, L. (2009) Generational order. In J. Qvortrup, W.A. Corsaro and M.-S. Honig (eds) The Palgrave handbook of childhood studies. Basingstoke: Palgrave Macmillan.

Ananthapadmanabhan, G., Srinivas, K. and Vinuta, G. (2007) Hiding behind the poor: A report by Greenpeace on climate injustice. Bangalore, India: Greenpeace India. 


\section{ENVIRONMENT IN THE LIVES OF CHILDREN AND FAMILIES}

Anantharaman, M. (2014) Networked ecological citizenships, the new middle classes and the provisioning of sustainable waste management in Bangalore, India. Journal of Cleaner Production, 63, 173-183.

Apparao, T. (2011) Implications of occupational mobility on the handloom weavers of Andhra Pradesh, South Asian Anthropologist, 11(2), 145-156.

Backett-Milburn, K., Wills, W.J., Gregory, S. and Lawton, J. (2006) Making sense of eating, weight and risk in the early teenage years: views and concerns of parents in poorer socio-economic circumstances. Social Science and Medicine, 63(3), 624-635.

Balagopalan, S. (2014) Inhabiting 'childhood': Children, labour and schooling in postcolonial India. Basingstoke: Palgrave Macmillan.

Beitin, B.K. (2012) Interview and sampling: how many and whom. In J.F. Gubrium, J.A. Holstein, A.B. Marvasti and K.D. McKinney (eds) The SAGE handbook of interview research: The complexity of the craft (second edition). London: Sage Publications.

Belfield, C., Cribb, J., Hood, A. and Joyce, R. (2014) Living standards, poverty and inequality in the UK: 2014. London: Institute for Fiscal Studies.

Bell, S.E. (2013) Seeing narratives. In M. Andrews, C. Squire and M. Tamboukou (eds) Doing narrative research. London: Sage Publications.

Bertaux, D. and Thompson, P. (1993) Introduction. In D. Bertaux and P. Thompson (eds) Between generations: Family models, myths and memories. Oxford: Oxford University Press.

Bertho, A., Pande, D., Shrichand, P. and Singh, S. (2012) Impact of disasters on children: A case study of five disaster-prone districts in Uttar Pradesh and Bihar, India. Knowledge Community on Children in India, KCCI / 2012-03. New Delhi, India: UNICEF India.

Boddy, J. (2014a) Stories told in passing? Disclosure in narratives of everyday lives in Andhra Pradesh. In M. Davis and L. Manderson (eds) Disclosure in health and illness: Routledge studies in the sociology of health and illness. London: Routledge. 
Boddy, J. (2014b) Research across cultures, within countries: hidden ethics tensions in research with children and families?, Progress in Development Studies, 14(1), 91-103.

Boddy, J., Phoenix, A., Walker, C., Vennam, U., Austerberry, H. and Latha, M. (2016) Telling 'moral tales'? Family narratives of responsible privilege and environmental concern in India and the UK, Families, Relationships and Societies, 5(3), 357-374.

Boyden, J. and Crivello, G. (2012) Political economy, perception, and social change as mediators of childhood risk in Andhra Pradesh. In J. Boyden and M. Bourdillon (eds) Childhood poverty: Multidisciplinary approaches. Basingstoke: Palgrave Macmillan.

Brannen, J. (2005) Introduction: cross-national seminar on biographical methods. Workshop on comparative biographical research, Thomas Coram Research Unit, Institute of Education, University of London, 24-25 November. http://eprints.ncrm.ac.uk/10/1/ JuliaBrannen-Introduction.pdf

Brannen, J. and Nilsen, A. (2005) Individualisation, choice and structure: a discussion of current trends in sociological analysis. Sociological Review, 53(3), 412-428.

Bronfenbrenner, U. (1977) Toward an experimental ecology of human development. American Psychologist, July, 513-531.

Bruner, J. (1991) The narrative construction of reality. Critical Inquiry, 18, 1-21.

Bulkely, H., Edwards, G.A.S. and Fuller, S. (2014) Contesting climate justice in the city: examining politics and practice in urban climate change experiments. Global Environmental Change, 25, 31-40.

Butler, J. (2004) Precarious life: The powers of mourning and violence. London: Verso.

Capstick, S.B., Pidgeon, N.F. and Henwood, K. (2015) Stability and change in British public discourses about climate change between 1997 and 2010. Environmental Values, 24(6), 725-753.

Carlsson, M. and Jensen, B.B. (2006) Encouraging environmental citizenship: the roles and challenges for schools. In A. Dobson and D. Bell (eds) Environmental citizenship. Cambridge, MA: MIT Press. 


\section{ENVIRONMENT IN THE LIVES OF CHILDREN AND FAMILIES}

Chappells, H. and Shove, E. (2005) Debating the future of comfort: environmental sustainability, energy consumption and the indoor environment. Building Research and Information, 33(1), 32-40.

Clark, A. (2004) The mosaic approach and research with young children. In V. Lewis, M. Kellett, C. Robinson, S. Fraser and $\mathrm{S}$. Ding (eds) The reality of research with children and young people. London: Sage Publications.

Clark, C. and Uzzell, D.L. (2002) The affordances of the home, neighbourhood, school and town centre for adolescents. Journal of Environmental Psychology, 22, 95-108.

Common Worlds Research Collective (2014) 'Website home page', www.commonworlds.net/

Corner, A. (2013) 'Every little helps' is a dangerous mantra for climate change. The Guardian, 13 December. https://www.theguardian. $\mathrm{com} /$ sustainable-business/plastic-bags-climate-change-everylittle-helps

Crivello, G., Morrow, V. and Streuli, N. (2013) Young Lives qualitative fieldwork guide: Round three (2010/2011): Technical Note 29. Oxford: Young Lives.

Darzi, A., Lord (2017) Today, BBC Radio 4, 30 January.

Defra (Department for Environment, Food \& Rural Affairs) (2008) A framework for pro-environmental behaviours. London: HM Government.

Defra (2014) Updated projections for nitrogen dioxide compliance. London: HM Government.

Deshingkar, P. (2012) Environmental risk, resilience and migration: implications for natural resource management and agriculture. Environmental Research Letters, 7(1). http://iopscience.iop.org/ article/10.1088/1748-9326/7/1/015603/meta

Duroy, Q.M.H. (2008) Testing the affluence hypothesis: a cross-cultural analysis of the determinants of environmental action. The Social Science Journal, 45, 419-439.

Duvall, J. and Zint, M. (2007) A review of research on the effectiveness of environmental education in promoting intergenerational learning. Journal of Environmental Education, 38(4), 14-24. 
DWP (Department for Work and Pensions) (2014) Households Below Average Income: An analysis of the income distribution 1994/5 2012/13 (United Kingdom). London: HM Government.

Edwards, R., Ribbens McCarthy, J. and Gillies, V. (2012) The politics of concepts: family and its (putative) replacements. British Journal of Sociology, 63(4), 730-746.

End Child Poverty (2014) London has highest child poverty rate. Media release, 15 October. www.endchildpoverty.org.uk/images/ ecp/Release\%20London\%20child\%20poverty\%20map.pdf

Espinosa, P. and Mezouar, S. (2016) Paris enters into force - celebration and reality check. Opinion, 4 November. http://newsroom. unfccc.int/paris-agreement/paris-agreement-enters-into-forcecelebration-and-reality-check/

Eurostat (2015) Being young in Europe today. Luxembourg: Publications Office of the European Union.

Evans, B. and Honeyford, E. (2012) 'Brighter futures, greener lives': children and young people in UK sustainable development policy. In P. Kraftl, J. Horton and F. Tucker (eds) Critical geographies of childhood and youth. Bristol: Policy Press.

Express News Service (2017) Smoke from burning garbage chokes residents. The New Indian Express, 13 February. www. newindianexpress.com/states/andhra-pradesh/2017/feb/13/ smoke-from-burning-garbage-chokes-residents-1570097.html

Finch, J. (2007) Displaying families. Sociology, 41(1), 65-81.

Fishbein, M. and Ajzen, I. (1975) Belief, attitude, intention and behavior: An introduction to theory and research. Reading, MA: Addison-Wesley. Fox, N. (2015) Take 7 [film]. www.youtube.com/ watch? $=$ Ew1aYAzRIz0

Freitas, T.C.B., Gabbard, C., Caçola, P., Montebelo, M.I.L. and Santos, D.C.C. (2013) Family socioeconomic status and the provision of motor affordances in the home. Brazilian Journal of Physical Therapy, 17(4), 319-327.

Galab, S., Reddy, P.P., Singh, R. and Vennam, U. (2011) The impact of growth on childhood poverty in Andhra Pradesh: Young Lives round 3 survey report. Oxford: Young Lives. 


\section{ENVIRONMENT IN THE LIVES OF CHILDREN AND FAMILIES}

Ghanbari-Azarneir, S., Sanbari, S., Hosseini, S.B. and Seyed-Abbas, Y. (2015) Identification of child-friendly environments in poor neighborhoods, Procedia - Social and Behavioral Sciences, 201, 19-29.

Ghertner, D.A. (2012) Nuisance talk and the propriety of property: middle class discourses of a slum-free Delhi. Antipode, 44, 11611187.

Gibson, J.J. (1979/2015) The ecological approach to visual perception (classic edition). Hove: Psychology Press.

Giddens, A. (2009) The politics of climate change. Cambridge: Polity.

Gillis, J.R. (1997) A world of their own making: Myth, ritual, and the quest for family values. Cambridge, MA: Harvard University Press.

Government of India (2011a) Urban agglomerations having population one lakh or above in Census of India 2011 (provisional population totals). New Delhi, India: Government of India.

Government of India (2011b) Report of the Committee on Slum Statistics / Census. New Delhi, India: Government of India.

Gregson, N. and Ferdous, R. (2015) Making space for ethical consumption in the South. Geoforum, 67, 244-255.

Guha, R. (2006) How much should a person consume: Environmentalism in India and the United States. Berkeley, CA: University of California Press.

Gupta, Y.K. and Peshin, S.S. (2014) Snake bite in India: current scenario of an old problem. Journal of Clinical Toxicology, 4(1), 182.

Guttikunda, S. K. and Kopakka, R. V. (2014) Source emissions and health impacts of urban air pollution in Hyderabad, India. Air Quality, Atmosphere and Health, 7, 195-207.

Haines, A., Kovats, R.S., Campbell-Lendrum, D. and Corvalan, C. (2006) Climate change and human health: impacts, vulnerability and public health. Public Health, 120(7), 585-596.

Hall, S.M. (2016) Moral geographies of family: articulating, forming and transmitting moralities in everyday life. Social and Cultural Geography, 17(8), 1017-1039.

Hantrais, L. (2009) International comparative research: Theory, methods, and practice. Basingstoke: Palgrave Macmillan. 


\section{REFERENCES}

Harvey, D. (1989) Time-space compression in the postmodern condition. In M. Waters (ed) Modernity: After modernity. Oxford: Blackwell.

Heise, U. (2008) Sense of place and sense of planet: The environmental imagination of the global. Oxford: Oxford University Press.

Henwood, K., Groves, C. and Shirani, F. (2016) Relationality, entangled practices, and psychosocial exploration of intergenerational dynamics in sustainable energy studies. Families, Relationships and Societies, 5(3), 393-410.

Hitchings, R. (2011) People can talk about their practices. Area, 44(1), 61-67.

Holloway, S.L. and Valentine, G. (2000) Children's geographies and the new social studies of childhood. In S.L. Holloway and G. Valentine (eds) Children's geographies: Playing, living, learning. London: Routledge.

Horton, J., Hadfield-Hill, S., Christensen, P. and Kraftl, P. (2013) Children, young people and sustainability: introduction to special issue. Children's Geographies, 18(3), 249-254.

Hulme, M. (2014) Climate change and virtue: an apologetic. Humanities, 3, 299-312.

Independent Schools Council (2016) ISC census and annual report 2016. London: Independent Schools Council. https://www.isc.co.uk/ media/3179/isc_census_2016_final.pdf

Ingold, T. (2000) The perception of the environment: Essays in livelihood, dwelling and skill. Abingdon: Routledge.

IPCC (Intergovernmental Panel on Climate Change) (2014) Contribution of Working Group II to the fifth assessment report of the Intergovernmental Panel on Climate Change: Impacts, adaptation and vulnerability. Geneva: IPCC. www.ipcc.ch/report/ar5/wg2/

Jamieson, L. (2016) Families, relationships and 'environment': (un)sustainability, climate change and biodiversity loss. Families Relationships and Societies, 5(3), 335-355.

Jamieson, L. and Milne, S. (2012) Children and young people's relationships, relational processes and social change: reading across worlds. Children's Geographies, 10, 265-278. 


\section{ENVIRONMENT IN THE LIVES OF CHILDREN AND FAMILIES}

Joffé, H. (1999) Risk and the other. Cambridge: Cambridge University Press.

Joshi, D., Fawcett, B. and Mannan, F. (2011) Health, hygiene and appropriate sanitation: experiences and perceptions of the urban poor. Environment and Urbanization, 23(1), 91-111.

Klocker, N. (2007) An example of 'thin' agency: child domestic workers in Tanzania. In R. Panelli, S. Punch and E. Robson (eds) Global perspectives on rural childhood and youth. Abingdon: Routledge.

Kofoed, J. and Staunaes, D. (2015) Hesitancy as ethics. Reconceptualising Educational Research Methodology, 6(1), 24-39.

Koo, H. (2016) The global middle class: how is it made, what does it represent? Globalizations, 13(4), 440-453.

Kyttä, M. (2003) Children in outdoor contexts: Affordances and independent mobility in the assessment of environmental child friendliness. Helsinki, Finland: Helsinki University of Technology.

Lansdown, G. (2010) The realisation of children's participation rights: critical reflections. In B. Percy-Smith and N. Thomas (eds) $A$ handbook of children and young people's participation: Perspectives from theory and practice. Abingdon: Routledge.

Lareau, A. (2011) Unequal childhoods: Class, race, and family life: Second edition with an update a decade later. Berkeley, CA: University of California Press.

Latour, B. (2004) Politics of nature: How to bring science into democracy. Cambridge, MA: Harvard University Press.

Lertzman, R. (2015) Environmental melancholia: Psychoanalytic dimensions of engagement. Abingdon: Routledge.

Lewinson, T. (2011) Capturing environmental affordances: lowincome families identify positive characteristics of a hotel housing solution. Journal of Applied and Community Psychology, 21(1), 55-70.

Livingstone, S. and Bulger, M. (2014) A global research agenda for children's rights in the digital age. Journal of Children and Media, 8(4), 317-335.

Lorenzoni, I. and Hulme, M. (2009) Believing is seeing: laypeople's views of future socioeconomic and climate change in England and in Italy. Public Understanding of Science, 18, 383-400. 


\section{REFERENCES}

Lorenzoni, I., Nicholson-Cole, S. and Whitmarsh, L. (2007) Barriers perceived to engaging with climate change among the UK public and their policy implications. Global Environmental Change, 17(3-4), 445-459.

Luttrell, W. (2010) 'A camera is a big responsibility': a lens for analysing children's visual voices. Visual Studies, 25(3), 224-237.

MacGregor, S. (2006) No sustainability without justice: a feminist critique of environmental citizenship. In A. Dobson and D. Bell (eds) Environmental citizenship. Cambridge, MA: MIT Press.

Mannion, G. (2007) Going spatial, going relational: why 'listening to children' and children's participation needs reframing. Discourse: Studies in the Cultural Politics of Education, 28(3), 405-420.

Massey, D. (2004) Geographies of responsibility. Geografiska Annaler: Series B, Human Geography, 86(1), 5-18.

Mawdsley, E. (2004) India's middle classes and the environment. Development and Change, 35(1), 79-103.

Middlemiss, L. (2014) Individualised or participatory? Exploring late-modern identity and sustainable development. Environmental Politics, 23(6), 929-946.

Miller, D. (2012) Consumption and its consequences. Cambridge: Polity Press.

Modi, N. (2015) The rich world must take greater responsibility for climate change, Financial Times, 29 October.

Moore, J. W. (2017) Metabolic rift or metabolic shift? Dialectics, nature, and the world-historical method. Theory and Society, online first.

Morgan, D.H.G. (2011) Locating 'family practices'. Sociological Research Online, 16(4), 14. www.socresonline.org.uk/16/4/14.html

Morgan, D.H.G. (2013) Rethinking family practices. Basingstoke: Palgrave Macmillan.

Morrow, V. (2013) Practical ethics in social research with children and families in young lives. Methodological Innovations Online, 8(2), 21-35. 


\section{ENVIRONMENT IN THE LIVES OF CHILDREN AND FAMILIES}

Morrow, V., Boddy, J. and Lamb, R. (2014) The ethics of secondary data analysis: Learning from the experience of sharing qualitative data from young people and their families in an international study of childhood poverty. Southampton: ESRC National Centre for Research Methods. http://eprints.ncrm.ac.uk/3301/

Morrow, V. and Vennam, U. (2012) Children's responses to risk in agricultural work in Andhra Pradesh, India. Development in Practice, 22(4), 549-561.

Newell, P. (2012) Globalisation and the environment: Capitalism, ecology and power. Cambridge: Polity Press.

Norgaard, K.M. (2011) Living in denial: Climate change, emotions, and everyday life. Cambridge, MA: MIT Press.

Novelli, M. (2016) Capital, inequality and education in conflictaffected contexts. British Journal of Sociology of Education, 37(6), 848-860.

Ochs, E. and Capps, L. (2001) Living narrative: Creating lives in everyday storytelling. Cambridge, MA: Harvard University Press.

Odell, M. (2009) "So, how many trees have you planted, Daddy?". The Observer, 31 January. www.theguardian.com/environment/2009/ feb/01/ethicalliving-family

O'Hare, P. and McClymont, K. (2008) We're not NIMBYS! Contrasting local protest groups with idealised conceptions of sustainable communities. Local Environment, 13(4), 1-15.

ONS (Office for National Statistics) (2012) 2011 Census - population and household estimates for England and Wales, March 2011. London: ONS.

ONS (2013) 2011 Census analysis - comparing rural and urban areas of England and Wales. London: ONS.Oswell, D. (2013) The agency of children: From family to global human rights. Cambridge: Cambridge University Press.

Pankhurst, A., Crivello, G. and Tiumelissan, A. (2016) Children's work in family and community contexts: Examples from Young Lives Ethiopia. Working Paper 147. Oxford: Young Lives. 
Pence, A.R. and Marfo, K. (2008) Early childhood development in Africa: interrogating constraints of prevailing knowledge bases. International Journal of Psychology, 43(2), 78-87.

Phoenix, A. (2013) Analysing narrative contexts. In M. Andrews, C. Squire and M. Tamboukou (eds) Doing narrative research. London: Sage Publications.

Pink, S. (2015 [2009]) Doing sensory ethnography. London: Sage Publications.

Prakash, A. and Singh, S. (2012) Gendered and caste spaces in household water use: A case of Aliabad village in peri-urban Hyderabad, India. Peri Urban Water Security discussion paper series 5. Andhra Pradesh, India: SaciWATERs.

Preston, I., White, V., Thumin, J., Bridgeman, T. and Brand, C. (2013) Distribution of carbon emissions in the UK: Implications for UK energy policy. York: Joseph Rowntree Foundation.

Punch, S. (2015) Possibilities for learning between childhoods and youth in the Minority and Majority worlds: youth transitions as an example of cross-world dialogue. In J. Wyn and H. Cahill (eds) Handbook of children and youth studies. Singapore: Springer Singapore.

Punch, S. and Tisdall, E.K.M. (2012) Exploring children and young people's relationships across Majority and Minority worlds. Children's Geographies, 10, 241-248.

Randall, C. (2011) Environment. Social Trends 41. London: Office for National Statistics.

Rao, N. (2007) Cities in transition: Growth, change and governance in six metropolitan areas. Abingdon: Routledge.

Räthzel, N., Mulinari, D. and Tollefsen, A. (2014) Transnational corporations from the standpoint of workers. Singapore: Springer Singapore.

Rautio, P. and Jokinen, P. (2015) Children and snow piles: children's relations to the more-than-human world beyond developmental views. In T. Skelton, J. Horton and B. Evans (eds) Geographies of children and young people: Play, recreation, health and well being. Singapore: Springer Singapore. 


\section{ENVIRONMENT IN THE LIVES OF CHILDREN AND FAMILIES}

Ravindranath, M.J. (2007) Environmental education in teacher education in India: experiences and challenges in the United Nation's Decade of Education for Sustainable Development. Journal of Education for Teaching, 33(2), 191-206.

Ridge, T. (2009) Living with poverty: A review of the literature on children's and families' experiences of poverty. London: HM Government.

Ridge, T. (2013) 'We are all in this together'? The hidden costs of poverty, recession and austerity policies on Britain's poorest children. Children \& Society, 27, 406-417.

Riessman, C.K. (2003) Analysis of personal narratives. In J.A. Holstein and J.F Gubrium (eds) Inside interviewing: New lenses, new concerns. London: Sage Publications.

Riessman, C.K. (2008) Narrative methods for the human sciences. London: Sage Publications.

Robson, E., Bell, S. and Klocker, N. (2007) Conceptualising agency in the lives and actions of rural young people. In R. Panelli, S. Punch and E. Robson (eds) Global perspectives on rural childhood and youth. Abingdon: Routledge.

Roy, K. (2014) How clean is my country? Reflections on the Swacchata pledge. Economic and Political Weekly, XLIX, 11 October.

Satchwell, C. (2013) Carbon literacy practices: textual footprints between school and home in children's construction of knowledge about climate change. Local Environment, 18(3), 289-304.

Schatzki, T. (2010) Materiality and social life. Nature and Culture, 5(2), 123-149.

Schultz, P.W. and Zelezny, L. (2003) Reframing environmental messages to be congruent with American value. Human Ecology Review, 10(2), 126-136.

Scott, S. (2009) Making sense of everyday life. Cambridge: Polity Press.

Scruggs, L. and Benegal, S. (2012) Declining public concern about climate change: can we blame the great recession? Global Environmental Change, 22(2), 505-515. 


\section{REFERENCES}

Shirani, F., Parkhill, K., Butler, C., Groves, C., Pidgeon, N. and Henwood, K. (2015) Asking about the future: methodological insights from Energy Biographies. International Journal of Social Research Methodology, 19(4), 429-444.

Shiva, V. (1993) The greening of the global reach. In W. Sachs (ed) Global ecology: A new arena of political conflict. London: Zed Books.

Shiva, V. (2006) Earth democracy: Justice, sustainability and peace. London: Zed Books.

Shove, E. (2010a) Social theory and climate change. Theory, Culture and Society, 27(2-3), 277-288.

Shove, E. (2010b) Beyond the ABC: climate change policy and theories of social change. Environment and Planning A, 42(6), 1273-1285.

Shove, E. (2012) Putting practice into policy: reconfiguring questions of consumption and climate change. Contemporary Social Science, 9(4), 415-429.

Shove, E., Chappells, H., Lutzenhiser, L. and Hackett, B. (2008) Comfort in a lower carbon society, Building Research and Information, 36, 307-311.

Shove, E., Pantzar, M. and Watson, M. (2012) The dynamics of social practice: Everyday life and how it changes. London: Sage Publications.

Shukla, N, Wilson, E. and Boddy, J. (2014) Combining thematic and narrative analysis of qualitative interviews to understand children's spatialities in Andhra Pradesh, India. Southampton: ESRC National Centre for Research Methods. http://eprints.ncrm.ac.uk/3269/

Smith, P. and Howe, N. (2015) Climate change as social drama: Global warming in the public sphere. Cambridge: Cambridge University Press. Smithers, R. (2016) British households fail to recycle a 'staggering' $16 \mathrm{~m}$ plastic bottles a day. The Guardian, 15 October. www. theguardian.com/environment/2016/oct/15/british-householdsfail-to-recycle-a-staggering-16m-plastic-bottles-a-day

Squire, C. (2013) From experience-centred to socioculturallyoriented approaches to narrative. In M. Andrews, C. Squire and M. Tamboukou (eds) Doing narrative research. London: Sage Publications. 


\section{ENVIRONMENT IN THE LIVES OF CHILDREN AND FAMILIES}

Stoll-Kleemann, S., O’Riordan, T. and Jaeger, C.C. (2001) The psychology of denial concerning climate mitigation measures: evidence from Swiss focus groups. Global Environmental Change, 11(2), 107-117.

Stromberg, J. (2013) What is the Anthropocene and are we in it? Smithsonian Magazine, January.

Swyngedouw, E. (2013) The non-political politics of climate change. ACME: An International E-Journal for Critical Geographies, 12, 1-8.

Taylor, A. (2013) Reconfiguring the natures of childhood. London: Routledge.

Taylor, A. and Giugni, M. (2012) Common worlds: reconceptualising inclusion in early childhood communities. Contemporary Issues in Early Childhood Education, 13(2), 108-120.

Taylor, A. and Pacini-Ketchabaw, V. (2015) Learning with children, ants, and worms in the Anthropocene: towards a common world pedagogy of multispecies vulnerability. Pedagogy, Culture and Society, 23 (4), 507-529.

The Hindu (2017) Air pollution kills 10 lakh Indians every year: study. The Hindu, 19 February. www.thehindu.com/sci-tech/energy-andenvironment/two-indians-die-every-minute-due-to-air-pollutionstudy/article17328922.ece

The Times of India (2016) 14 ways to protect your children from air pollution. The Times of India, 2 December. http://timesofindia. indiatimes.com/life-style/health-fitness/health-news/14-ways-toprotect-your-children-from-air-pollution/articleshow/55745540. $\mathrm{cms}$

Thomson, R. (2009) Unfolding lives: Youth, gender and change. Bristol: Policy Press.

Tyrrell, N. and Harmer, N. (2015) A good move? Young people's comparisons of rural and urban living in Britain. Childhood, 22(4), 551-565.

UNDESA (United Nations Department of Economic and Social Affairs) (no date). Open working group proposal for sustainable development goals. Accessed 7/717: https://sustainabledevelopment. un.org/focussdgs.html 


\section{REFERENCES}

UNDP (United Nations Development Programme) (2014) Human development report 2014: Sustaining human progress, reducing vulnerabilities and building resistance. New York, NY: UNDP.

UNESCO (no date) Education for sustainable development: Three terms and one goal. Accessed 7/717: http://www.unesco.org/new/en/ education/themes/leading-the-international-agenda/educationfor-sustainable-development/three-terms-one-goal/

UNESCO (1997) Educating for a sustainable future: A transdisciplinary vision for concerted action. New York: United Nations Educational Scientific and Cultural Organisation.

UNICEF UK (2013) Climate change: Children's challenge. London: UNICEF UK.

United Nations (2012) The future we want. Resolution adopted by the General Assembly on 27 July 2012 [without reference to a main committee (A/66/L.56)] 66/288. Rio de Janeiro: United Nations Conference on Sustainable Development, 20-22 June.

United Nations (2015) Transforming our world: The 2030 agenda for sustainable development. New York City, New York, NY: United Nations.

Urry, J. (1995) Consuming places. London: Routledge.

Urry, J. (2007) Mobilities. Cambridge: Polity Press.

Urry, J. (2011) Climate change and society. Cambridge: Polity Press.

Uzzell, D. (1999) Education for environmental action in the community: new roles and relationships. Cambridge Journal of Education, 29, 397-413.

Uzzell, D. (2000) The psycho-spatial dimension of global environmental problems. Journal of Environmental Psychology, 20(4), 307-318.

Uzzell, D. (2016) Families in an environmental context. Families, Relationships and Societies, 5, 3, 481-85.

Vennam, U., Crivello, G. and Kongara, H. (2010) Children's perspectives on risk and vulnerability in contexts of poverty and change: Findings from Andhra Pradesh, India. Oxford: Young Lives.

Walker, C. (2016) Environment and children's everyday lives in India and England: experiences, understandings and practices. Unpublished $\mathrm{PhD}$ thesis, UCL Institute of Education. 


\section{ENVIRONMENT IN THE LIVES OF CHILDREN AND FAMILIES}

Walker, C. (2017) Tomorrow's leaders and today's agents of change? Children, sustainability education and environmental governance. Children E Society, 31(1), 72-83.

Warde, A. (2005) Consumption and theories of practice. Journal of Consumer Culture, 5(2), 131-153.

Weintrobe, S. (2012) The difficult problem of anxiety in thinking about climate change. In S. Weintrobe (ed) Engaging with climate change: Psychoanalytic and interdisciplinary perspectives. Hove: Routledge.

Wetherell, M. (1998) Positioning and interpretative repertoires: conversation analysis and post-structuralism in dialogue. Discourse and Society, 9, 387-412.

Wetherell, M. and Potter, J. (1992) Mapping the language of racism: Discourse and the legitimation of exploitation. New York, NY: Columbia University Press.

Wilkinson, R. and Pickett, K. (2009) The spirit level: Why equality is better for everyone. London: Penguin.

Wilson, C. and Chatterton, T. (2011) Multiple models to inform climate change policy: a pragmatic response to the 'beyond the ABC' debate. Environment and Planning A, 43(12), 2781-2787.

Wilson, S.J. and Snell, C. (2010) 'Bad for the penguins ... because they need ice and that to live on': an exploratory study into the environmental views, concerns and knowledge of socially disadvantaged young people. Journal of Youth Studies, 13(2), 151-168. 


\section{Index}

Page numbers in italics refer to photographs.

\section{A}

ABC model (Attitudes,

Behaviour, Cognition) 6, 115 'affluence hypothesis' 138

Africa, stories of holidays in 129-32

agriculture crop failures 33, 44-5, 66, 94 diversifying from $66-7$ socioeconomic security cushioning against environmental shocks in 86-9, 93-5

Ahmed, S. 140, 141, 142 air conditioning 50, 111, 121-2, 126-7, 132-3, 137-8

Ajzen, I. 5, 6

Anantharaman, M. 23, 92

\section{C}

Capstick, S. B. 7, 9 car usage 137, 142 and carpools in India 123 doing without, in UK rural areas $73,74,91-2$ justifying UK rural 51-2 prohibitive costs 91-2

traffic and pollution narratives 49-52, 80

carbon emissions 24

care, relations of 137-8, 146, 147-8

and environmental affordances linked to hard work in India 53-67 attitudes to climate change $56,60,61$

ecological refugees living in a small apartment 59-61 extreme weather 56-7, 57, $58,64-6$

gendered practices in home 55,59

lack of sanitation 58-9

living in a temporary shelter 54-9

loans and interest repayments $63-4,65$ water scarcity $62-3,64$ weaving caste family $61-6$ superseding concerns with climate change 82-6 caste, intersection with socioeconomic resources and geographical positioning 62 , 67, 89 
children

concerns over local and global environmental issues 111-12

constrained agency over environmental issues 143-4, 146

constraints on situated agency 109-17

outdoor play 109, 110, 112-13

technical resources in daily lives 109-11, 110, 112 waste disposal concerns $112-14,114$

in discourses of environmental issues 9-12

disproportionate impact of climate change on 9-10, 66, 101

framing in policy reports 10-12, 102

as parents' objects of environmental concern 104-8 parents taking seriously environmental concerns of 114, 143

political agency 113-14, 143, 147

positioned as agents for environmental change 10-11, 12, 101, 102 problems with 96-7, 102-3, 119, 146 protecting innocence of 125-32, 142-3, 146-7 recruited into household survival practices 61,147 tips to protect from air pollution $69-70$

Clean India initiative (Swachh Bharat) 25, 58, 92 climate change agricultural workers forced to diversify as a result of $66-7$ beliefs in irrelevance of responses to $72-82$

affluent family living in rural England 76-9

low income family living in rural England 72-6, 74 middle income family in India 79-82

rural Indian families 44 changes in understanding of practices 7-9 concerns overtaken by more pressing issues of work for survival 56, 60, 61 and crop failures in India 33, 44-5, 66, 94

disproportionate impact according to socioeconomic position 23-4, 86-9 on children 9-10, 66, 101 disrupting notion of individual responsibility for $2-3$ 'every little helps' 138-40, 144-5

families' understandings and constructions of 98-9 global financial crisis and weakened belief in 8 impact on child health in south Asia 101 ineffective narratives of 136 , 144-5

need for holistic approach to 136-7, 144-8

and the 'other' 71, 95-6 policy focus on individuals 4-7, 24-5, 115, 135, 138-40 relations of care superseding concerns with 82-6 
reluctance to make sacrifices to deal with 2

'social drama' of 136, 140 a worried parent's imagined future 106-8 common world approach 13-14, 15, 40, 72, 112, 136, 141 building on 'humanity-innature' approach 136 implications for policy and practice $144-8$ to study of family lives $21-2$ consumption environment as a place of 106 socioeconomic disparities in levels of 24, 92, 98 contrasting context approach $22-5$

culture-as-therapy discourse 131

\section{D}

data collection analytic approach $37-8$ interviews with families 35-6 methods 34-6 piloting and methodological development 30-2 sample 32-4, 34 school visits 36 debt 63-4, 65 drought and floods in India 44-5

\section{E}

ecological niches 53

ecological refugees 59-61, 66-7, 141

education, environmental $10-11,12,132,143-4$ environment, definitions of $43-4,52,82-3$ environmental affordances

15-17

commonalities across

socioeconomic groups 76 , 77-8

constraints on children's situated agency 109-17

family beliefs in irrelevance of responses to climate change 72-82 importance of state to 89-93 relations of care superseding concerns with climate change $82-6$

work and relations of care in Indian families 53-67 attitudes to climate change $56,60,61$ ecological refugees living in a small apartment 59-61 extreme weather 56-7, 57, 58, 64-6 gendered practices in home 55,59 lack of sanitation 58-9 living in a temporary shelter 54-9

loans and interest repayments 63-4, 65 water scarcity $62-3,64$ weaving caste family 61-6 environmental concerns children as parents' object of 104-8

of committed environmentalists 93-7 families in UK 95-7 landowning family in India 93-5, 139-40 framed as characteristic of India's developing modernity 122-4 
generational positioning and

117-32

finding protective strategies within families 125-32, 142-3, 146-7

limited intergenerational exchanges in families 122 , 144

parents' framing of, as a value for upbringing and family life 118-25 telling of 'moral tales' 117 humour as a protective strategy $108,126,128,132-3$

moral discourses of $4-5,140-2$ narratives of responsible privilege 118, 119-20, 121, 124, 129, 132, 141

over a proposed industrial development and 104-6, 126 'unbearable anxiety' of 108 , $125,142,146$

environmental education 10-11, $12,132,143-4$

environmental issues in everyday lives 43-53

car usage 49-52

drought and floods in India 44-5

snakes $46-7$

traffic dangers and play restrictions in India 47-8, 50,80

traffic levels and pollution in UK 48-50

environmental justice 14, 148

environmental messages

children represented as future of 10-11, 11, 13

and families in precarious

living arrangements 18, 138, 147-8 ineffectiveness of abstract 138, 145

need to reframe Minority world 8-9

requirements for effective 147 targeted at individuals 5-6

ethics 38-40

'every little helps' discourse 138-40, 144-5

extreme weather disproportionate economic impact on poor 66 economic impact on a weaving family 64-6 living in a temporary shelter in $56-7,57,58$

see also flooding

F

families $12-13,137-8$ beliefs in irrelevance of human responses to climate change 72-82 children as agents of change in 10-11, 12, 96-7, 101, 102, 119, 142, 143, 146 common world approach to study of lives of 21-2 environmental affordances interlinked with state interventions 89-93 environmental issues in everyday lives 43-53 generational positioning and environmental concerns 117-32

and implications for policy and practice $144-8$ interviews with 35-6 justifying high carbon practices 139-41

protected from engaging in environmental practices $86-9$ 
relationality and materiality of everyday lives 26-7

relations of care and environmental affordances 53-67

relations of care superseding concerns with climate change 82-6

situation of environmental concerns in narratives of affluent 93-7, 139-40

Family Lives and Environment study 28

flooding

an affluent family experiences minimal effects of 86-9

devastating economic impact on a weaving family 64-6 and droughts in India 44-5 living in a temporary shelter and dealing with 56, 57, 58 socioeconomic resources and differentiated impact of 89

UK families' views on 45-6 fuel

coal fires in rural England 74-5

poverty, UK study of families living in 148

futurity 9, 102, 142

\section{G}

generational positioning 146-7

limited intergenerational exchanges on environmental concerns 122, 144 parents' framing of environmental concerns as a value for family life 118-25 protective strategies 125-32, 142-3, 146-7

telling of 'moral tales' 117

Gibson, J. J. 15, 16
Giddens, A. 1

Giugni, M. 21, 40

Guha, R. 4, 13, 23, 59, 67, 86, 92, 105, 141

\section{$\mathrm{H}$}

high carbon practices 50, 109, 140-1

families justifying 51-2, 139-41

humanity in nature concept 135,136

humour as a protective strategy 108, 126, 128, 132-3

\section{I}

identities as committed environmentalists 93-7 aspects considered unattractive 96, 97

in India $93-5,139-40$

in UK 95-7

individuals in climate change policy, focus on 4-7, 24-5, $115,135,138-40$

interviews with families 35-6

\section{J}

Jamieson, L. 2, 3, 14, 17, 25, 73, 98, 138, 146

Japanese environmental policy 145-6

K

'knowledge-behaviour gap' 6

L

lifestyle studies, India 23-4

loans and interest repayments 63-4, 65 
M

Majority world

juxtapositioning understanding of environmental issues in Minority world and 136-7

Minority world narratives of responsible privilege and visits to $129-32$

Minority world policy imposed on 13 study contrasting Minority world and $22-5$

Massey, D. 40, 70, 132

Minority world environmental policy from perspective of 13

juxtapositioning understanding of environmental issues in

Majority and 136-7

moralising conceptions of environmental practice $4-5$, 140-2

narratives of responsible privilege and visits to Majority world 129-32 need to reframe environmental messages for 8-9

practising care at a distance 132, 137

problems with imaginary of depopulated pristine world 70-1, 106

study contrasting Majority world and 22-5

Modi, Narendra 4

Moore, J. W. 135, 136

moralising conceptions of environmental practice $4-5$, 140-2
$\mathbf{N}$

narrative analysis $27,37-8,39$

natural disasters 10, 25

NOVELLA research programme 28

O

'other'

in Africa 129-32

superiority to $95-6,124$

vilification of 71

P

Pacini-Ketchabaw, V. 13-14

Paris Climate Accord 4, 5

photographs $31,35,36,62,81$

play, outdoor 48, 109, 110, 112-13

polar bears $126,132-3$

sponsoring $127-8$

policy, environmental

'every little helps' discourse

138-40, 144-5

families at heart of 12

focusing on individuals 4-7, $24-5,115,135,138-40$

framing of children in reports

on 10-12, 102

implications of study for 144-8

Minority world perspective

on 13

need for 'common but

differentiated' approaches 24

positive example from Japan

145-6

recourse to futurity in 9

political agency 113-14, 143, 147 
pollution, air $41,48-50,80$ affluent families protection from 49, 50, 50

tips to protect children from 69-70

poor

attitude of, to climate change in India 56, 60, 61

blamed by middle classes in

India for climate change 24

consumption levels of 24,92 , 148

disproportionately affected by climate change 3, 23-4, 66, 142

environmental messages

irrelevant to $18,138,147-8$

hard work inextricably linked to environmental experiences in India 53-67

see also socioeconomic position poverty

absolute, in India 23

child 24

fuel 148

relative, in UK 24

Young Lives study of child 29-30

pristine nature, problems with

Minority world imaginary of 70-1, 106

\section{$\mathbf{R}$}

Räthzel, N. 136

recycling

in India, and training maids 123-4

motives for $75,76-7,85-6$, 137

plastic bottles 1

resistance to $90-1$ responsible privilege, narratives of 118, 119-20, 121, 124, 129, 132, 141

rural-urban migration 66

\section{S}

sample 32-4, 34

sanitation, lack of 58-9

school visits 36

Schultz, P. W. 8

Shiva, V. 69, 70, 98

Shove, E. 6, 7, 8, 17, 26, 109, $133,139,142,145,145-6$, 147

slum clearance scheme, impact on a family $54-5,59$

snakes 46-7

social practice theory $6-7$

socioeconomic position

buffering against environmental shocks 25 , 86-9, 93-5, 142

disparities in levels of consumption and 24, 92, 98 and growing polarity of experiences in India 23-4 and intersections with geographic locations 62, 89, 141-2 and protection from air pollution $49,50,50$ and retreat from summer heat in India 50, 111, 121-2 state

importance to environmental affordances 89-93 interventions 114, 145-6 slum clearance policy and impact on family $54-5,59$ 'sticky Affects' 140-1, 142 
sustainable development agendas

6, 9

in environmental education 10-11

paying little attention to structural factors 24-5

Sustainable Development Goals (SDGs) 4 references to 'future generations' 9

\section{$\mathrm{T}$}

Taylor, A. 13-14, 21, 40, 72, 132

technical resources in children's daily lives 109-11, 110, 112 parental concern over 119

traffic

affluent families protection

from dangers of 49

dangers and play restrictions in India 47-8

high levels of pollution and, in India 48-50

high levels of pollution and, in UK 48-50

transnational corporations, study of workers in 136

\section{U}

'unbearable anxiety' of environmental concerns 108 , $125,142,147$

UNICEF 10

Urry, J. 40, 106

Uzzell, D. 6, 12, 16, 17, 33, 103, 132, 143
W

waste disposal 92-3

children's concerns 112-14, 114

waste management study,

Bangalore 23-4

water

doubting value of conservation in UK 79

fetching 64, 93-4

scarcity 62-3

family discussion of 120

use

a child's story of 125

family discussion of 129-30

weaving family 61-6

Y

Young Lives study 23, 31, 33, 38, 147

collaboration with 29-30

Z

Zelezny, L. 8 
"Offers important insights on engaging families and compelling recommendations for communication about climate change, including greater focus on political agency."

Clare Shakya, Director of Climate Change, International Institute for Environment and Development

\section{P Policy Press}

UNIVERSITY OF BRISTOL

www.policypress.co.uk

SHORTS RESEABCH
How do environmental policies link to

dynamic and relational family practices for children and parents? This Policy Press Short presents innovative cross-national research into how 'environment' is understood and negotiated within families, and how this plays out in everyday lives.

\section{Based on an ESRC study that involved}

creative, qualitative work with families in India and the UK who live in different contexts, this book illuminates how environmental practices are negotiated within families, and how they relate to values, identities and society. In doing so, it contributes to understanding of the ways in which families and childhood are constructed as sites for intervention in climate change debates.

In an area that is increasingly of concern to governments, NGOs and the general public, this timely research is crucial for developing effective responses to climate change. 